\title{
SENSITOMETRY OF PHOTOGRAPHIC EMULSIONS AND A SURVEY OF THE CHARACTERISTICS OF PLATES AND FILMS OF AMERICAN MANUFACTURE
}

\author{
By Raymond Davis and F. M. Walters, jr.
}

\section{ABSTRACT}

For several years the Bureau of Standards has been conducting tests and measurements of the characteristics of photographic light-sensitive materials. The ultimate object of the investigation is to standardize methods and the necessary conditions for testing these materials. At the present time workers in this field are using different standards, with the result that the data obtained are not directly comparable. It is hoped that this work will lead to the standardization that is so much needed.

The paper is in three parts: Part $\mathrm{x}$ is a discussion of the general characteristics of photographic emulsions; part 2 describes the apparatus and conditions of testing as practiced at this Bureau; and part 3 gives data on practically all brands of emulsions (made in the United States) caated on glass and celluloid, the trade names of the emulsions being omitted.

\section{CONTENTS}

I. Introduction

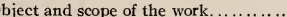

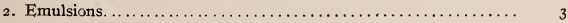

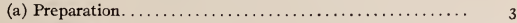

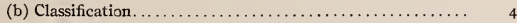

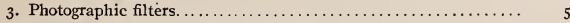

4. Relation between exposure and density $\ldots \ldots \ldots \ldots \ldots \ldots \ldots \ldots . \ldots$

5. Effect of time of development on contrast.............. II

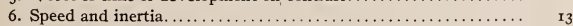

7. Scale and latitude. . . . . . . . . . . $\ldots \ldots \ldots \ldots \ldots \ldots \ldots \ldots$

8. Other methods of measuring plate speeds. .............. 14

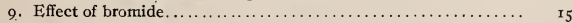

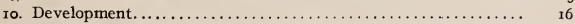

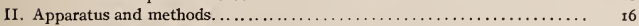

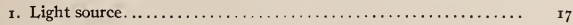

2. Sensitometer. . . . . . . .

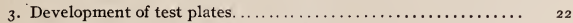

4. Measurement of density of test plates.................... 22

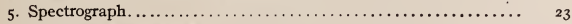

6. Filter factor apparatus $\ldots \ldots \ldots \ldots \ldots \ldots \ldots \ldots \ldots \ldots \ldots \ldots \ldots, \quad{ }_{25}$

7. Resolution...................................... 29

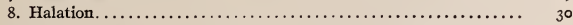

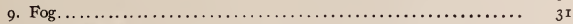

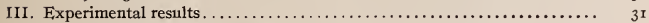

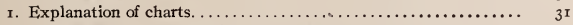

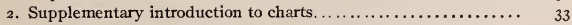

3. Charts of characteristics of plates and films.............. 34 


\section{INTRODUCTION}

\section{OBJECT AND SCOPE OF THE WORK}

In the spring of 1920 there was made for the information of the Government a confidential survey of the characteristics of the plates and films made in the United States. In this survey some 90 different brands of sensitive material were studied. The characteristics investigated were speed, development, color sensitiveness, filter factors, and scale.

It was thought that the methods of testing were of sufficient novelty and soundness to merit publication in the hope that some at least of the principles upon which they were based might serve as a basis for the standardization of photographic testing-a standardization which is badly needed.

It is particularly difficult if not impossible to make a number of batches of emulsion having exactly the same speed and other characteristics. The variations in speed that may be expected are from 5 to 25 per cent, although much larger variations are occasionally found. To have permanent value the speed and other data should be averaged from a number of batches and published periodically, but unfortunately the Bureau of Standards is unable to do this.

The results are therefore given without the names of the plates or the makers. Though they can not serve the practical photographer as a reference book of plate speeds, they do show the various characteristics which differentiate one type of material from another and give information as to what material is available.

In general the photographic public is primarily interested in speed. It should be noted, however, that from the practical standpoint speed (within reasonable limits) is by no means the most important characteristic of a brand of plates. In many cases relative lack of speed can be balanced by lengthening the exposure or increasing the illumination. There are, on the other hand, properties of sensitive material which are absolutely essential to successful work, the most important of which is freedom from defects and uniformity of manufacture. Then come freedom from fog, the contrast which can be developed, the magnitude of the scale, ${ }^{1}$ and fineness of grain. Freedom from defects and uniformity of manufacture are two characteristics which must be tested by the user and which can hardly be subjected to laboratory tests. The others can be measured very nicely.

\footnotetext{
'By some writers termed "latitude," As used in this article see definition, p. r3. $_{3}$.
} 
It is hoped that the presentation of the results obtained in these tests may lead to the adoption, by the different manufacturers, of some general classification and designation of the various brands of plates. At present some of the names given are meaningless, while in other cases they are actually misleading. Furthermore, it would appear that some manufacturers might very well reduce the number of different brands of plates, since to all intents and purposes some of these are identical.

To account for the variations to be met with in different plates, a brief description of the preparation of an emulsion is given. This is followed by a discussion of the different classes into which plates may be divided according to speed and color sensitiveness. The relation between exposure and the density of the negative is discussed, together with the development characteristics of plates. The apparatus used in testing is described, and the reasons are given for the adoption of the light source used. The methods of studying the color sensitiveness are explained. The method of testing resolution is described, and the effects of irradiation and halation are discussed. A discussion of the results and interpretation of the graphs precedes the charts, which show data on practically all of the plates and films made in the United States.

\section{EMULSIONS}

(a) PREPARATION

A photographic dry plate is a sheet of glass on which is coated a thin layer of gelatin containing the light-sensitive silver bromide (or other silver halide). A film has the sensitive layer coated on celluloid. Such material is used for making negatives and transparencies.

A typical method of manufacture of emulsions may be briefly described as follows: To a solution of gelatin which contains soluble halides is added a solution of a silver salt (usually the nitrate). This mixing produces an insoluble silver halide which is suspended in the gelatin in a finely divided state. The emulsion thus formed is comparatively insensitive, so it is necessary to "ripen" it. This is accomplished by maintaining the emulsion at a definite temperature until it develops the desired characteristics. In addition to the silver halide, the emulsion contains other salts detrimental to the working of the emulsion. These are removed by washing the emulsion in cold water after it has been "set" and shredded. After washing, it may be further ripened by standing at ordinary temperatures, or it may be melted and coated at once. The coating is done by a machine which first flows the emulsion 
in a thin layer on the glass or celluloid and then passes the plate into a cooling chamber, where the thin coating is allowed to set. The plate is then set on edge to dry.

The character of the finished product is very sensitive to all of the processes of its manufacture. For example, the purity of the salts used, the proportions used, the rate and temperature of mixing, the concentration of the solutions used, the character of the gelatin, the temperature and time of ripening, the character of the water used in washing the emulsion, and the rate of drying are some of the many factors which must be controlled in the process. The formulas used and most of the other conditions of manufacture are trade secrets.

(b) CLASSIFICATION

Plates and films may be classified either by their speed and the use to which they are best adapted or by their color sensitiveness, as follows:

By SPEED AND USE.--(I) Ultra-fast plates (for focal-plane shutter cameras and portraits in dull light); (2) fast plates (portraits, outdoor groups, and slowly moving objects); (3) Medium-speed plates (landscapes and buildings); (4) slow plates (commercial work, copying photographs and line drawings); and (5) very slow plates (lantern slides and transparency plates).

The extreme rapidity of the first group is obtained at the sacrifice of other qualities. Usually they are not very clean working, fog easily, and have large grain, therefore not the best resolving power.

The fast plates are in general moderately clean working. They do not fog so easily and have slightly finer grain.

Medium-speed plates are usually clean working, give brilliant negatives, and have good resolving power. These plates are generally used in photographing landscapes, buildings, machines, in fact, anything not having rapid motion.

Slow plates are usually very contrasty and short scaled.

Lantern slide, transparency, and process plates fall in the "very slow" class. They give moderately high contrast, are very clean working, and thinly coated. The grain size is usually small, hence they give excellent resolution.

By Color Sensitiveness.-In addition to the above classification plates may be classified with respect to their sensitiveness to color as well as to their speed and use.

(a) Ordinary Photographic Plates. - These owe their sensitiveness to the silver halides alone. They are affected only by the 
so-called chemical rays, ultra-violet, violet, and blue, as shown in Fig. I, which gives the distribution of spectral sensitivity of such a plate.

An ordinary photographic plate does not give the same color contrasts that the eye sees. On such a plate sky and clouds both photograph white, while green trees together with yellow and red flowers photograph as black.

(b) Orthochromatic or Isochromatic Plates.-The region of sensitiveness of a photographic plate may be extended by the addition of certain dyes, the so-called optical sensitizers or photosensitizing dyes. These dyes may be incorporated at various stages in the preparation of the emulsion, or the dry plates may be bathed in solutions of them.

Plates which are sensitive to the yellow green in addition to the blue and violet are termed orthochromatic or isochromatic. Fig. 2 shows such a plate with its two regions of sensitiveness.

(c) Panchromatic or Spectrum Plates.-As shown by Fig. 3, these are sensitive to all colors. The comparatively lower sensitiveness in the green is taken advantage of to use a green dark-room light for developing these plates because they fog readily with a red dark-room light.

\section{PHOTOGRAPHIC FILTERS}

Orthochromatic and panchromatic plates, however, do not have the same spectral sensitiveness as does the eye, so their color rendering is improved by the use of filters which diminish relatively the intensity of certain colors before they reach the plate. Such a photographic filter or color screen is either colored glass or a sheet of dyed transparent material such as gelatin, which may either be used alone or cemented between two pieces of glass.. Color filters are used extensively to increase color contrasts and record on the plate color differences which are visible to the eye, but which, without the filter, are of such luminosity as not to appear on the photographic plate. They are used also to eliminate colors, for example, in the case of three-color work or in the copying of stained drawings and pictures.

The spectrograms of Fig. 4 were taken on a panchromatic plate to show the effect of the eight Wratten filters used for testing the color sensitiveness of plates in common use.

Red filters can be used only with panchromatic plates, while the others can be used on orthochromatic plates as well. 


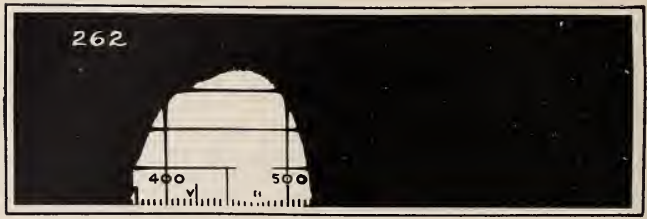

F1g. 1.-Spectrogram of Ordinary Plate

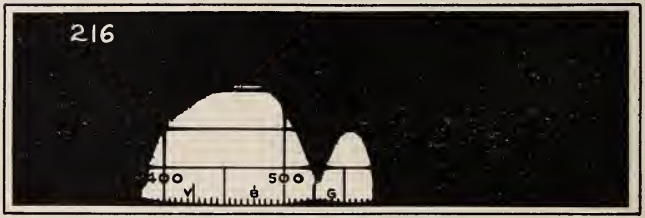

F1g. 2.-Spectrogrum of Orthochromat 1c Plate

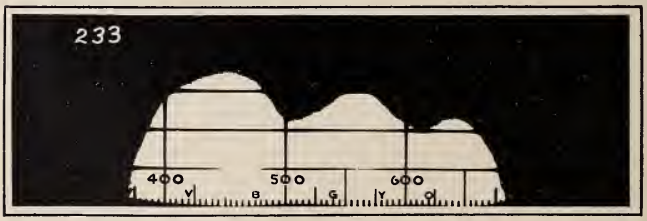

F1g. 3.-Spectrogram of Panchromat 1c Plate

The letters at the bottom of each spectrogram refer to the color of the light falling on the plate; UV. ultra-violct; V, violet; $B$, blue; $G$, green; $Y$, yeilow; $O$, orange; and $R$, red. The numbers give the wave length of the light in millionths of a millimeter. 


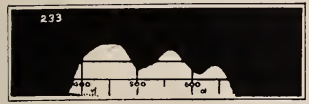

No Filter

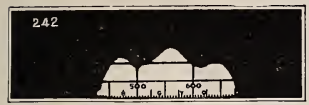
$K_{1}$ Light Yellow - Cuts

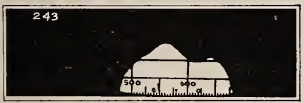

$\mathrm{K}_{2}$ Medium Yellow - Cuts down blue

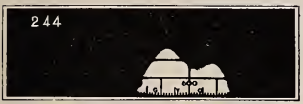

$\mathrm{K}_{3}$ Deep Yellow - Cuts

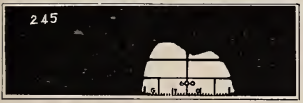

G Orange - Contrast
Chart to ohow the effeot of Wratten fllters on a panohromat 10 plate

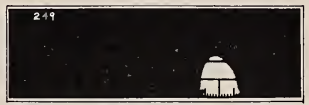

5 Deep Red - Cortrast

fliter to photograph red as white

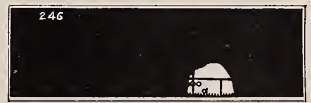

A Light Red for three color work

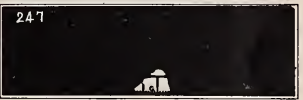

B Green for three color work

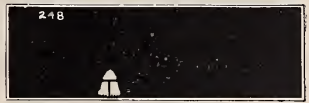

C Blue for three oolor work

FIG. 4 


\section{RELATION BETWEEN EXPOSURE AND DENSITY}

The relation between the quantity of light falling on the lightsensitive material and the density resulting from development is of fundamental importance in the study of the properties of photographic materials.

Viewed by transmitted light, the photographic negative has the greatest density in those parts which are brightest in the subject and least where the subject is darkest. In order to specify the characteristics of photographic materials, it is necessary to make this idea of density precise by means of a mathematical definition. This definition is "Density is equal to the common logarithm of the opacity." Opacity is defined as the reciprocal of the transmission; and transmission, in turn, is defined as the ratio of the transmitted to the incident light. Thus if a portion of a negative transmits one-tenth of the light falling on it, its opacity is Io; and since the common logarithm of ro is $\mathrm{r}$, its density is $\mathrm{r}$. See Table $\mathrm{r}$.

TABLE 1.-Values of the Opacities and Densities for Certain Values of the Transmission

\begin{tabular}{|c|c|c|c|c|c|}
\hline Transmission & Opacity & Density & Transmission & Opacity & Density \\
\hline 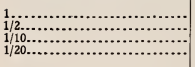 & $\begin{array}{r}1 \\
2 \\
10 \\
20\end{array}$ & $\begin{array}{l}0 \\
.3 \\
1.0 \\
1.3\end{array}$ & 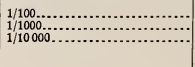 & $\begin{array}{r}100 \\
1000 \\
10000\end{array}$ & $\begin{array}{l}2.0 \\
3.0 \\
4.0 \\
\end{array}$ \\
\hline
\end{tabular}

If a plate which transmits one-half be placed in front of a plate which transmits one-tenth the transmission of the two will be one-half of one-tenth, or one-twentieth.

In studying the relation between the density of a negative and the light exposure required to produce it, the nature of the problem makes it most convenient to vary the exposure according to the law of geometrical progression. Usually the exposures are proportional to $\mathrm{I}, 2,4,8,16,32,64 * * *$ While a set of exposures may be produced in a variety of ways, the simplest is to keep the intensity of the light constant and vary the time of exposure. The term exposure is here understood to mean the product of the intensity of light by the time of exposure. This product, while not exactly constant, may be so regarded when the variation in the factors is less than, say, a thousand. Schwarzschild ${ }^{2}$ observed that with equal exposures the photographic effect of a light of small intensity was less than that of one having a much greater intensity. 
Consider that a set of geometrically increasing exposures has been made and the plate developed, fixed, washed, and dried in the usual manner. If now the densities be measured, it will be found that within certain limits the differences in density are constant. For example, one might obtain a record as shown in Table 2.

TABLE 2.-Density Difference for Varying Exposure

\begin{tabular}{r|r|r|r|r|r|r|r}
\hline Exposure (E) & \multicolumn{1}{c|}{ Log E } & Density & \multicolumn{1}{c}{$\begin{array}{c}\text { Differ- } \\
\text { ence }\end{array}$} & Exposure (E) & Log E & Density & \multicolumn{1}{l}{ Differ- } \\
ence
\end{tabular}

a Candle meter-seconds.

If a graph be made to show the relation between the density and exposure, it is obviously more convenient to plot the logarithm

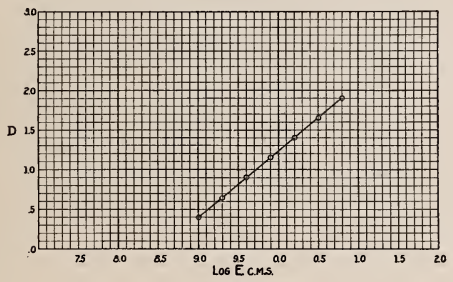

FIG. 5.-Part of the density-exposure curve

of the exposure, because the range in exposure is often as great as I to Iooo, so that plotting the exposure would make the scale too small.

The constant difference relation of the density holds true only for intermediate exposures. For example, if exposures longer and shorter than those given above be made, the corresponding densities will not show constant differences, and the points will not lie on a straight line. One would, for example, obtain results something like those in Table 3.

TABLE 3.-Nonuniform Differences in Density

\begin{tabular}{|c|c|c|c|c|c|c|c|}
\hline Exposure (E) & $\log E$ & Density & $\begin{array}{c}\text { Differ- } \\
\text { ence }\end{array}$ & Exposure (E) & $\log E$ & Density & $\begin{array}{c}\text { Differ- } \\
\text { ence }\end{array}$ \\
\hline $\begin{array}{l}1 / 160 \ldots \ldots \\
1 / 80 \ldots \ldots \\
1 / 40 \ldots \ldots \\
1 / 20 \ldots \ldots \\
1 / 10 \ldots \ldots\end{array}$ & $\begin{array}{l}7.8 \\
8.1 \\
8.4 \\
8.7 \\
9.0\end{array}$ & $\begin{array}{l}0.00 \\
.03 \\
.08 \\
.20 \\
.40\end{array}$ & $\begin{array}{r}0.03 \\
.05 \\
.12 \\
.20\end{array}$ & $\begin{array}{l}64 / 10 \\
128 / 10 \\
256 / 10 \\
512 / 10 \\
1024 / 10 \ldots \ldots . . .\end{array}$ & $\begin{array}{l}0.8 \\
1.1 \\
1.4 \\
1.7 \\
2.0\end{array}$ & $\begin{array}{l}1.90 \\
2.13 \\
2.30 \\
2.45 \\
2.55\end{array}$ & $\begin{array}{l}0.23 \\
.17 \\
.15 \\
.10\end{array}$ \\
\hline
\end{tabular}


Here successive doubling of the exposure does not give a constant increase in the density; that is, the opacity is not proportional to the exposure. The graph of this table is shown in Fig. 6. This curve giving the relation between density and exposure is known as the "characteristic curve" of the plate. It is also called the "H \& D" curve after Hurter and Driffield, ${ }^{3}$ who were the first to state the relation between density and exposure. The underexposure part (below $\log E=8.9$ ) is called the "toe." The overexposure region (above $\log E=\mathrm{I}$. I) is sometimes referred to as the "shoulder."

Since, in the correct representation of the light and shade of the subject photographed, the opacity of the negative should be proportional to the quantity of light coming from the subject, it

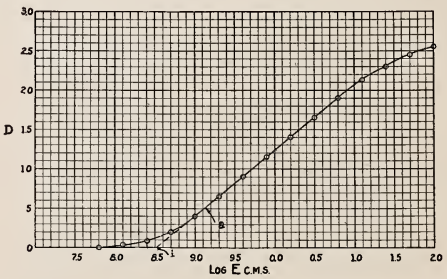

FIG. 6-Density-exposure curve showing toe, straightline, and shoulder

follows that the time of exposure should be such as to give densities on the plate which lie on the straight-line portion of the density-exposure curve. It is found that if the exposure is too short, there is no detail in the shadows, although there may be a slight deposit of silver all over the plate, or if the development has been such that detail does show, the representation of light and dark in the picture does not correspond to the light and dark of the subject.

When the exposure is too long, there is not sufficient difference in density to give detail in the portions of the negative which represent the brightness parts of the subject.

Hurter and Driffield, who were the first to express the relation between the darkening of the negative and the light coming from the subject, in terms of density and exposure, have expressed this fundamental law of photography as follows:

3 Journal of the Society of Chem. Ind.; May, 1890. 
In a theoretically perfect negative, the amounts of silver deposited in the various parts are proportional to the logarithms of the intensities of light proceeding from the corresponding parts of the object.

That the density of a negative is proportional to the quantity of silver reduced by the developer has been corroborated by many independent investigators.

\section{EFFECT OF TIME OF DEVELOPMENT ON CONTRAST}

It is a matter of common experience that the longer a plate is developed, the more contrast and density it has. This is shown very clearly by means of the following experiment. A number of strips of the same plate were given identical step exposures, then each strip developed for a different length of time, the plate fixed, washed, and dried, and the density measured. Fig. 7 shows devel-

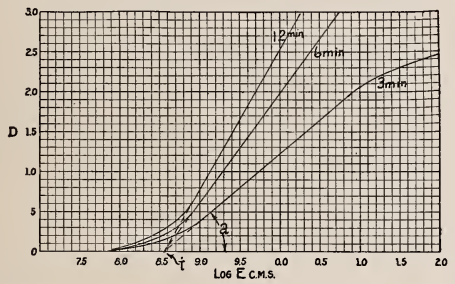

FIG. 7.-Density-exposure curves for developments of 3,6 , and 12 minutes

opment for 3,6 , and 12 minutes, respectively. It is to be noticed first that the density for a given exposure becomes greater with the time of development, as should of course be expected. It is also to be observed that the straight-line part of the curve becomes steeper with the time of development. Thus the contrast is increased, since with longer development there is a greater difference in density for the same difference in exposure. The degree of contrast is made definite by giving it a numerical definition. The straight-line part of the characteristic curve continues downward until it cuts the exposure axis, makes an angle $a$ with it. The contrast is then defined as equal to the tangent of angle $a$. This is called gamma $(\gamma)$, so that

$$
\gamma=\tan a
$$

Thus a gamma of $\mathrm{I}$ means that the ratio of the densities in the negative is the same as the corresponding ratio of the logarithms 
of the intensity of light coming from the subject. Or expressed in another way, the degree of contrast indicated by the number expressing gamma is the relative differences of the intensities of light coming from the subject as recorded on the negative. A gamma of 2 means that the plate shows twice the contrast of the subject, and a gamma of 0.5 means that the plate shows only half the contrast of the subject.

If the values of the contrast $(\gamma)$ be measured from the graph, interesting information can be obtained by plotting them against the time of development (Fig. 8). There is a certain period before the deposit of silver becomes visible, then the contrast increases rapidly with the time, and finally more slowly, so that after

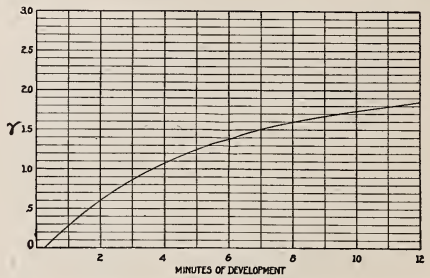

FIG. 8.-Curve showing growth of contrast with time of development

a certain time the negative gains very little in contrast by further increasing the time of development.

The statement is sometimes made that all negatives should be developed to give unit contrast. But it must be remembered in controlling development that the print is the basis upon which the correct rendering of the subject is to be judged. If printing papers gave gammas of $\mathrm{I}$, then a negative might well be developed to unit contrast, but most of the papers in use have gammas greater than I when developed to give the proper tone, so that negatives are developed not to unit contrast, but to a less contrast. It must be borne in mind that the scale of a paper is commonly much less than the scale of the usual subject, so that the development of a negative must be stopped when the highest and lowest tones of the subject it is desired to reproduce have reached the limit of representation of the paper used. With studio lighting; it is often desired to soften the contrasts which occur in lighting the subject, and for this reason the use of a plate which is not capable of reach- 
ing an extreme gamma in development is no detriment. In the reproduction of line drawings, it is desirable to increase the contrasts presented by the ink and paper of the drawing, and to get the variation of light on the surface of the paper recorded on the negative by a density so great that the printing paper has no chance to show it.

\section{SPEED AND INERTIA}

It is observed in Fig. 7 that if the straight line portion of each development curve be continued until it cuts the exposure axis, all lines cut the axis in the same place. ${ }^{4}$ The value of the exposure at this point is called the "inertia" of the plate. The faster a plate, the shorter the minimum time required to give an image, and hence the less its inertia. However, one's idea of speed is such that the greater the speed, the larger must be the number representing it, so that to indicate speed the reciprocal of the inertia is taken. This was Hurter's original idea, but to fit an actinometer of his design, he took $34 / i$ ( 34 divided by the inertia) which is the usual $\mathrm{H} \& \mathrm{D}$ number, as his measure of speed. The Bureau of Standards, however, has chosen $10 / i$ as its definition of speed..$^{5}$

Figs. 7 and 9 serve to illustrate the process of obtaining plate speeds from the plate curves. In Fig. 7 the logarithm of the inertia is 8.56 . This is the logarithm of the number 0.0363 . The reciprocal of 0.363 is $\frac{I}{0.0363}$ equal to 27.5 , and Io times the reciprocal is 275 , the Bureau of Standards's speed. In Fig. 9 the data for the two plates are:

\begin{tabular}{|r|c|c|c|}
\hline Log $i$ & $i$ & $1 / i$ & $\begin{array}{r}\text { Bureau } \\
\text { of Stand- } \\
\text { ards's } \\
\text { speed }\end{array}$ \\
\hline 8.42 & $\begin{array}{r}0.0263 \\
\text { 8. } 0589\end{array}$ & $\begin{array}{r}38.0 \\
17.0\end{array}$ & $\begin{array}{r}380 \\
170\end{array}$ \\
\hline
\end{tabular}

\section{SCALE AND LATITUDE}

From the characteristic curve the scale of the plate may be obtained. By scale is understood the range of light intensity that a plate is able to record correctly. Latitude is the variation which

\footnotetext{
${ }^{4}$ This always occurs, provided there is no free bromide in the plate or in the developer and that the plate does not fog badly.

B The number $1 / i$ would have been more logical, but ro/ $i$ was chosen so that all usual speed numbers might be represented by integers and the confusion of fractions be avoided.
} 
it is possible to make in the time of exposure and still retain a correct representation of the subject.

The scale is measured by the projection on the exposure axis of the straight-line part of the characteristic curve. The difference of the logarithms of the two extremes is taken, and the number corresponding is the scale. Thus in Fig. 9 the curve to the left represents a plate which has a scale of $\mathrm{I}_{32}$ and that to the right a scale of 10.5 .

$0.90-8.78=2.12=\log$ of $\mathrm{I}_{32}$ for the first plate.

$0.43-9.4 \mathrm{I}=\mathrm{I} .02=\log$ of $\mathrm{I} 0.4$ for the second plate.

If the subject photographed on the plate possessing a scale of I 32 has a range of light intensity from $I$ to $I 32$ (the brightest part of the subject giving 132 times as much light as the darkest part), the exposure would have to be precise, for an under or over

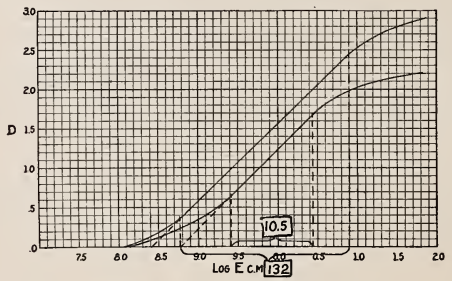

FIG. 9.-Plates with different scales

exposure would shift the negative off the straight-line part of its characteristic curve, so that the reproduction of light and shade would no longer be correct. If, however, the subject had an intensity range of $\mathrm{I}$ to 33 , the plate would have a latitude of 4 for such a subject; so that if I second were the shortest correct exposure, 4 seconds could be given and the plate would still show a correct tone representation.

\section{OTHER METHODS OF MEASURING PLATE SPEEDS}

A method often used for comparing plate speeds is to measure the exposure required to give a visible image on the plate. In actual application, the plate to be tested is exposed either behind a set of standard densities or behind a sector wheel. There are, however, several objections to this method: (I) It depends upon the observer as to what density is just visible; (2) the density 
upon which speed is judged is too small to have a printing value, hence actually plays no part in the average negative; (3) a quick developing plate is judged to be faster than a slow developing plate, although when developed to the same contrast the latter might require the smaller exposure. A more serious objection (4) is that a plate with a long toe appears to be much faster than it really is. For example, by this method the two plates of Fig. 9 would be classed as having practically the same speed; but when correct tone rendering is considered, as shown above, one is actually more than twice as fast as the other.

In plate factories, speeds are frequently tested under actual working conditions. A negative of a standard test object is made in the camera and developed under standard conditions. An

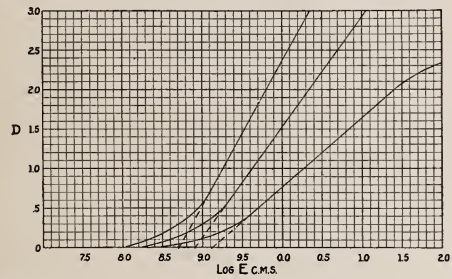

FIG. 10.-Decrease of inertia with time of development with a developer containing potassium bromide

observer who is trained through long familiarity with the appearance of the type of plate which he desires to reproduce is able to judge very exactly whether or not the plate under test comes up to standard in speed, scale, and contrast.

\section{EFFECT OF BROMIDE}

Typical development curves of clean working emulsions which are free from bromide show the straight-line parts intersecting in a point on the exposure axis for all times of development. On the other hand, the presence of potassium bromide in the developer or emulsion produces a marked effect on the properties of photographic emulsions. The inertia becomes less as the time of development increases, shown in Fig. Io. The addition of potassium bromide is necessary with some developing agents, particularly metol. It retards the appearance of chemical jog and per$90002^{\circ}-22-2$ 
mits the development of a higher degree of contrast. However, its presence produces a marked decrease in speed. Fig. II shows the decrease in speed of three brands of plates with increasing amounts of bromide in pyro developer of tray strength.

\section{DEVELOPMENT}

There are two methods in general use for judging when the development of a negative is complete: (I) That of the amateur who feels that development must be carried until the image comes through the back or until the unexposed edges begin to fog, and (2) that of the professional who is able to tell when the negative

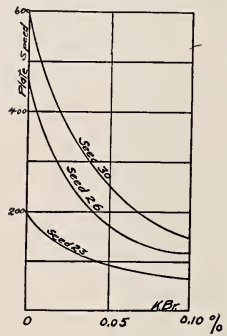

Fig. II.-Decrease of speed with increasing amounts of bromide in the developer has the desired brilliance and printing quality as he views it by the transmitted light of his dark-room lamp. The method of the amateur is unsatisfactory, since it depends upon the thickness of emulsion and since it does not take account of the variation in the natural contrast of the subject.

The use of the tank development is to be recommended for the production of negatives of the subjects which have the same degree of contrast. Tank development takes care of small differences in exposure without disturbing contrast ratios. For example, a plate which is slightly overexposed will merely require longer to print.

In addition to the time of development, and the temperature and concentration of the developer, account must be taken also of the development characteristics of the plate used.

Equally important, though not mentioned in the manuals of photography, is the necessity of adapting the length of development to the intrinsic contrast of the subject and the character of the printing medium.

In developing it is important to keep the rate and method of stirring constant unless the negatives are examined for contrast. By proper rocking, the time of development may be cut in half of that required for no motion of the developer.

\section{APPARATUS AND METHODS}

The apparatus for obtaining the exposure-density curves consists of two parts: (I) The source of light, and (2) the sensitometer, or the means of obtaining graduated exposures. 


\section{LIGHT SOURCE}

An object owes its color not only to selective reflection and absorption, but also to the composition of the light falling upon it. As an extreme illustration of this may be taken the appearance of colored objects when viewed by the light of a mercury vapor lamp. The sun is the natural source by which color of objects is determined. Other sources differ from it not only in intensity but in the relative amounts of the various colors which they radiate.

Daylight is sunlight reflected from the sky and clouds. In general it varies in composition somewhat with the time of day and year and geographical location. Sunlight itself changes with the time of day and time of year. Its color is changed by the altitude of the sun and the condition of the atmosphere.

Sunlight being by far the more constant of the two, it was decided to reproduce in color average yearly noon sunlight at the latitude of Washington as the source of energy for the sensitometry of photographic materials.

Since an exposure of 100 candle meters for I second gives a greater photographic effect than I candle meter for roo seconds (the effect referred to as the failure of the reciprocity law), the intensity of the light source must be specified as well as its color. In accordance with Hurter and Driffield, this is taken as I candle meter (visual); that is, the light at the plate shall be equal in intensity to that of a source of $\mathrm{I}$ candlepower at a distance of $\mathrm{I} \mathrm{m}$. The intrinsic brilliancy of the source should lie between $I$ and 4 candlepower since an intensity less than I candlepower would make the distance to the test plate too small to give a sufficiently uniform distribution of intensity; and a candlepower greater than 4 would make the apparatus cumbersome. Considerations of intensity and constancy led to the adoption as a source of 6 to 8 volt Mazda C automobile headlight, operating on approximately 2.4 amperes. A Brooks's deflection potentiometer is used in order to regulate the current accurately. These lamps were standardized by the colorimetry section of this Bureau, so that when used with a special blue glass filter they gave a light closely approximating the color of average noon sunlight; then they were measured for visual candlepower by the photometric section, which also measured the special blue glass filter for its visual transmission when used with these lamps. The lamps without filter gave an average of 15 candlepower; the filter trans- 
mission was 18.2 per cent, making an average intensity of the lamps seen through the filter of 2.73 candlepower.

\section{SENSITOMETER}

The sensitometer ${ }^{6}$ is of the sector disk type. The disk (shown in Fig. I2) contains nine apertures, the angle of each being twice as great as the preceding and having a radial length of one-half inch. The disk is about 18 inches in diameter, being twice the usual size in order to give greater accuracy of the small angles. Table 4 gives the calibration.

TABLE 4.-Aperture Calibration in Fractions of $360^{\circ}$

\begin{tabular}{|c|c|c||c|c|c|}
\hline $\begin{array}{c}\text { Intended } \\
\text { aperture }\end{array}$ & $\begin{array}{c}\text { Actual } \\
\text { aperture }\end{array}$ & $\begin{array}{c}\text { Per cent } \\
\text { error }\end{array}$ & $\begin{array}{c}\text { Intended } \\
\text { aperture }\end{array}$ & $\begin{array}{c}\text { Actual } \\
\text { aperture }\end{array}$ & $\begin{array}{c}\text { Per cent } \\
\text { error }\end{array}$ \\
\cline { 1 - 2 } 0.001953 & 0.00183 & -6.3 & 0.0625 & 0.06238 & \\
0.003906 & .00393 & \pm .6 & .125 & .1222 & -0.2 \\
.007812 & .00770 & -1.4 & .25 & .2502 & -2.2 \\
.015625 & .01553 & -.6 & .50 & .4997 & \pm .1 \\
.03125 & .03104 & -.7 & & & -.06 \\
\hline
\end{tabular}

The disk, which was carefully balanced and mounted on a shaft with cone bearings, is shown with its light-tight box in Fig. I3 (section on $\mathrm{G}-\mathrm{G}$ ).

Connected to this box is a light tunnel, provided at one end with an electrically operated shutter and the compensating color filter,

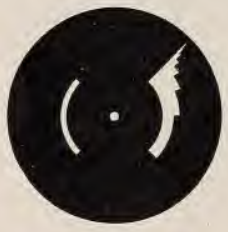

FIG. 12,-Sector wheel the light source being in front of the shutter.

On the shaft of the sector wheel are two commutators. One of these, which is adjustable, is connected through a battery to a pair of telephone receivers so that a tick is heard for each revolution of the wheel. These ticks are compared with those received from a seconds pendulum clock through a microphone circuit. The wheel speed is regulated so that the clock beats and the ticks of the wheel contact coincide. The telephone receivers may be replaced by a chronograph to obtain a graphical record.

The second commutator is fixed in position and connected through a battery to the timing device, this (Fig. 14) consisting of a toothed wheel $W$ driven by a spring $S$ and operated through the electromagnet $M$ by the escapement $E$. At each revolution

\footnotetext{
${ }^{6}$ See patent No. 1,382,272 (dedicated to the public), Raymond Davis, sensitometer for testing plates and films.
} 
of the sector wheel, the toothed wheel of the timing device is moved forward one tooth, half a tooth when the current is made and the other half when the current is broken. Opposite each tooth is a hole into two of which are placed contact pins $P$. These pins make contact with the brush $B$ which is placed so that the contact pin moves under it when the current is broken. The frame of the timing device and the contact brush are connected to the electrically operated shutter and the circuit which operates the timer.

The shutter is opened when the first pin moves under the contact brush, at the instant the circuit is made by the commutator on the sector wheel shaft. It remains open until the second pin comes under the contact brush when the circuit is closed by the commutator. The commutator is placed on the shaft of the shutter wheel in such a position that the shutter is both opened and closed while one of the solid quadrants of the wheel covers the test plates. This sensitometer is distinctive in that the sector wheel gives not only the graduated exposure, but the total exposure as well.

The sector wheel is driven by a one-eighth horsepower shunt motor connected as shown in Fig. 15. This arrangement gives excellent speed control continuously from o to $1700 \mathrm{rpm}$. The current is supplied by storage batteries.

The test strips ( $1 / 2$ by 5 inches) are put into a holder specially designed to display the three plates radially from the center of the wheel (Fig. 13). A track is so arranged that the plates are slid up to within $2 \mathrm{~mm}$ of the back of the sector wheel, since it is important to have the plates as close to the apertures of the sector wheel as possible, in order to get the true effective aperture and to eliminate partially illuminated shadows.

In this method of testing plates it is assumed that the exposure is equal to the product of the intensity and the time of exposure, whatever their values. This is not strictly true; for example, an exposure of ro candle meters for I second will give a greater photographic effect than an exposure of one one-hundredth candle meters for rooo seconds. A sensitometer which gives exposures of varying intensity for the same exposure time might be thought preferable. There are, however, two objections to such a method: First, speeds so determined would be applicable only to the time of exposure used; and, second, the apparatus required would be very complicated if accuracy in the measurement of time and in- 


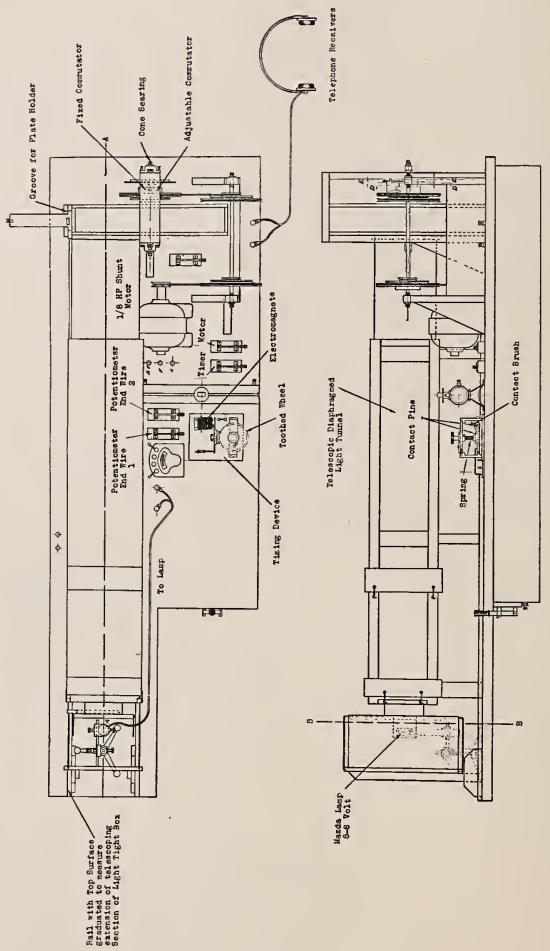




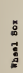
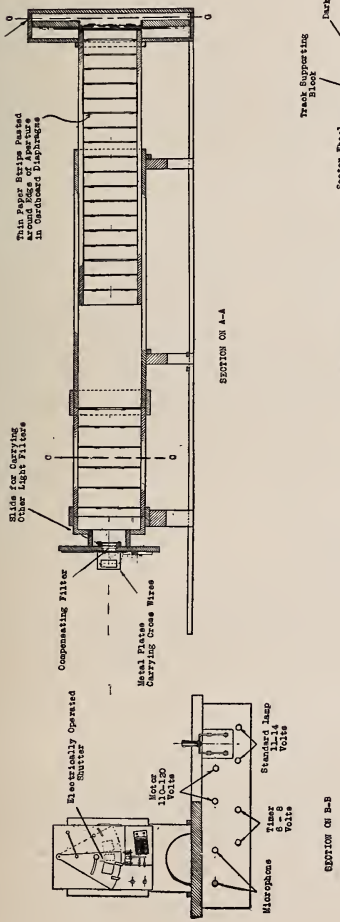
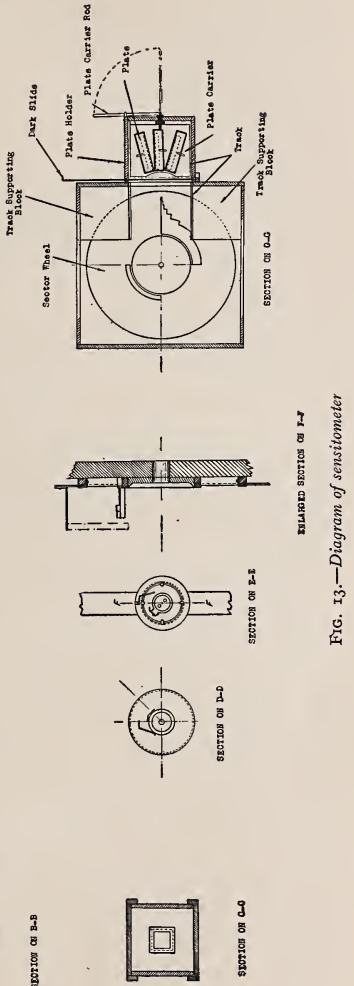
tensity of light were attempted. The method of a constant intensity and varying time of exposure offers the advantages of ease of operation and exactness in the measurement of time and intensity.

A criticism made of the sector disk method as usually employed is that the effect of an intermittent exposure is less than a contin-

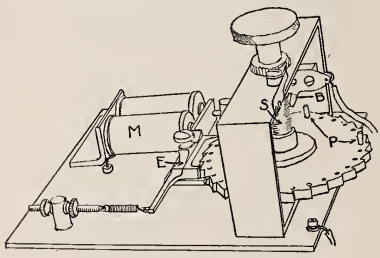

FIG. 14.-Timing device of sensitometer uous exposure of the same duration; that is, IOO exposures of onetenth second are not equivalent to a single exposure of io seconds.

Tests showed this effect to be inappreciable (not more than a few per cent and considerably less than the variation due to coating) under the conditions used, namely, the number of revolutions of the disk 16 , the intensity of the light 1 candle meter visual, and comparatively slow rate of the wheel of I revolution per second.

\section{DEVELOPMENT OF TEST PLATES}

Development is carried out in silver-plated cans placed in a water bath, the temperature of which is kept constant by a thermostat regulator which controls the heating units through a relay. The test plates are put in silver cages, each holding four, and stirred in

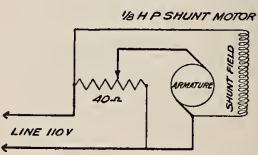

Fig. 15.-Wiring diagram of speed control of sensitometer motor the developer by rotating the cages at 40 revolutions per minute.

\section{MEASUREMENT OF DENSITY OF TEST PLATES}

The photometer used for measuring the density of the test strips is a Martens polarization instrument (Fig. 17 ). One beam of light passes through the square $a$, the density of which is to be measured, while the other beam passes through the fog strip $b$. By this means, the effect of the density of the glass and gelatin and also of chemical fog is automatically eliminated, so that the 
measured density is due solely to the exposure. The illumination is diffuse, the light is reflected from ground surface opal glass $g$, surrounded by ground glass $o, o$, outside of which are placed electric lamps $(L ., L)$ symmetrically arranged so as to give uniform illumination. The test strip is placed in a sliding holder which, by means of stops, brings the center of each square under the photometer. The angular readings of the polarization instrument are reduced to densities by means of a table computed for the purpose.

It may be remarked that densities measured visually do not represent

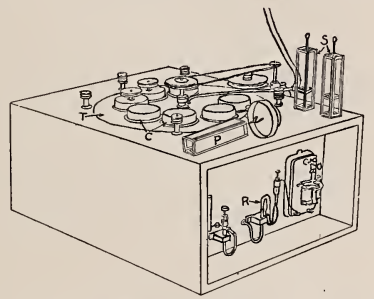

FIG. 16.-Thermostat for developing test plates photographic densities. The photographic density depends upon the region of sensitiveness of the printing medium, the quality of the light used to print, and the manner of printing, whether it be contact printing or enlarging. The plates measured in this work are neutral in color, although developed with pyro, and
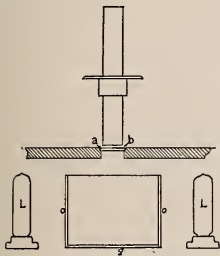

FIg. r7.-Photometer and illumination box for measuring the density of test plates the only results which may be affected materially by the difference between visual and photographic density are the values of the contrast, but in that case they still give reliable comparative data.

\section{SPECTROGRAPH}

Two methods are used in studying the color sensitivity; first, a spectrum is photographed on the plate, and second, the filter factors of the plate are measured. The first method is excellent for determining if the plate is sensitive to a particular color, and the second from a practical standpoint in determining how one plate compares with another in speed when used with a particular filter. 
The apparatus for projecting a spectrum on the plate may be described as follows (Fig. I9): The light source $L$ is a roo-watt tungsten lamp whose brightness is kept constant by adjusting a rheostat to maintain a constant current through the filament. Around the lamp is a white reflector $R$, while in front of the slit is a piece of ground glass, to give uniform illumination along the slit which is 2 inches high. Between the ground glass and the slit is placed a rotating disk $D$ out of which is cut a variable aperture such that the brightness of the slit decreases geometrically with the distance from its lower end. The successive horizontal lines on the spectrograms indicate geometrically diminishing exposuresthat is, the exposure at the first line from the bottom is one-quarter that at the bottom; at the second line, one-sixteenth; at the third,

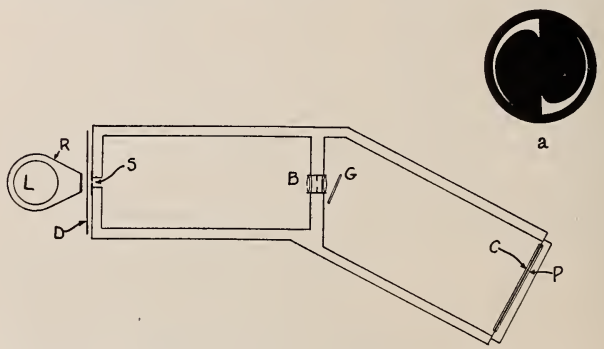

FIG. 19.-Diagram of spectrograph. a, Disk for varying exposure along the slit

one sixty-fourth; at the fourth, one two-hundred-and-fifty-sixth; and at the top, one one-thousand-and-twenty-fourth. The light from the slit passes through first a photographic lens $B$, then a replica of a diffraction grating $G$, which disperses it into a normal spectrum. Just in front of the plate $P$ is a screen $C$ bearing on it reference lines to mark intensities, and also wave lengths on the plate. The end of this plate, through which the red part of the spectrum passes, is stained with a yellow filter dye to screen out the second order violet light which in the grating spectrum is superposed on the first-order red.

The tungsten lamp is used without any correcting screen because the red and yellow sensitiveness of any plate is so small compared with its blue sensitiveness that the humps showing theorthochroma- 
tism of the plates would have been too small to compare readily. It should be kept in mind, therefore, that the spectrograms do not represent rigorously the spectral sensitiveness of the plates to average noon sunlight, but rather to a light which is deficient in the violet and blue.

\section{FILTER FACTOR APPARATUS}

A filter factor is the ratio of exposure time required with a given filter to the exposure without a filter; hence, to obtain the proper time of exposure when using a filter, the correct exposure time required without a filter must be multiplied by the filter factor in order to get an equivalent negative.

The apparatus ${ }^{7}$ for measuring filter factors (Fig. 20) is constructed as follows: Light from the two sides of a standard metal filament lamp $L$ is reflected by similar mirrors $M_{1}, M_{2}, M_{3}, M_{4}$, and by similar prisms, $P_{1}$ and $P_{2}$, so that the two beams fall side by side on the photographic plate, $E$, the filter factors of which are to be determined. In front of the plate is a simple shutter. The source of light, $L$, is movable along the line joining $M_{1}$ and $M_{2}$. At $F$, between $M_{3}$ and $M_{4}$, carriers to hold the filters may be inserted.

The method of procedure is as follows: The lamp initially at the position $a$ gives two beams of equal intensity at the photographic plate, provided the distances traversed by the two beams are the same, and identical optical conditions of reflection and absorption obtain for the various media through which the beams pass.

If a filter be inserted in one path, the intensity of that beam is decreased. Equal illumination on the plate is obtained by shifting the lamp toward the filter, thus shortening that path and increasing the other. Since the intensity of illumination varies as the square of the distance from the source, the ratio by which the filter cuts down the intensity of the light is equal to the square of the length of the path containing the filter divided by the square of the length of the other path. The filter factor is the inverse of this ratio.

In practice the point of balance is obtained by making a series of exposures on the plate with the lamp set at arbitrary distances from the center position $a$, choosing these distances so that some are on one side of the point of balance and some on the other. The

${ }^{7}$ A detailed description of this is given in B. S. Sci. Papers, No. ${ }_{409}$. 
plate is then developed and fixed and the density differences measured on the photometer. These differences are finally plotted against the distance as positive or negative, according to whether the setting made the lamp distance too large or too small, and the setting for a balance is obtained from this curve.

In the apparatus the two paths are each $\mathrm{I} \mathrm{m}$ long when balanced without a filter, and the lamp has a movement of about $69 \mathrm{~cm}$, so that the range of factors which can be measured is from $\mathrm{I}$ to 30 . The filters used must belarger than one-half inch square. The strips of the photographic plate to be tested are $\mathrm{I} 1 / 8$ by 5 inches and exposures for two filter factors may be conveniently recorded on each.
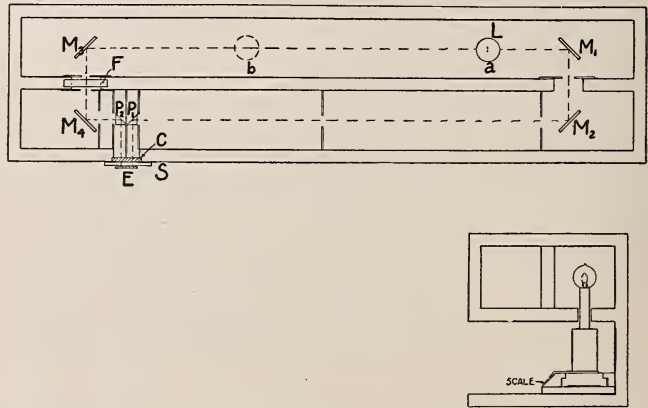

FIG. 20.-Diagram of apparatus for measuring the filter factors

In order to get filter factors applicable to outdoor use, it is necessary to modify the distribution of spectral energy of the metal filament lamp by placing in both beams a suitable screen. It is also necessary to burn the lamp at a constant and specified current, so as to keep constant its spectral distribution of energy. The combination of lamp and filter is identical with that used as the standard source of this Bureau's sensitometer. How successful the apparatus described has proved, together with the closeness of approximation of the light source to sunlight, is shown in Fig. 21. Exposure times were given which were proportional to the filter factors as measured, and the two plates on which the eight exposures were made were developed together for the same 


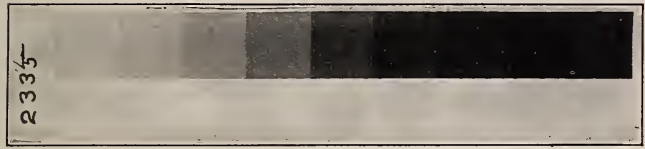

Fic. 18.-Test strip (slightly reduced) showing the nine densities due to exposure and the fog strip 


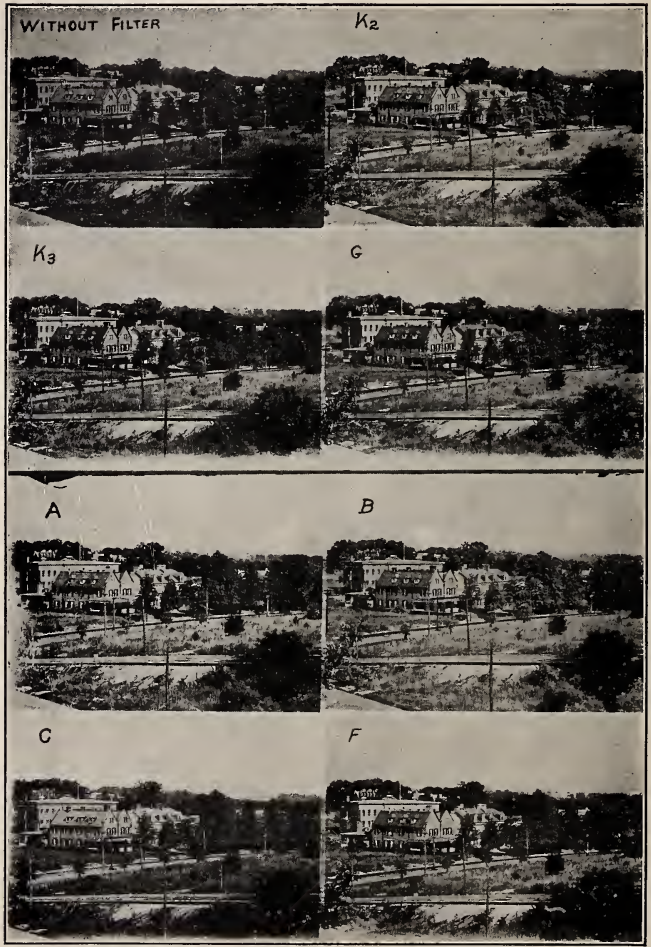

FIG. 21.-Photographs taken with and without filters. The exposure times with filters were adjusted according to the measured factors 
length of time and printed together on one sheet of paper. Had the negatives not been practically equal, it would not have been possible to secure prints of equal depth.

\section{RESOLUTION}

It is common experience that when a negative is to be enlarged there is a practical limit, beyond which the enlargement takes on a. granular appearance and the tones instead of being smooth become discontinuous. The same effect is observed when examining a negative under a microscope. There is a limit to the detail which can be recorded with a given photographic material. This limit may be expressed as the distance by which two points of light must be separated on the sensitive film so that they will be recorded as two images and not as one. For ordinary photographic negatives, this limit lies between four ten-thousandths and sixteen ten-thousandths inch (one-hundredth to fourhundredths $\mathrm{mm}$ ). As a general rule, the faster a plate the larger will be its grain size and the poorer its resolution, while the slower plates (such as lantern slides, transparency, and process plates) give the best resolution. But this is not strictly

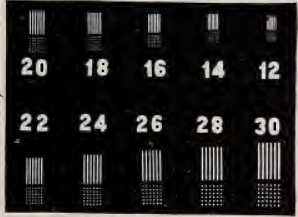

Fig. 22,-Test chart (reduced) used in determining the resolving power true. It is often desirable to use that brand of a given class of plates which has the highest resolving power.

To compare the resolving power of the plates and films, a test object was made which consisted of a glass plate with a series of apertures equal in width to the spaces separating them, evenly illuminated from behind by electric lamps. The test object was photographed on the plate under test by means of a $50 \mathrm{~mm}$ Zeiss Tessar (the resolving power of which exceeded that of the plates tested) carefully focussed and stopped down to $\mathrm{f} / \mathrm{i} 6$. The size of the test object and its distance from the lens were so chosen that the distance from center to center of the various sets of lines and dots when projected on the photographic plate were 0.012 , $0.014,0.016,0.018,0.020,0.022,0.024,0.025,0.028$, and $0.030 \mathrm{~mm}$. The various brands of plates were developed uniformly for six minutes in pyro developer, tray strength. (This development represents fairly the conditions under which plates are used, 
inasmuch as a portrait plate is developed for low contrast, which it reaches in about the same time that a slow plate reaches the high contrast for which it is used.)

They were then examined with a fairly high-power microscope (I00 to 300 diameters) and the resolution "number" taken corresponding to the separation which the plate was just able to make. Thus a resolution number of 18 means that the plate was able to resolve lines whose centers were $0.018 \mathrm{~mm}$ apart. The principle used in deciding when the lines were resolved was whether or not the number of lines of the test pattern could be distinctly counted. ${ }^{8}$

Besides the grain size, other factors which affect the resolving power of a plate are irradiation and the spreading of the image in development. Irradiation is the spreading of the image due to the reflection of light in the film from one silver grain to another. It is found that the greater the exposure the lower the resolution of a plate. ${ }^{9}$

\section{HALATION}

A careful distinction must be made between irradiation and halation. Halation (which may be noticed in the "halo"surrounding the image of a bright point of light against a dark background) is due to the total reflection of light inside the glass or celluloid support. The silver grains spread or diffuse the light in all directions. The light passes into the glass at all angles; that which strikes the second surface of the glass at less than the so-called critical angle of total reflection is largely transmitted, while that which strikes the second surface at an angle equal to or greater than the critical angle is all reflected back into the glass and its coating. It is this reflected light that causes the halo. The size of the halo is determined by the thickness of the glass and its critical angle, which may be calculated from its refractive index.

Halation may be avoided by the use of backed plates, or by surface development. If the back surface of the glass plate 3 is coated with a substance having practically the same index of refraction as glass, but containing light-absorbing materials, the light which would otherwise be reflected is absorbed, and halation thereby prevented. For this purpose caramel containing burnt sienna or lampblack is commonly used. A backing which dries

\footnotetext{
${ }^{8}$ It is our experience that the values assigned to given plates depend somewhat upon the observer. The values given are the mean of several observations by four different observers.

'It is, therefore, advisable not to place too much confidence in any measurements of resolution, as these will depend upon both the observer and the method used. It is doubtful if consistent values by independent observers can be obtained until the method and exact procedure are better standardized.
} 
quickly and which does not come off in the developer consists of lampblack in alcoholic shellac. All the plates used in the sensitometric work of this article were backed with the black shellac.

Halation occurs in the same way with films, but since the film support is thinner, the spreading is smaller. A film is difficult to back for the purpose of preventing halation.

\section{FOG}

The fog which occurs in development is one of the properties of a plate which is of importance to the user. It is well known that the density of chemical fog increases with the time of development and accordingly with the increase of contrast. The latter is the most important factor in choosing a plate. Since the photographer must develop a plate to a certain contrast, what he wants to know is whether one plate fogs worse than another in being developed to a given contrast. For this reason chemical fog in this work is plotted against the contrast (gamma) and not against the time of development.

\section{EXPERIMENTAL RESULTS}

\section{EXPLANATION OF CHARTS}

Density Exposure Curves (Fig. I of THE Charts).-The three characteristic curves represent developments of 3,6 , and I 2 minutes in pyro developer of tray strength at $20^{\circ} \mathrm{C}$, rate of stirring, 40 rpm. Each curve is the graphical mean of the density measurements of three test strips. The usual exposure time was $16 \mathrm{sec}-$ onds (the squares received, respectively, $8,4,2, \mathrm{I}, \mathrm{I} / 2, \mathrm{I} / 4, \mathrm{I} / 8$, I/I6, I/32 seconds) and the intensity of the light at the test strip was I candle meter. In case the I6 seconds' exposure did not include all of the toe and shoulder of the curve, shorter or longer exposures were made.

Contrast-Development Curve (Fig. 2 of the Charts). - The values of gamma were obtained from Fig. I and plotted against time of development. From this curve may be obtained the time required to reach a given contrast, in chart 2 , for example, 3 minutes' development would be required to give unit contrast $(\gamma=\mathrm{r})$ under the conditions of development employed in making this test. With different developers, or the same developer at a different temperature, a change in the time of development as indicated on these charts would be required for a given contrast. Some idea of the contrast which it is possible to obtain with a

$90002^{\circ}-22-3$ 
given plate may be found from this curve since 12 minutes' development with tray-strength developer marks the time limit of practical development

Fog-Contrast CURVE (FIg. 3 of CharTs).-In this diagram are plotted the values of the fog (exclusive of glass and gelatin) for the various contrasts which the plate reached in development. Plates may thus be compared for freedom from fog at a desired contrast.

SPECTROGRAM (Fig. 4 OF CharTs).-In comparing the color sensitiveness of different plates by means of their spectrograms it must be remembered that the ratio of blue sensitiveness to yellow or red sensitiveness for a given plate must be made the basis of comparison. For example, the yellow "hump" of one plate must not be compared directly with the magnitude of the yellow hump of another plate.

FILTER FACTORS. - The filters referred to by letter are Wratten filters. Those referred to by name are Cramer filters. In some cases where the value of the filter factor is greater than 30 it has been omitted.

SPEED.-The number gives this Bureau's speed which is defined as $10 / i$. The speed given is calculated from the average of the inertias of the three development times. The intensity and color of the light used in these measurements is different from that of other observers, and accordingly B. S. speed numbers can not be converted into H. \& D. numbers, particularly in the case of color-sensitive plates.

SCALE.-The scale was measured on the straight-line part of the characteristic curve from the toe to the shoulder.

RESOLUTION NUmbER.-The resolution number represents the smallest distance from center to center of the lines on the negative which was resolved. In Table 5 are given the numbers which correspond approximately to distances in millimeters and in inches.

TABLE 5,-Resolution Numbers and Corresponding Intervals

\begin{tabular}{|c|c|c||c|c|c|}
\hline $\begin{array}{c}\text { Res- } \\
\text { olu- } \\
\text { tion } \\
\text { num- } \\
\text { ber. }\end{array}$ & $\begin{array}{c}\text { Cor- } \\
\text { respond- } \\
\text { ing } \\
\text { intervai } \\
\text { in miill- } \\
\text { meters. }\end{array}$ & $\begin{array}{c}\text { Cor- } \\
\text { respond- } \\
\text { ing } \\
\text { interval } \\
\text { in } \\
\text { inches. }\end{array}$ & $\begin{array}{c}\text { Res- } \\
\text { olu- } \\
\text { tion } \\
\text { num- } \\
\text { ber. }\end{array}$ & $\begin{array}{c}\text { Cor- } \\
\text { respond- } \\
\text { ing } \\
\text { intervai } \\
\text { in mill- } \\
\text { meters. }\end{array}$ & $\begin{array}{c}\text { Cor- } \\
\text { respond- } \\
\text { ing } \\
\text { interval } \\
\text { in } \\
\text { inches. }\end{array}$ \\
\cline { 1 - 5 } 12 & 0.012 & 0.00047 & 22 & 0.022 & 0.00087 \\
14 & .014 & .00055 & 24 & .024 & .00094 \\
16 & .016 & .00063 & 26 & .026 & .00102 \\
18 & .018 & .00071 & 28 & .028 & .00110 \\
20 & .020 & .00079 & 30 & .030 & .00118 \\
\hline
\end{tabular}


Developer Formulas.-These are as recommended by different plate manufacturers.

DEVELOPER FORMULA W

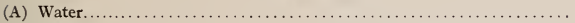

Sodium bisulphite. . . . . . . . . . . . . . . . . . . . . . .

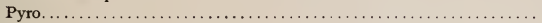

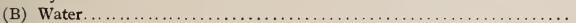

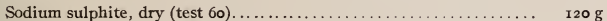

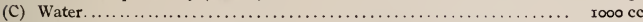

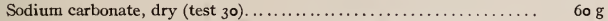

To develop take one part each of $\mathrm{A}, \mathrm{B}$, and $\mathrm{C}$ and seven parts of water.

DEVELOPER FORMULA $\mathrm{X}$

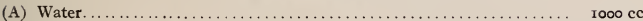

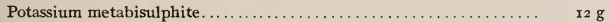

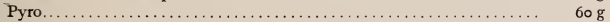

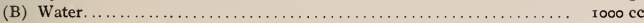

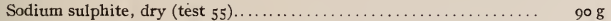

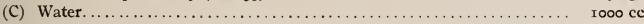

Sodium carbonate, dry (test 40 )........................... $75 \mathrm{~g}$

To develop take one part each of A, B, and C and seven parts of water.

DEVELOPER FORMULA Y

(A) Water. . . . . . . . . . . .

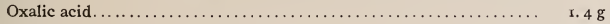

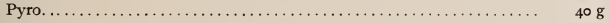

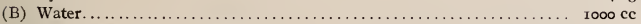

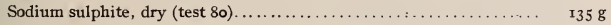

(C) Water. . . . . . . . . . . . .

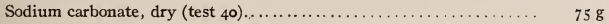

To develop take one part each of $\mathrm{A}, \mathrm{B}$, and $\mathrm{C}$ and seven parts of water.

DEVELOPER FORMULA $z$

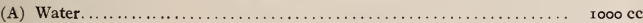

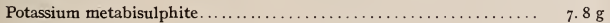

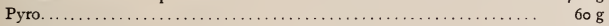

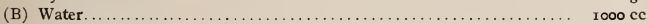

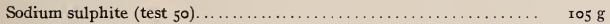

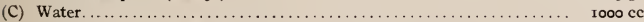

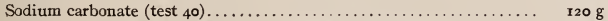

To develop take one part of A, B, and C and seven parts of water.

\section{SUPPLEMENTARY INTRODUCTION TO CHARTS}

It should be reiterated that the manufacturers of photographic plates and films are continually striving to improve the quality of their products. Materials now on the market may have, therefore, higher sensitiveness than given on these charts. It is equally true that some of the newer material may not equal in general or in some particular characteristic the quality given on the charts. Even where a manufacturer continues to use the same formula and procedure it is not at all certain that the resultant products will be uniform in all respects.

Some manufacturers appear to be making special efforts to improve the quality of their film products. In a year one maker's product whose film was only slightly 
orthochromatic and slow in speed more than doubled in speed and color sensitiveness. Another nearly equalled this record. Furthermore, several new brands of films and plates have been placed on the market that were not in existence when this work was done.

Another word of caution, the spectrograms on these charts are not in all instances true copies of the spectrograms on the original charts. The method of reproduction, zinc etching, is not well adapted to reproduce half tones. In the region of the spectrum where a plate or film had only a small comparative sensitiveness much has been lost. In some cases (the orthochromatic plates and films in particular), the sensitiveness in the yellow green is entirely lost. It is, therefore, advisable to judge the color sensitiveness by the filter factors only. The charts without filter-factor data are blue sensitive only, or so slightly color sensitive as to be of no practical value in this respect.

\section{CHARTS OF CHARACTERISTICS OF PLATES AND FILMS} Plates:

Ordinary ( 1 to 37 ) - Chart numbers

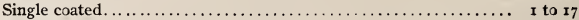

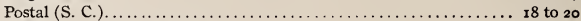

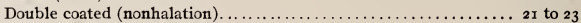

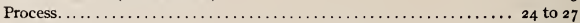

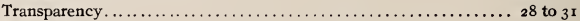

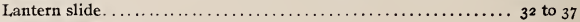

Orthochromatic ( 38 to $6 \mathrm{r})$ -

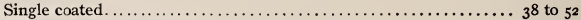

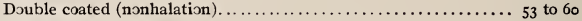

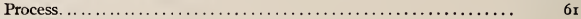

Panchromatic ( 62 to $7 \mathrm{I})$ -

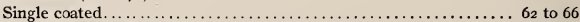

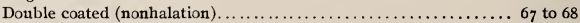

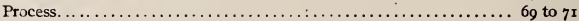

Films $(72$ to 83$)$ :

Orthochromatic-

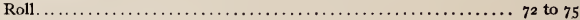

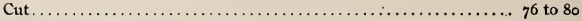

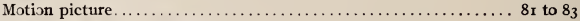

Plates and films for aerial photography $\ldots \ldots \ldots \ldots \ldots \ldots \ldots \ldots \ldots \ldots \ldots \ldots \ldots$ to 86 


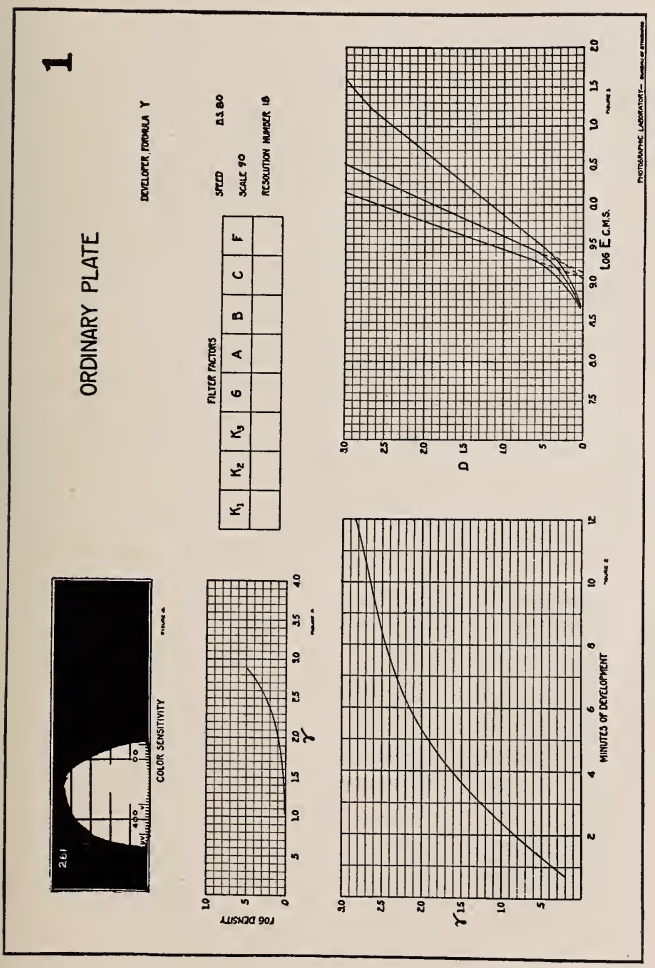




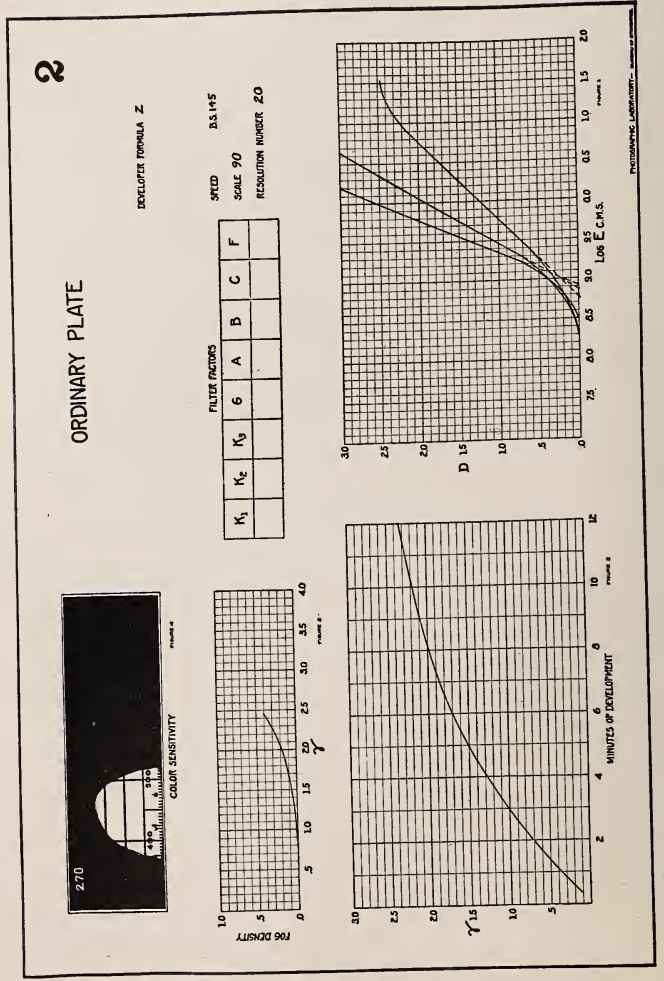




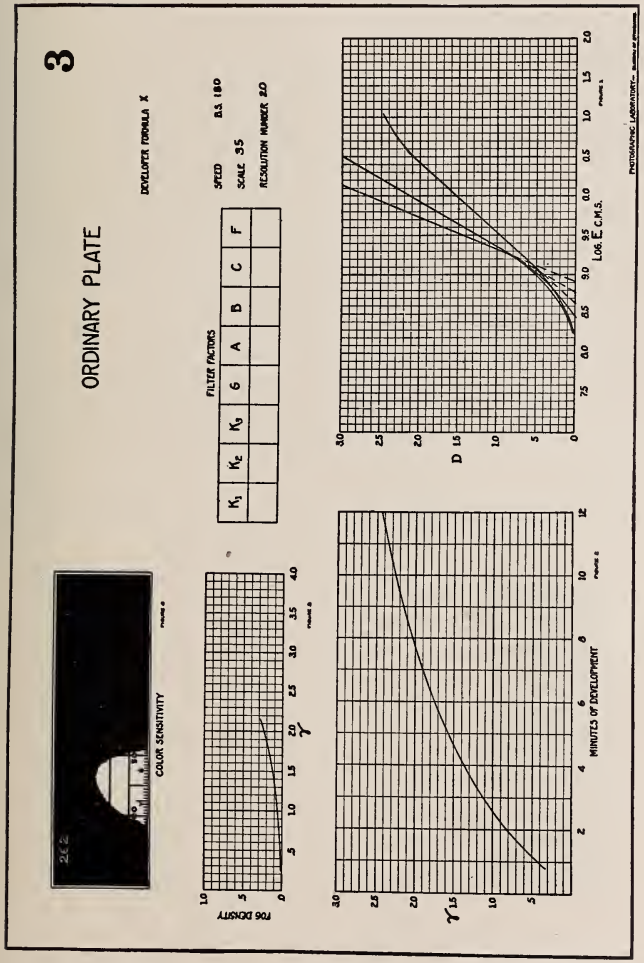




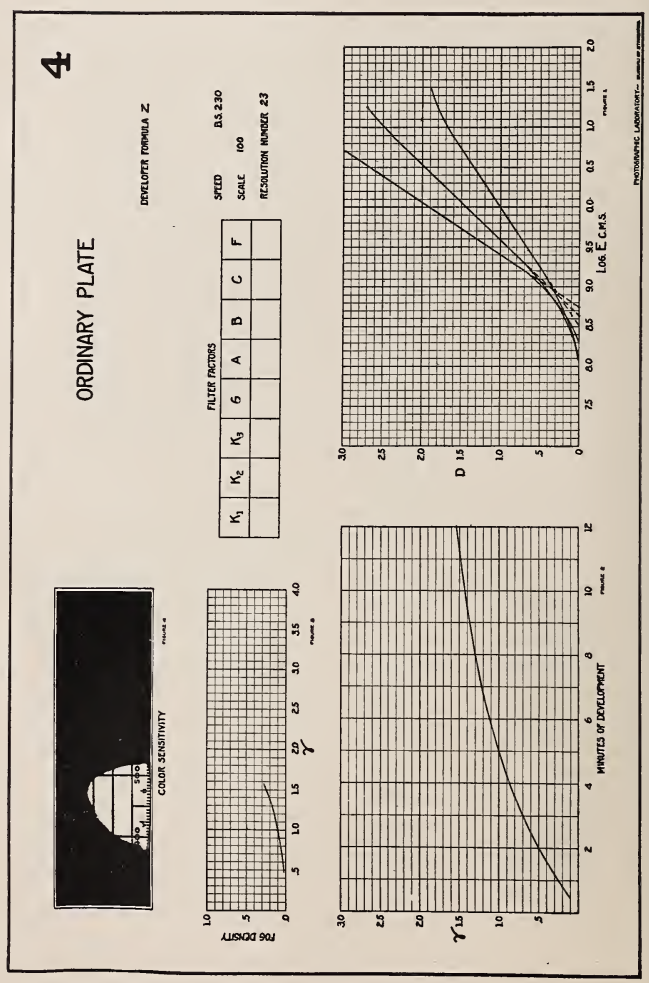




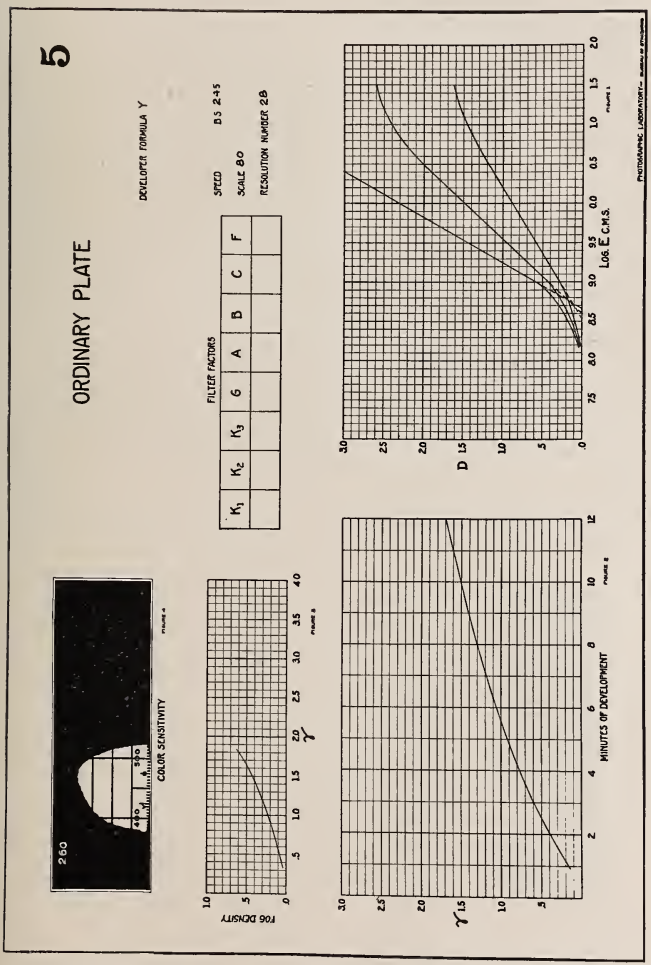




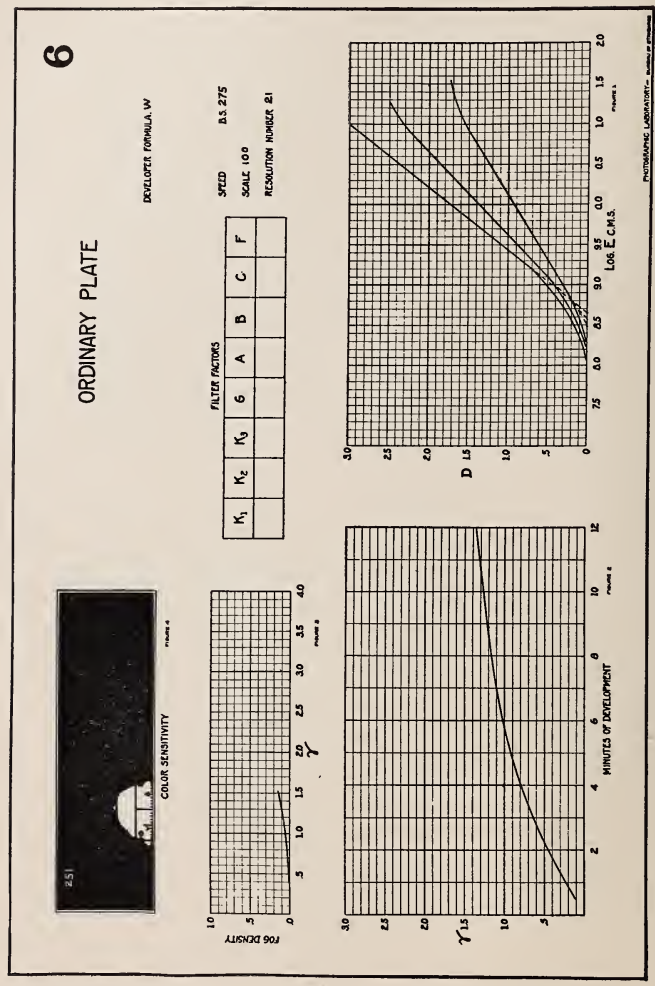




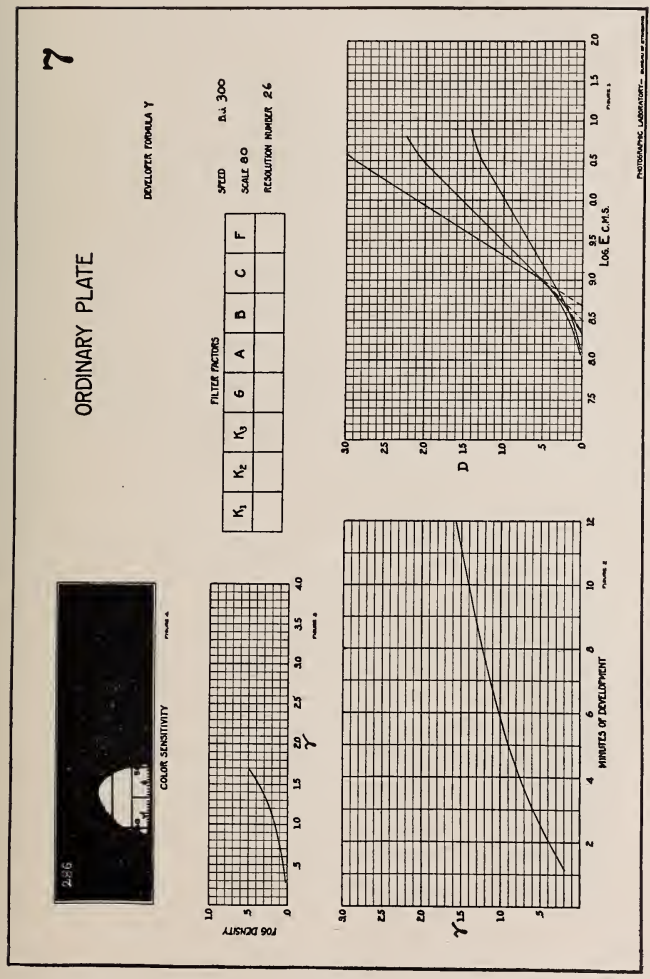




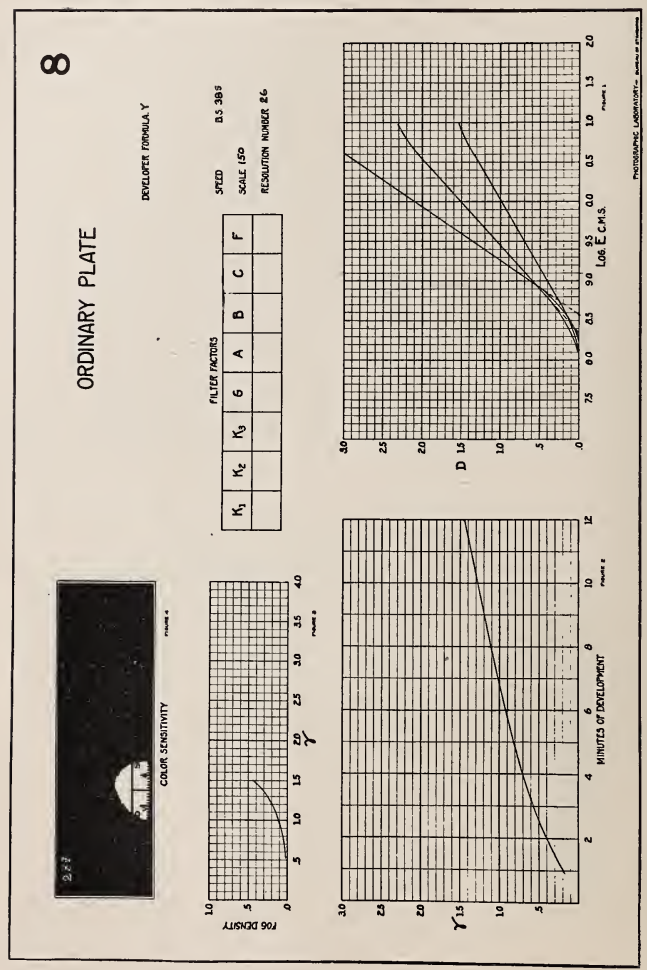




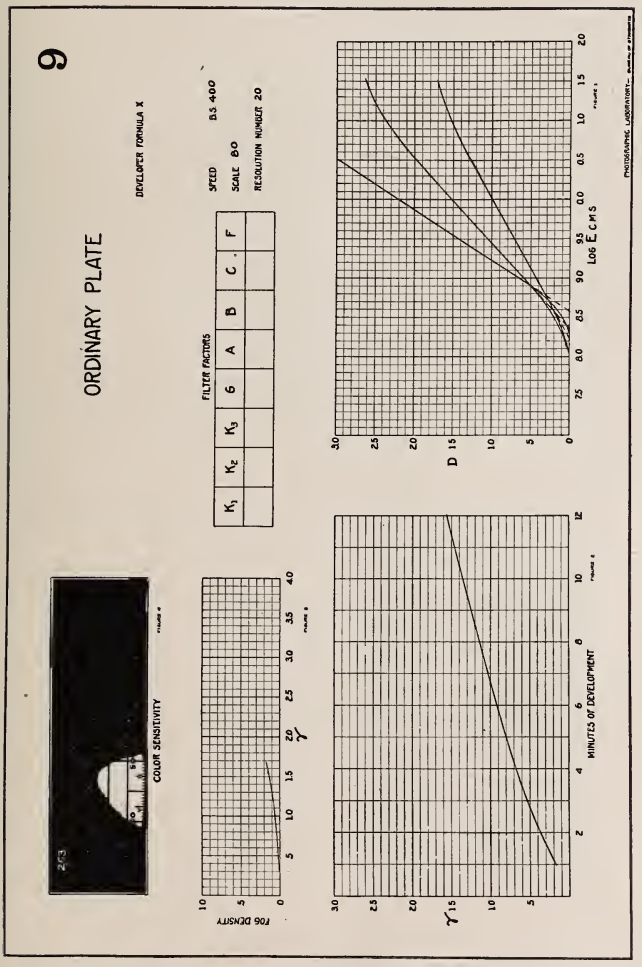




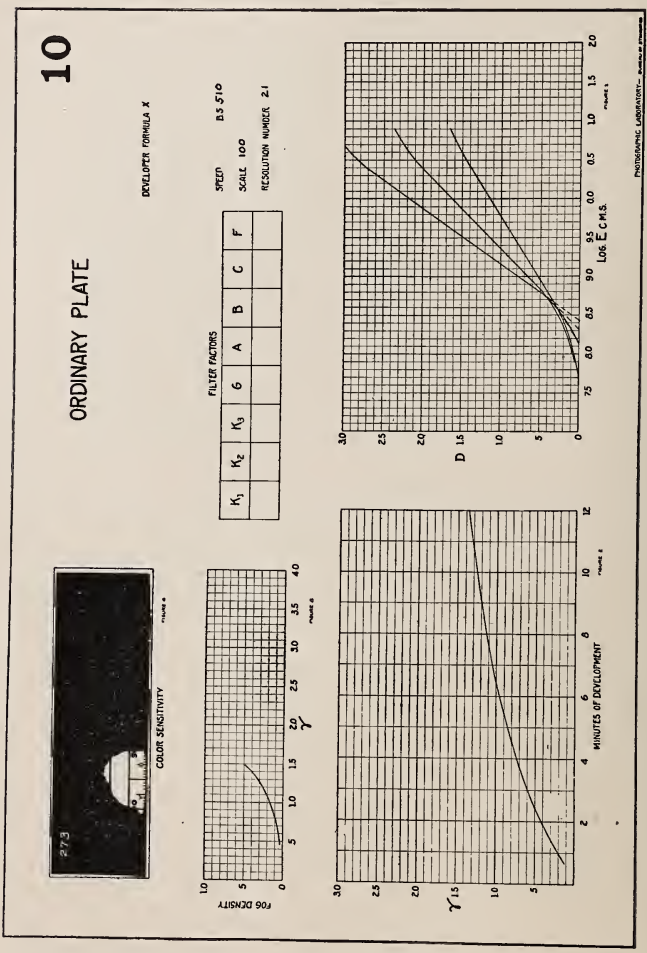




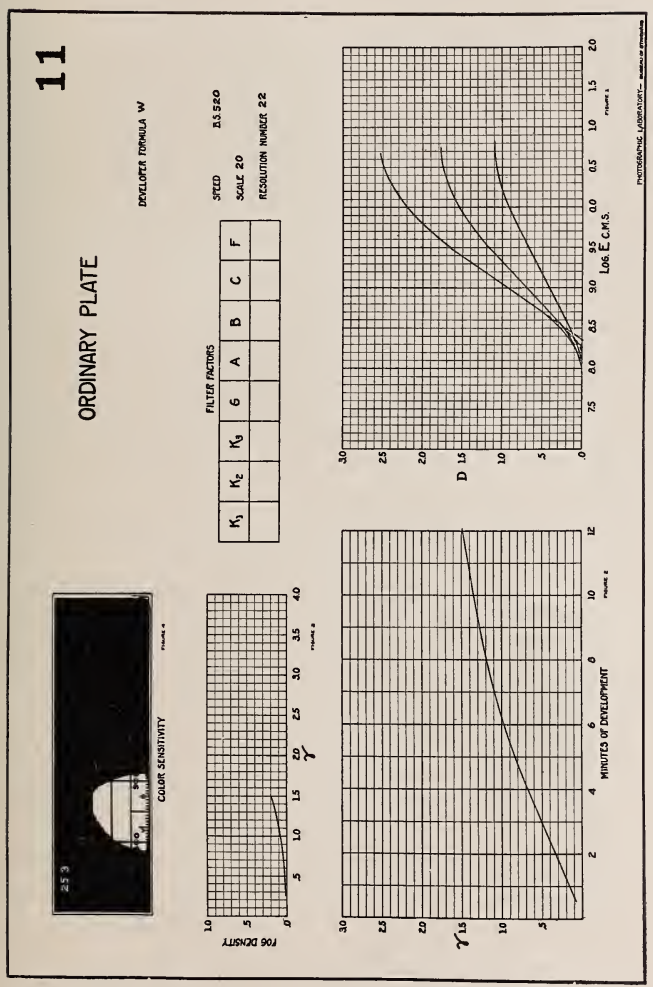




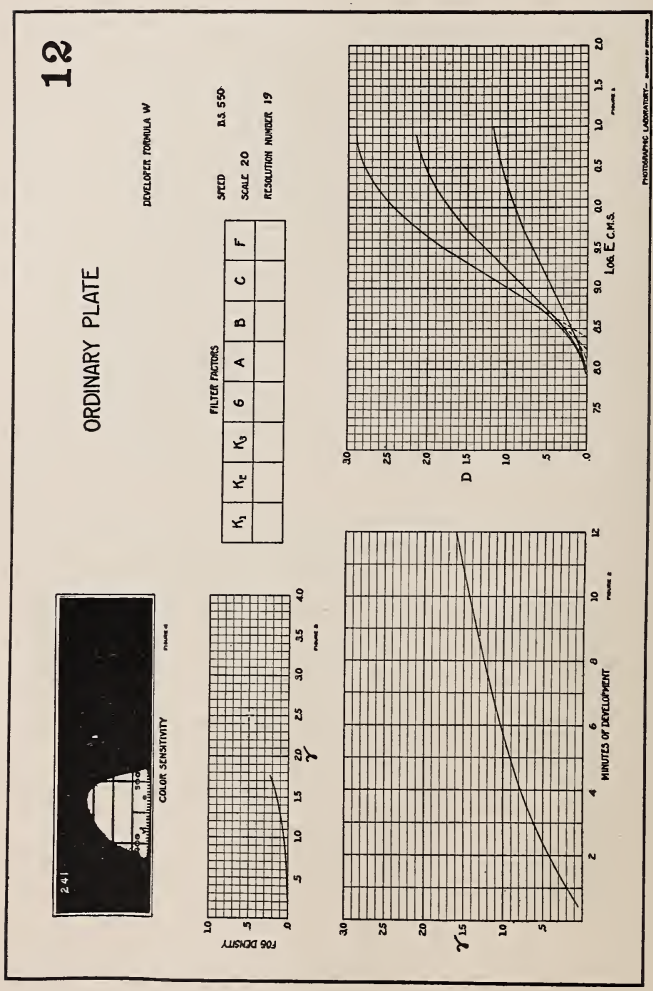




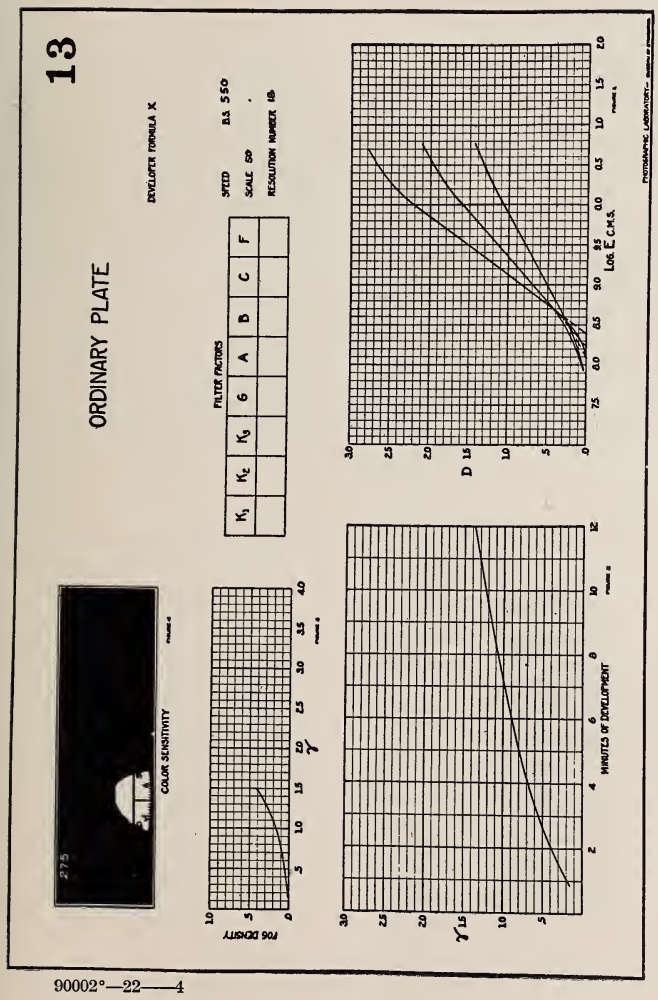




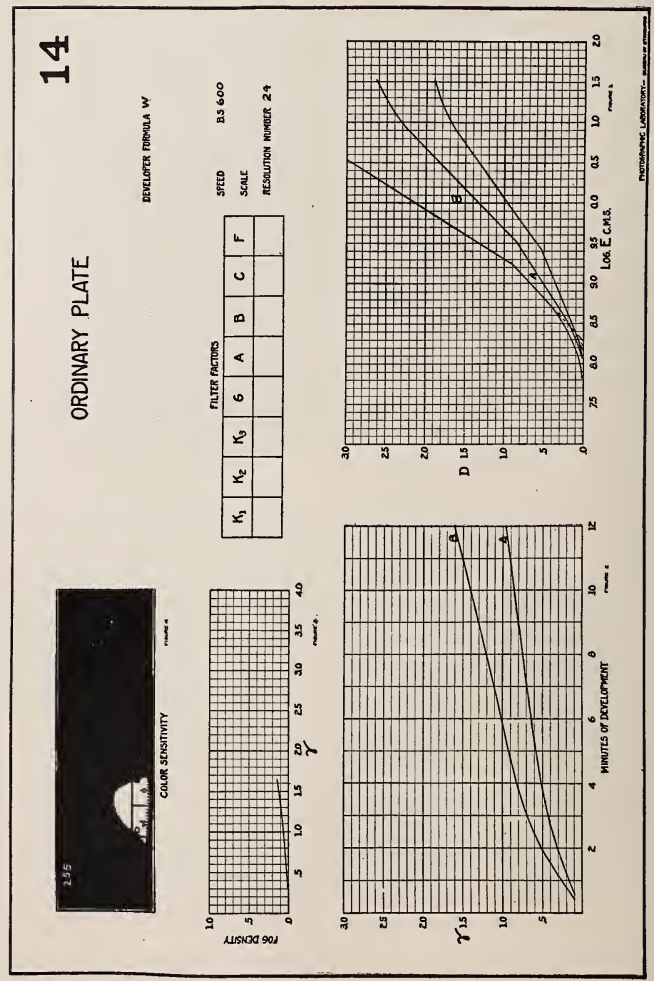




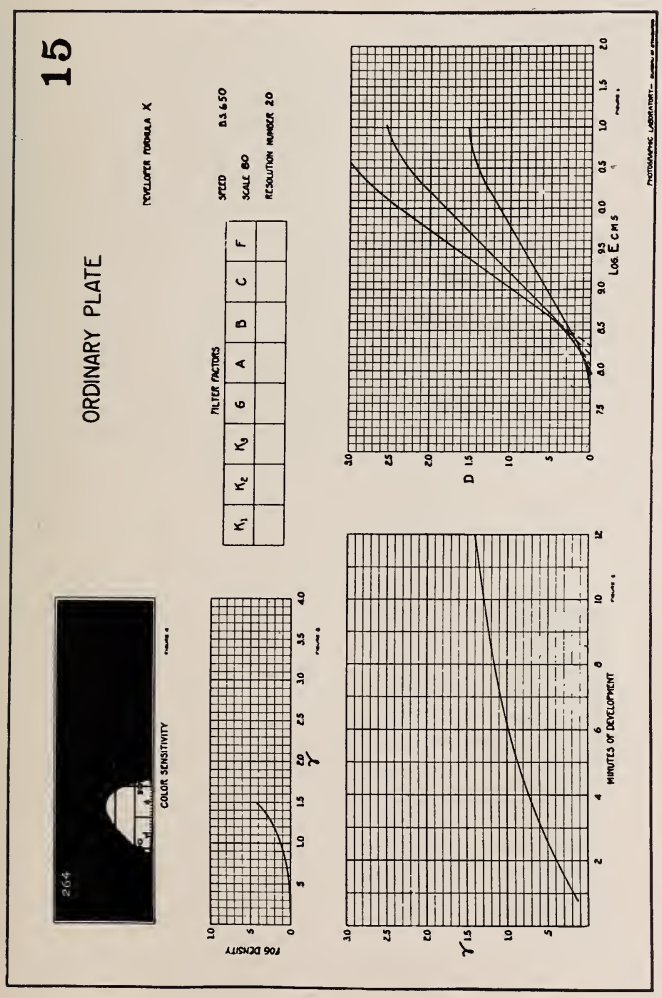




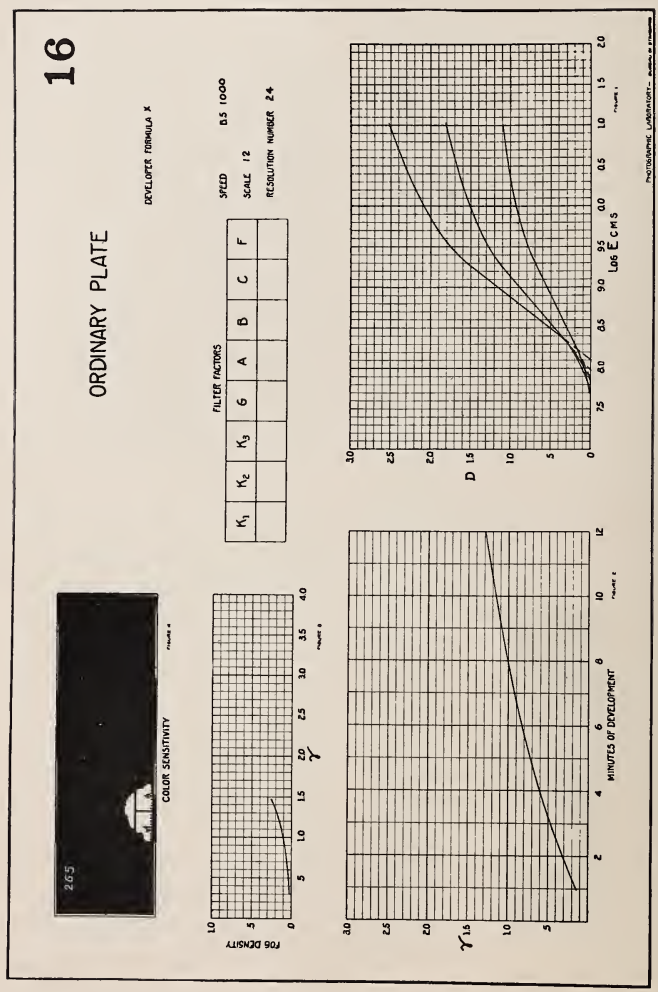




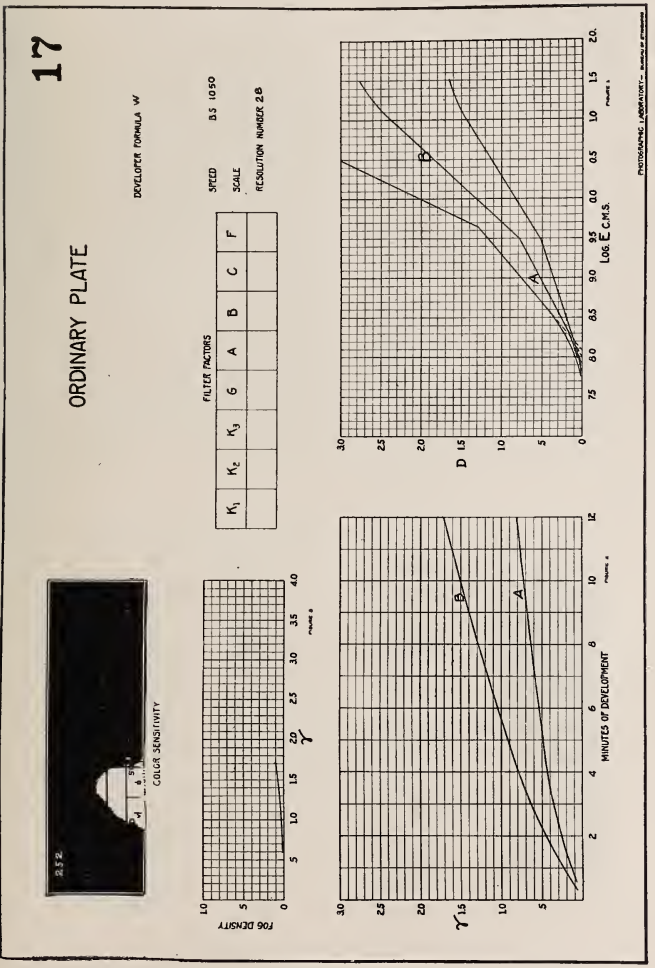




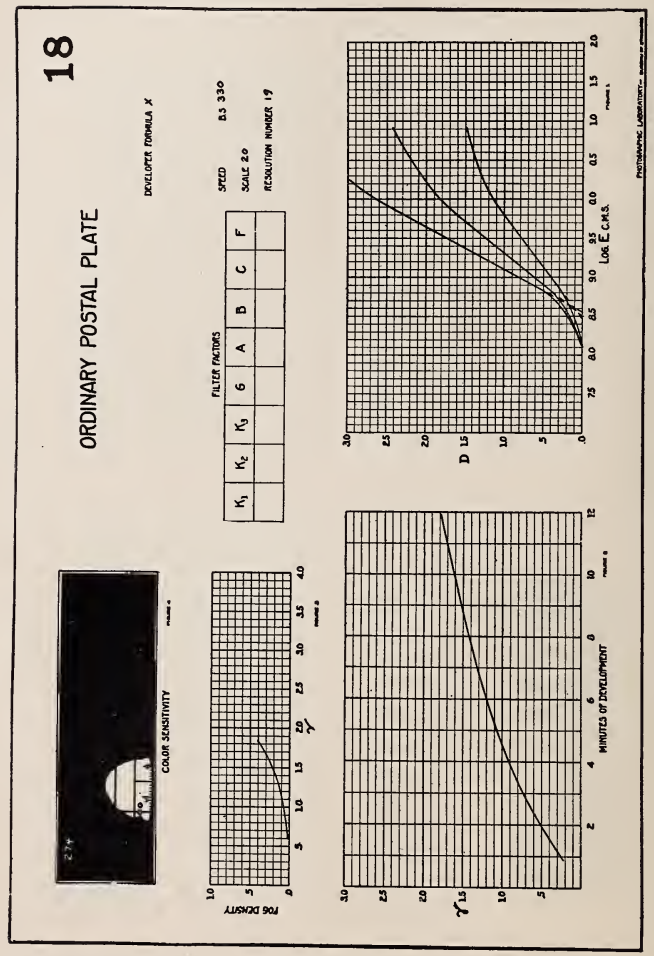




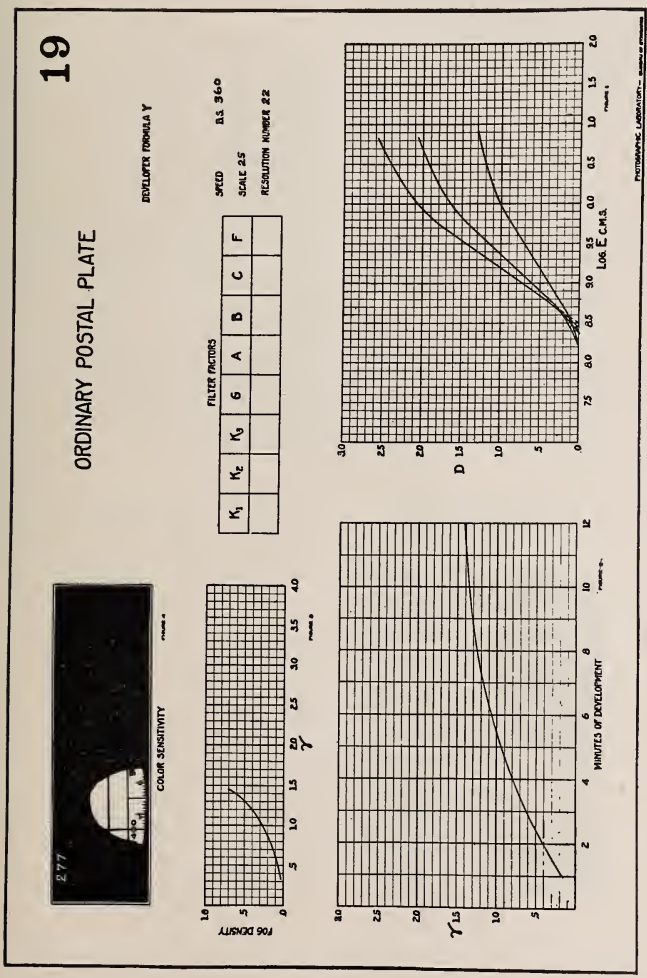




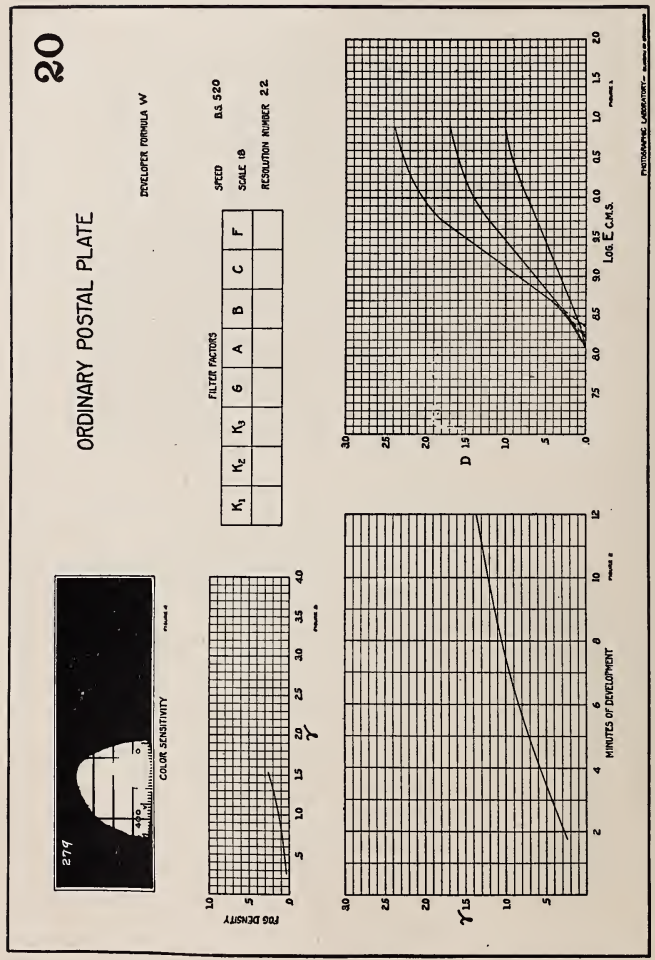




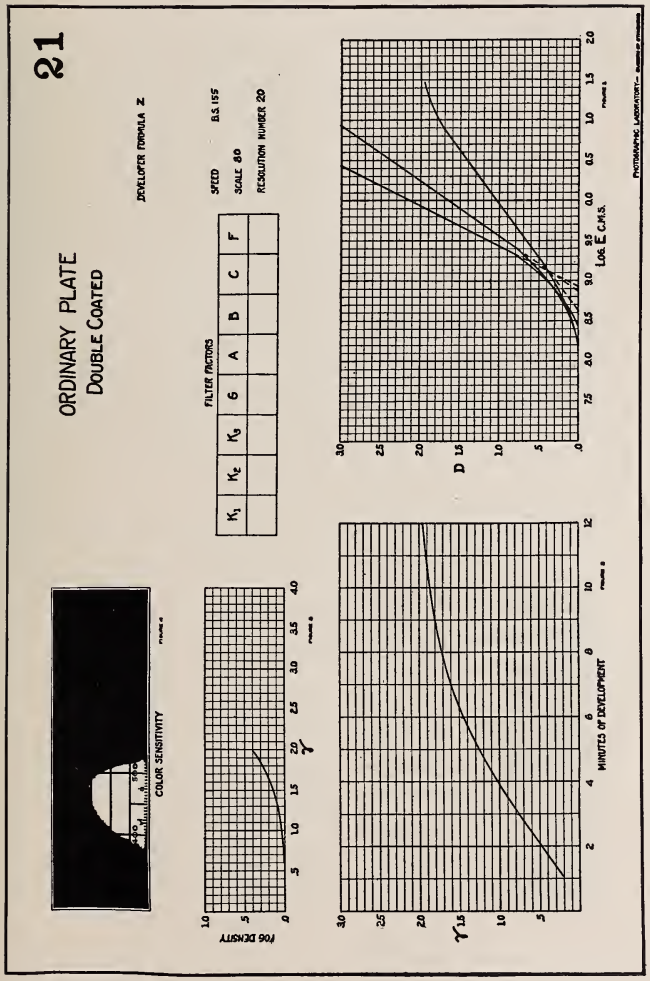




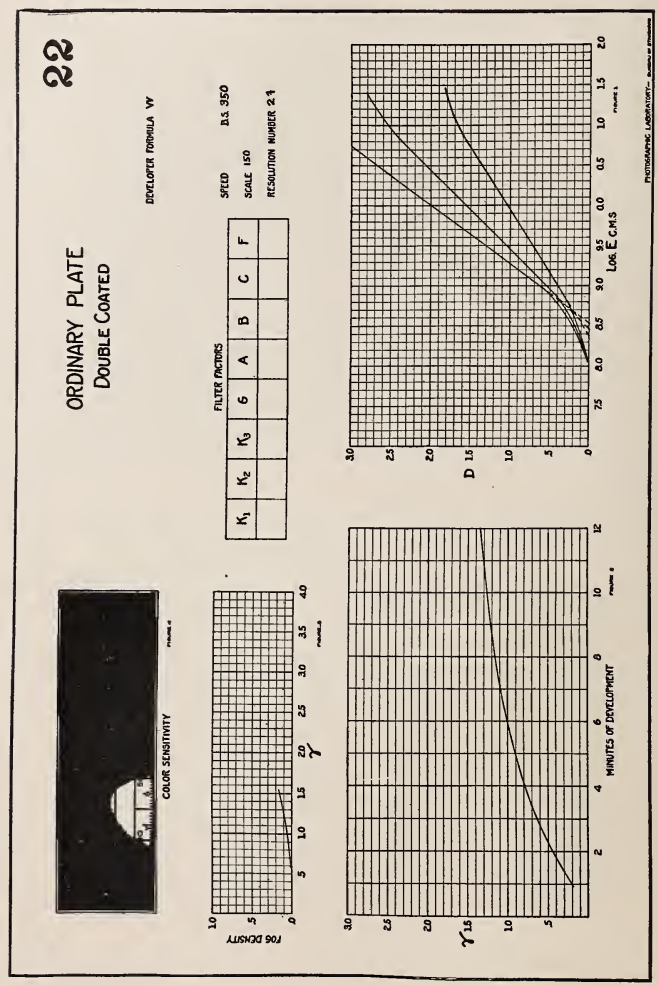




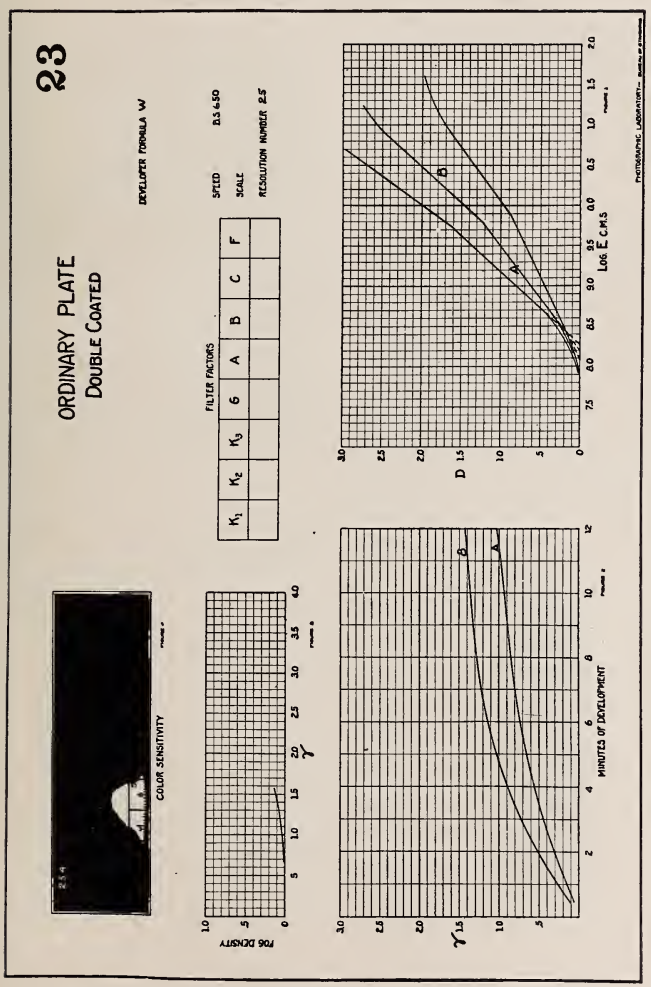




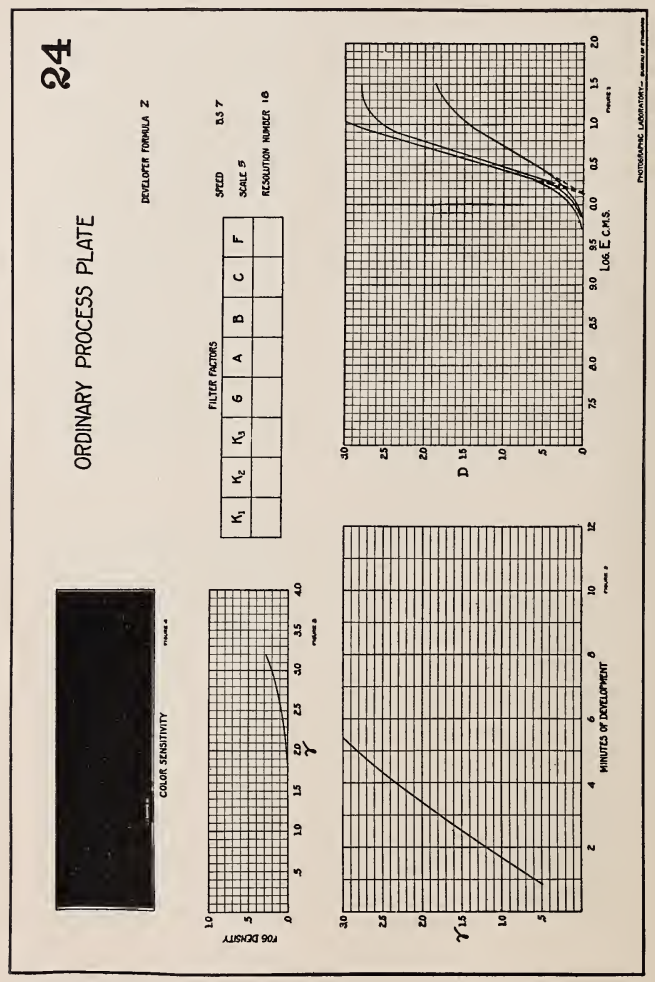




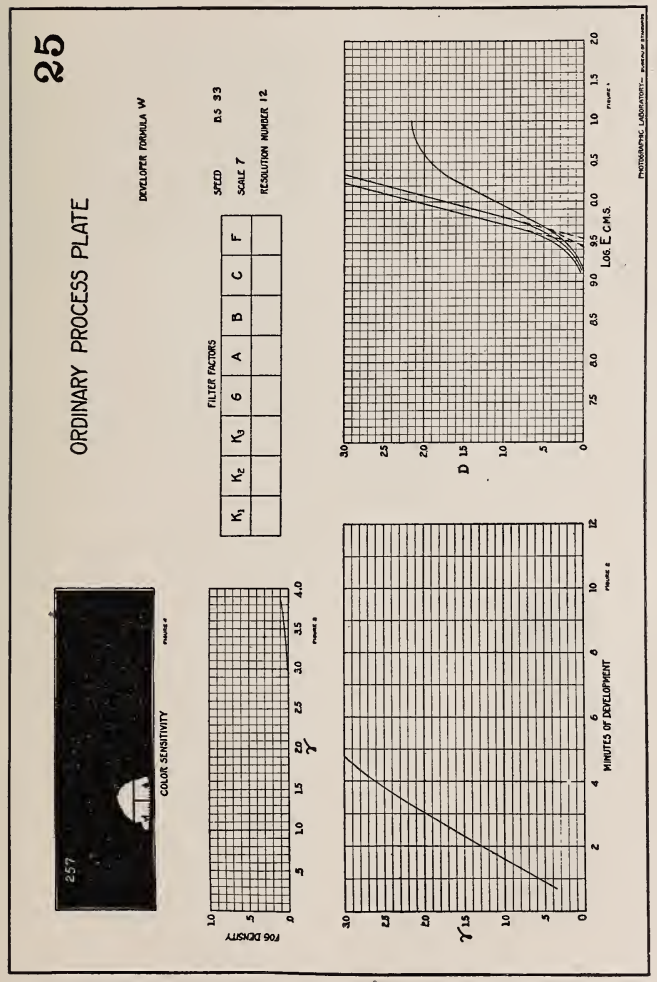




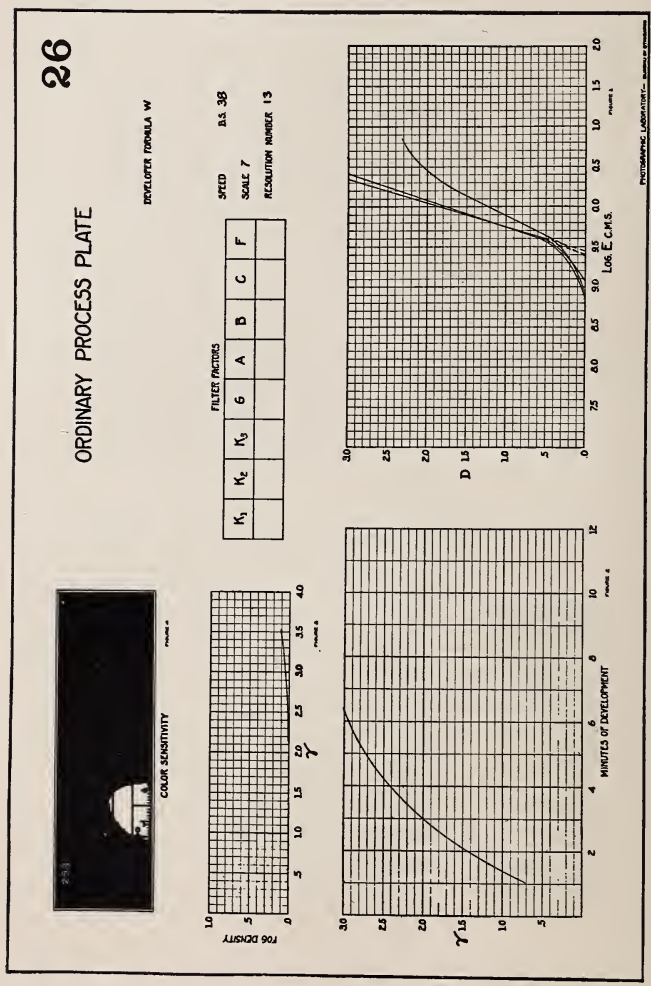




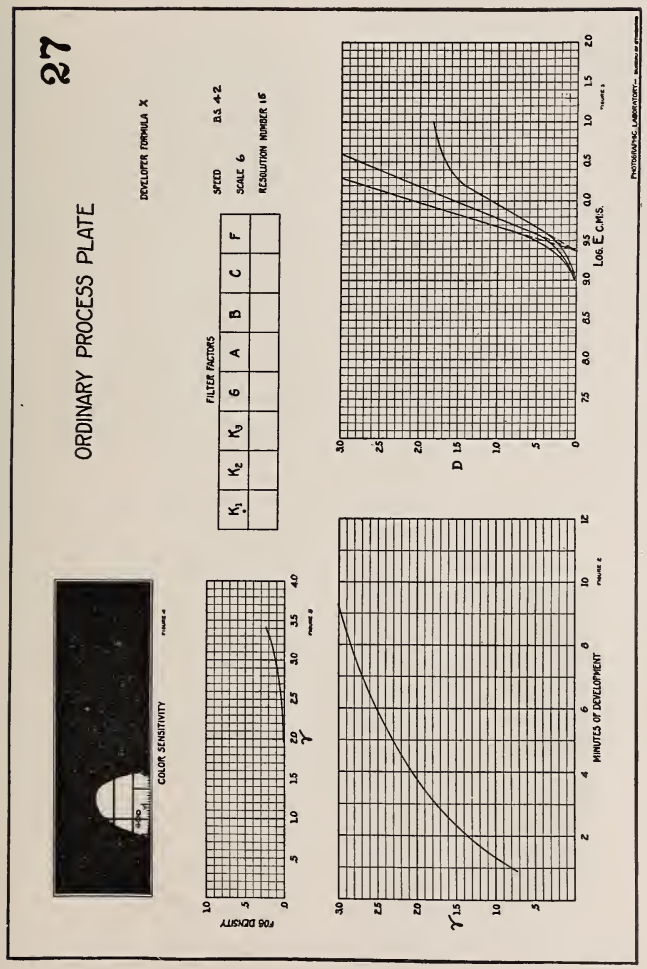




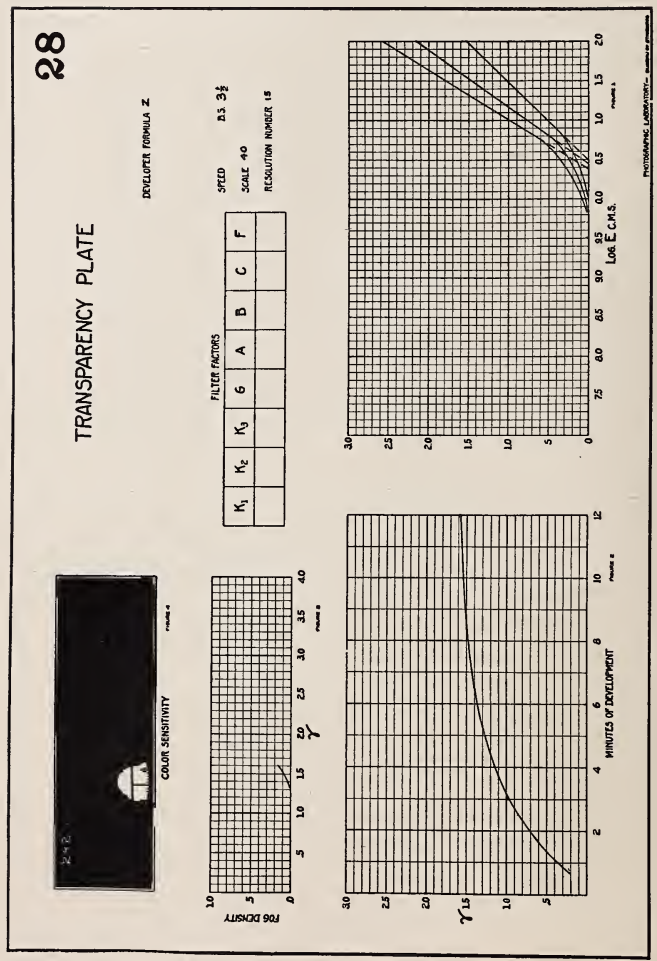




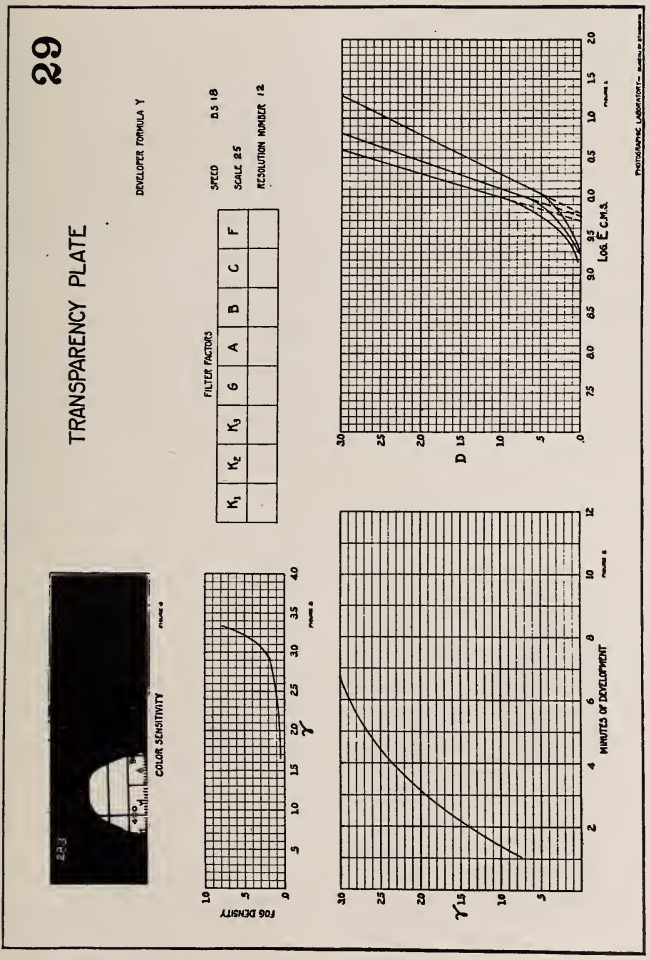

$90002^{\circ}-22-5$ 


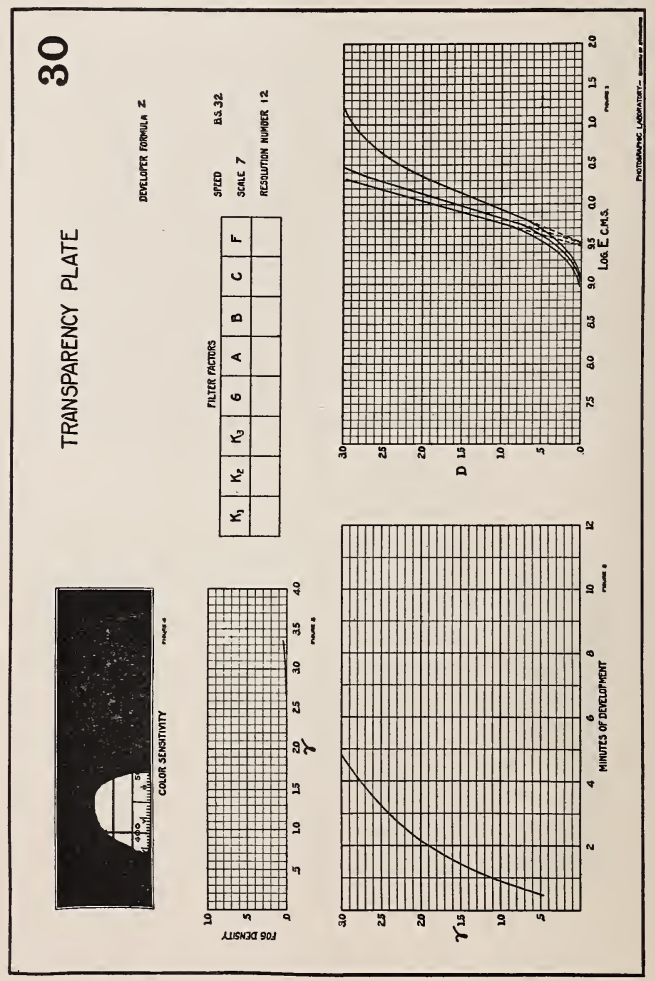




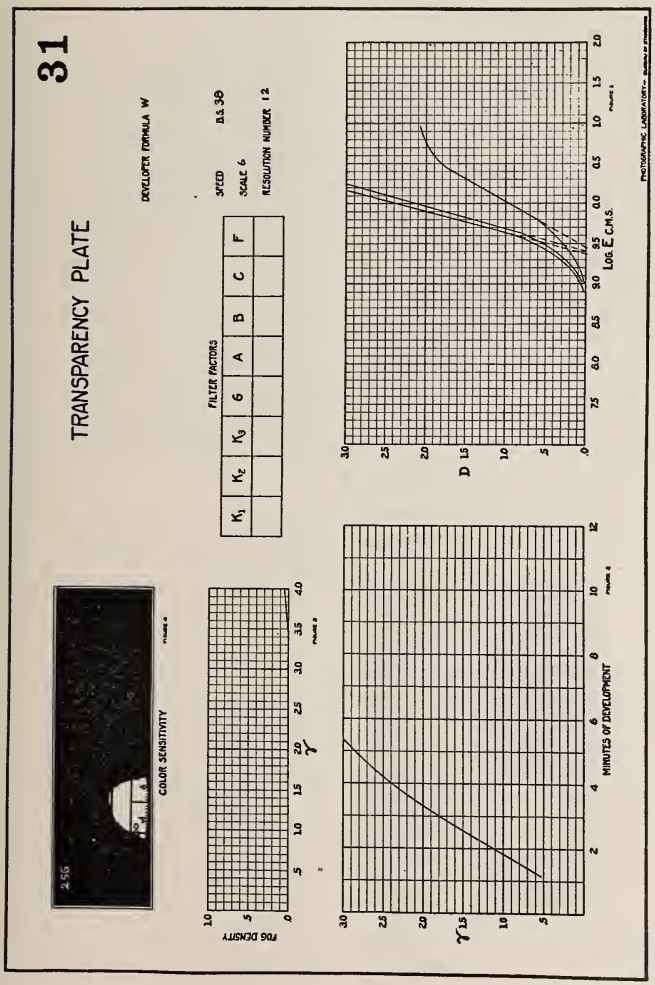




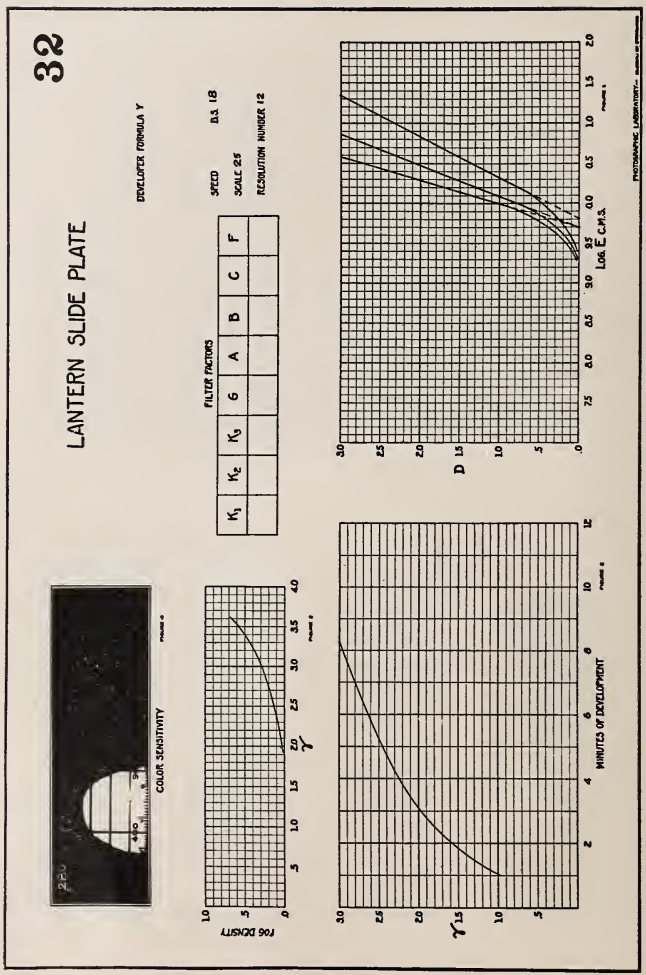




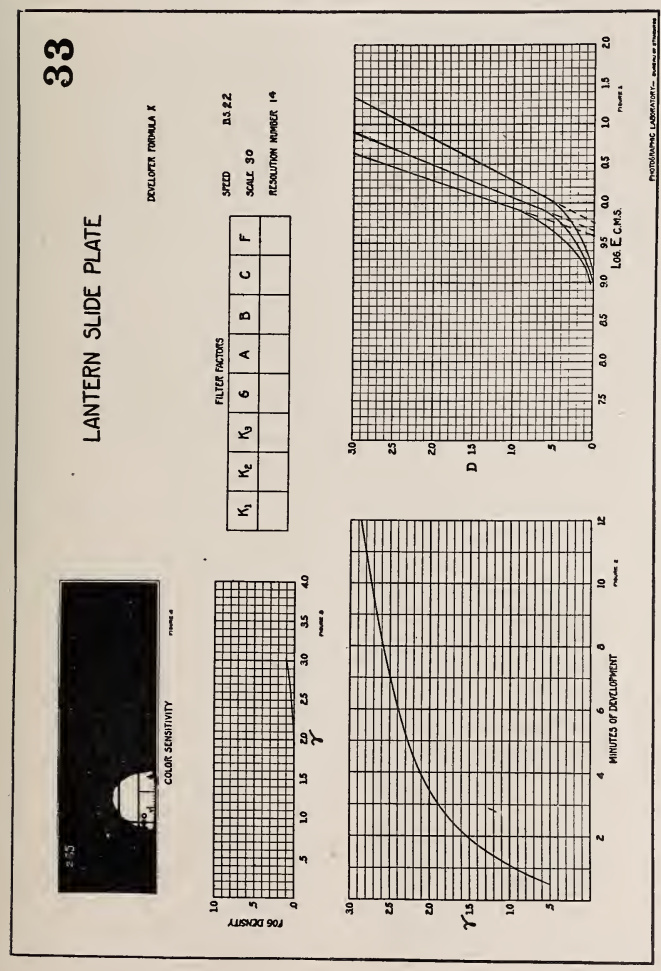




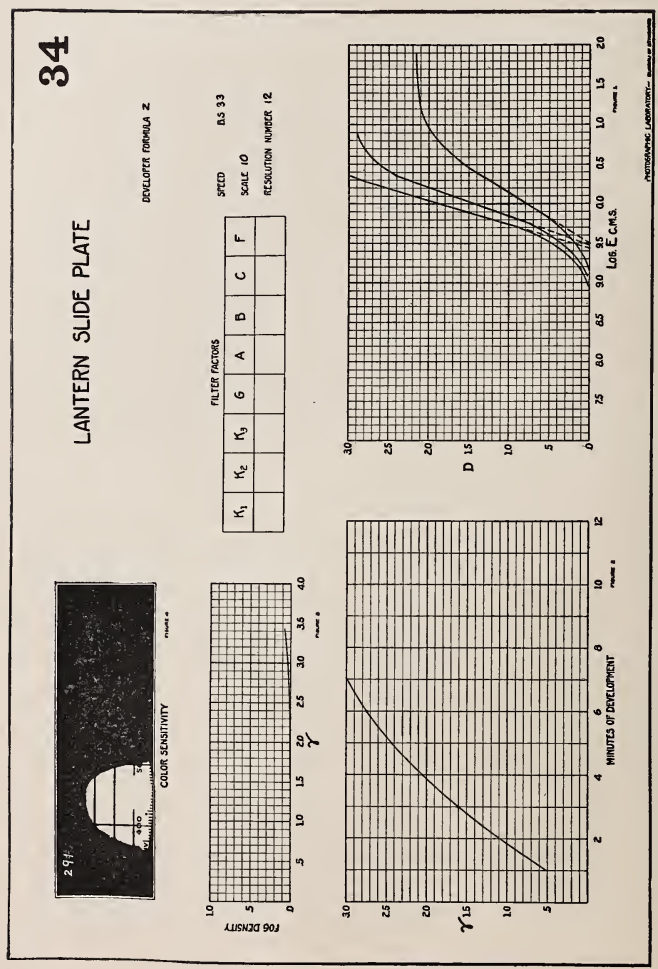




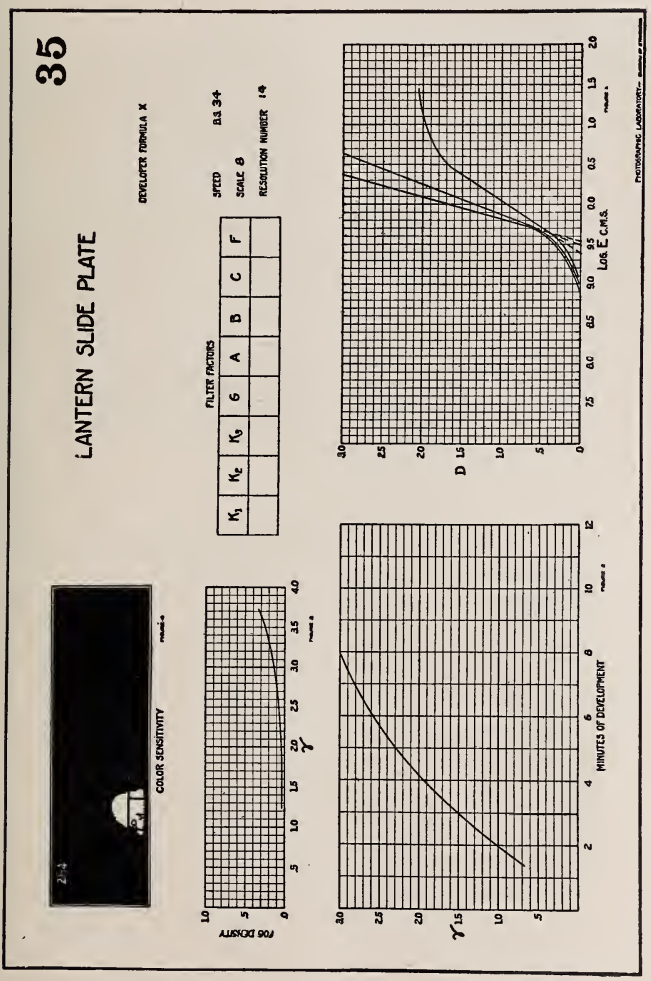




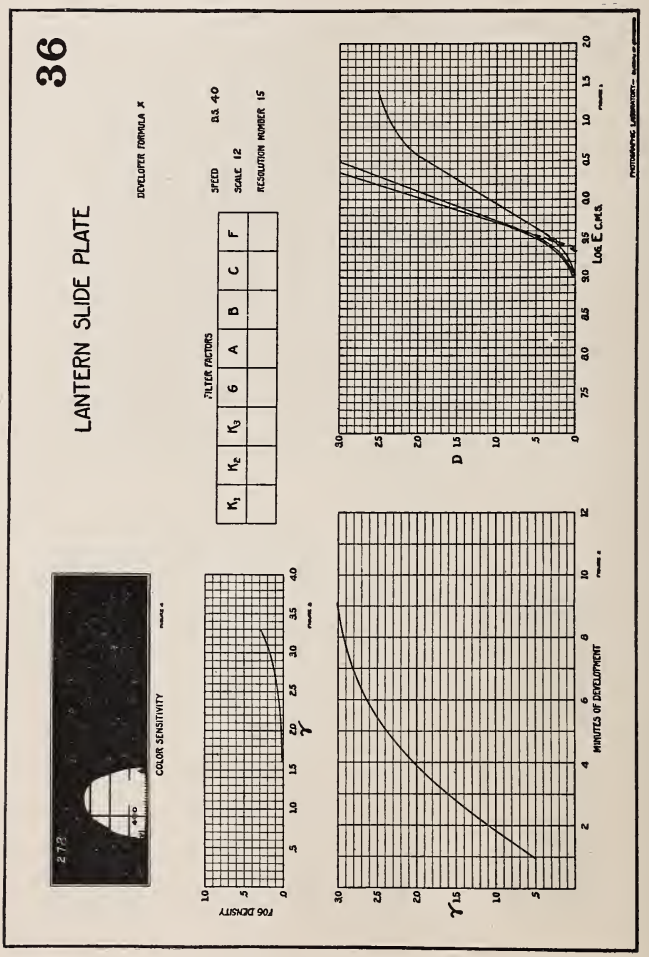




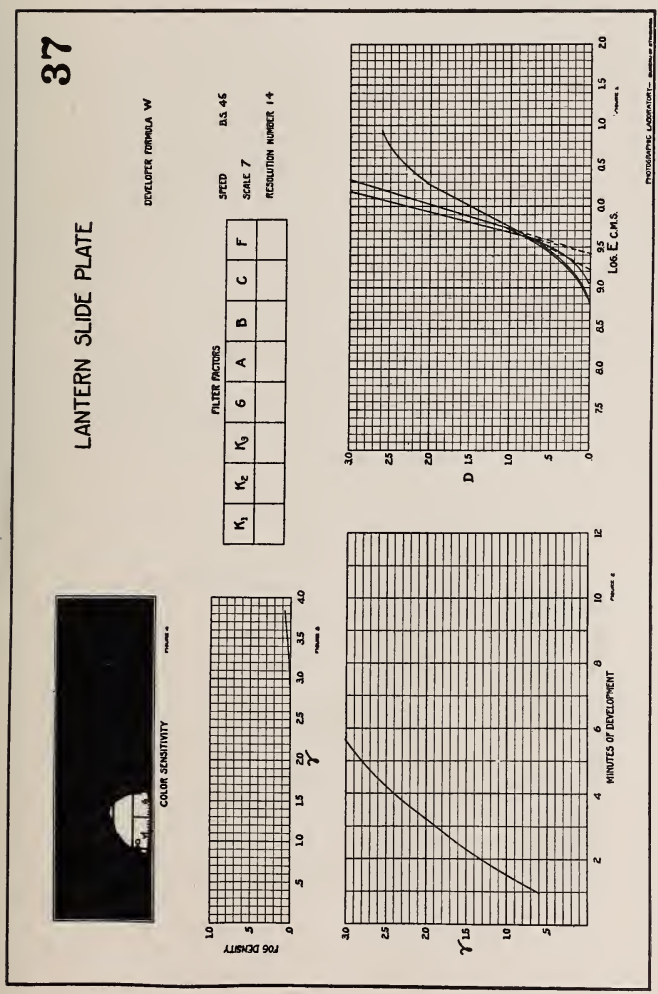




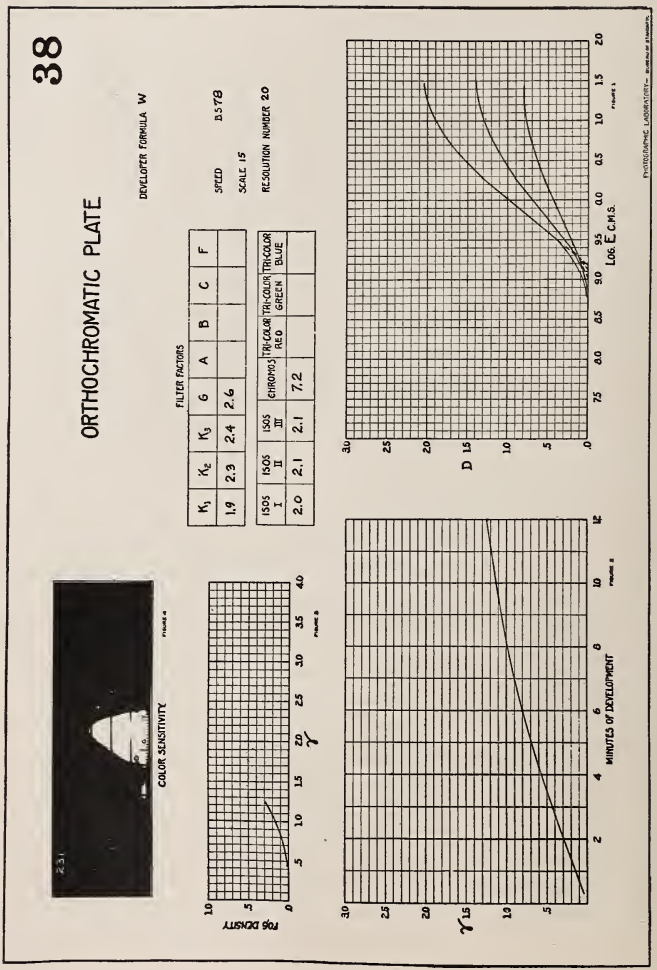




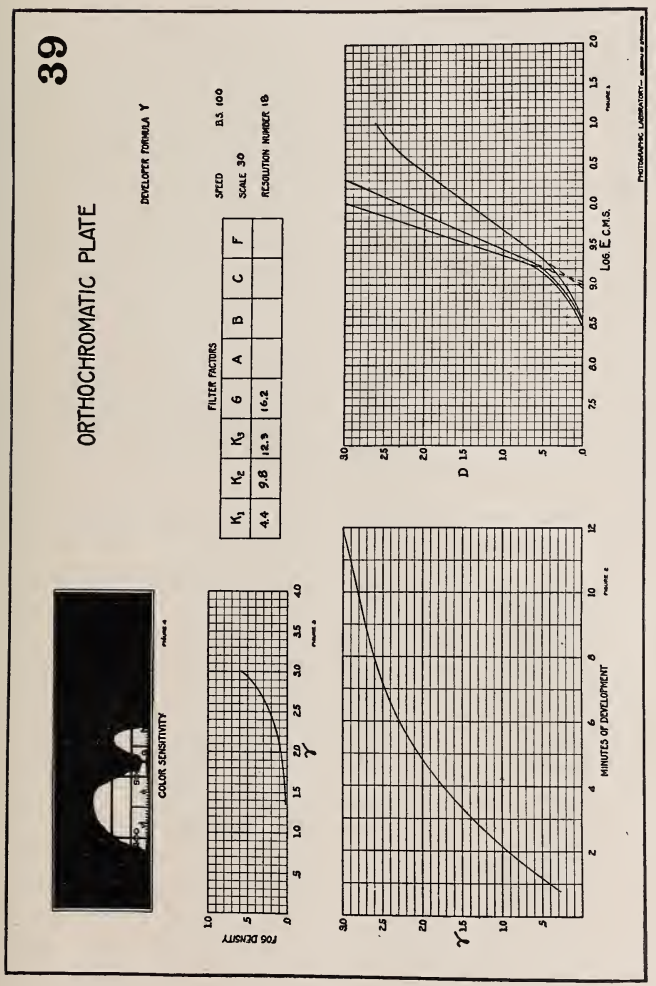




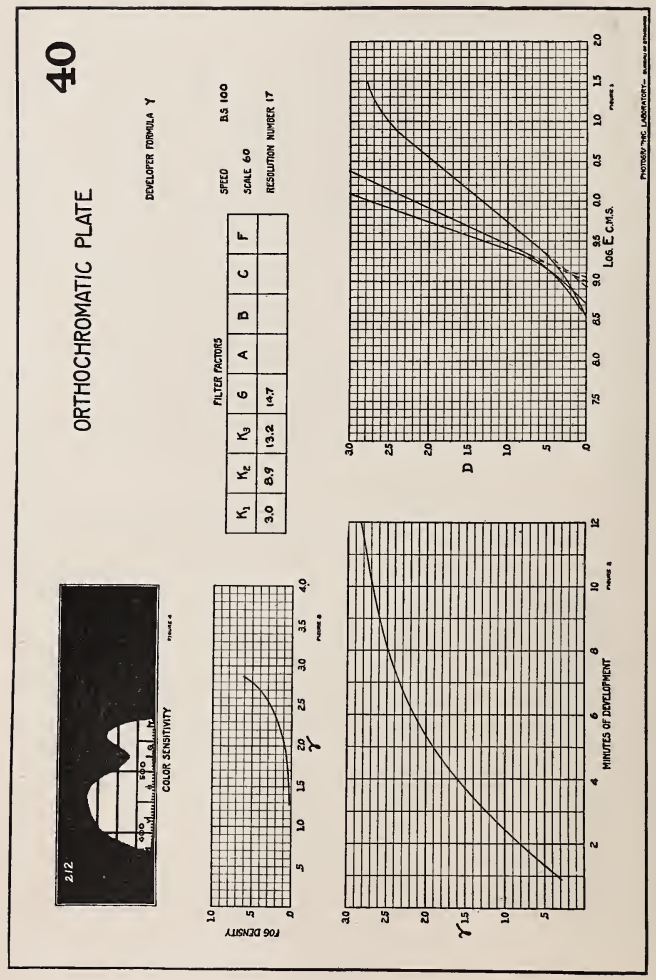




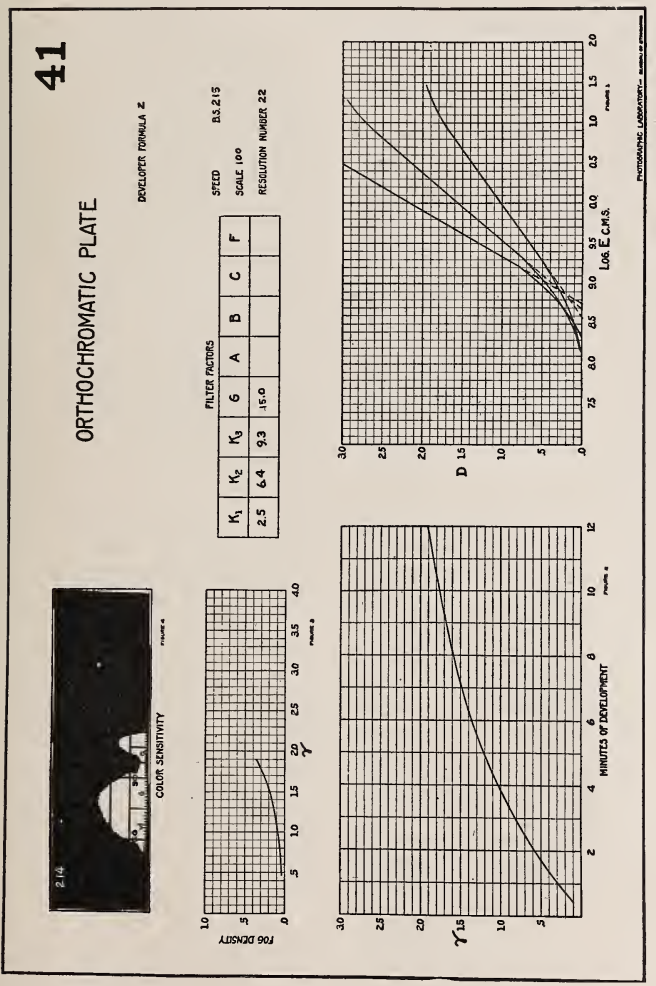




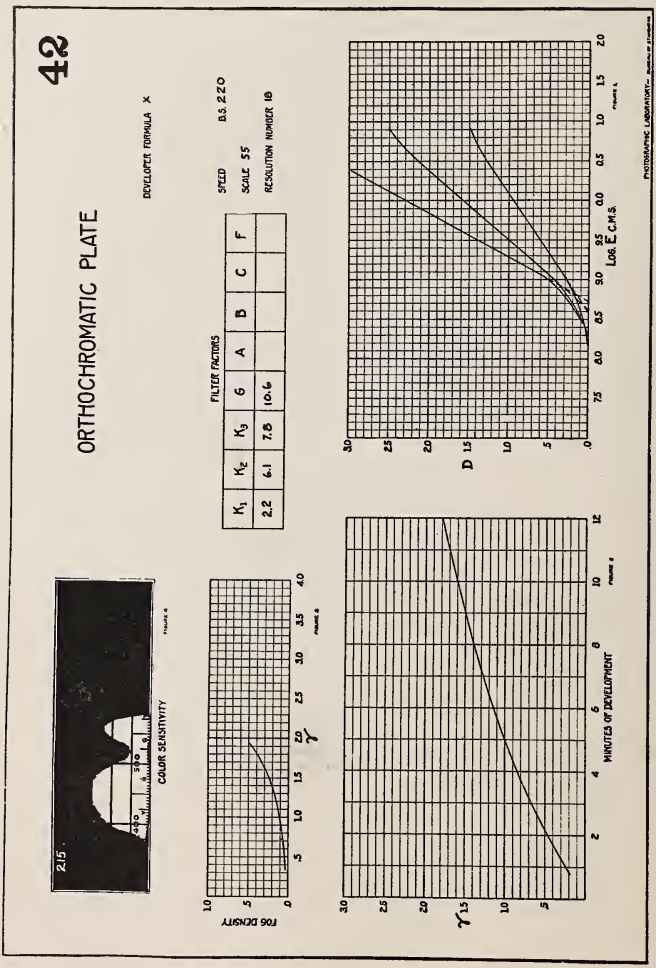




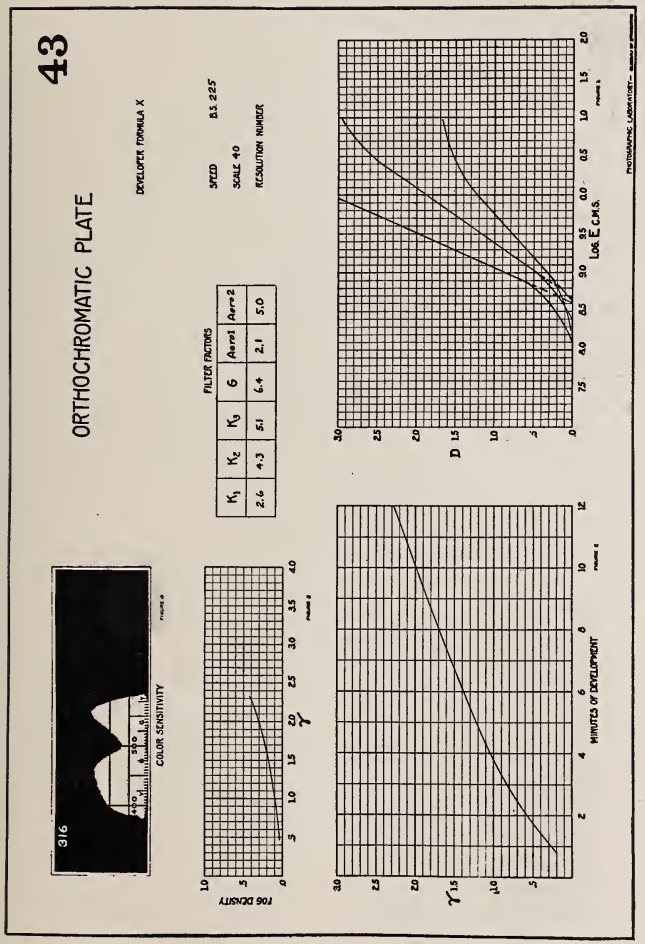




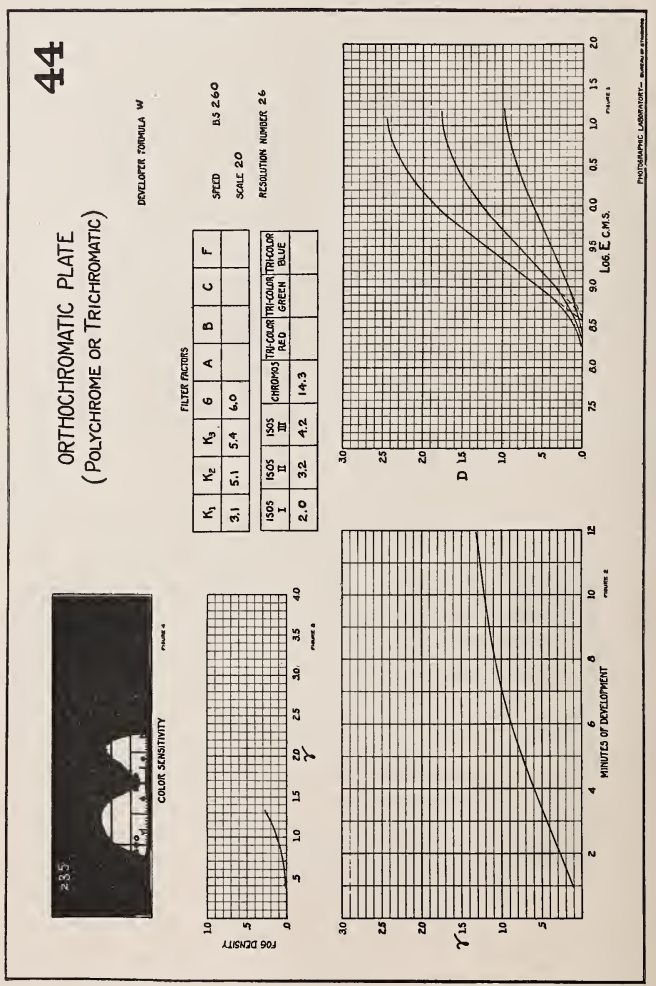




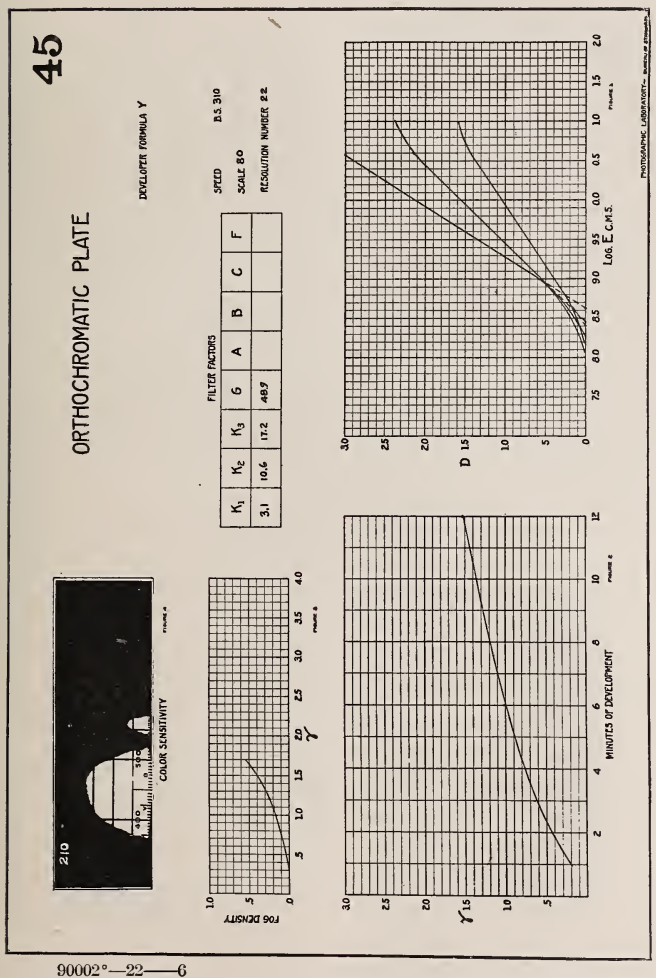

$90002^{\circ}-22-6$ 


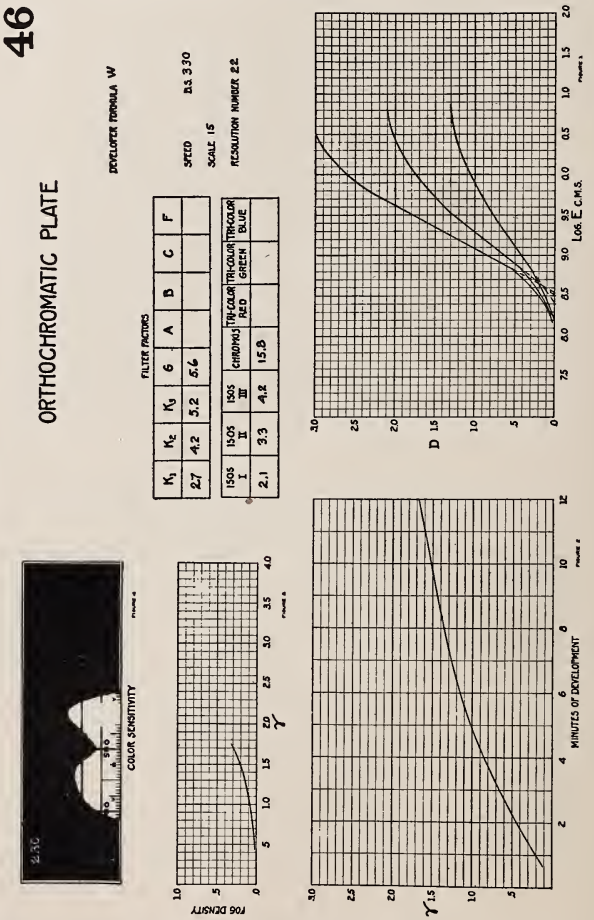


$\stackrel{T}{4}$
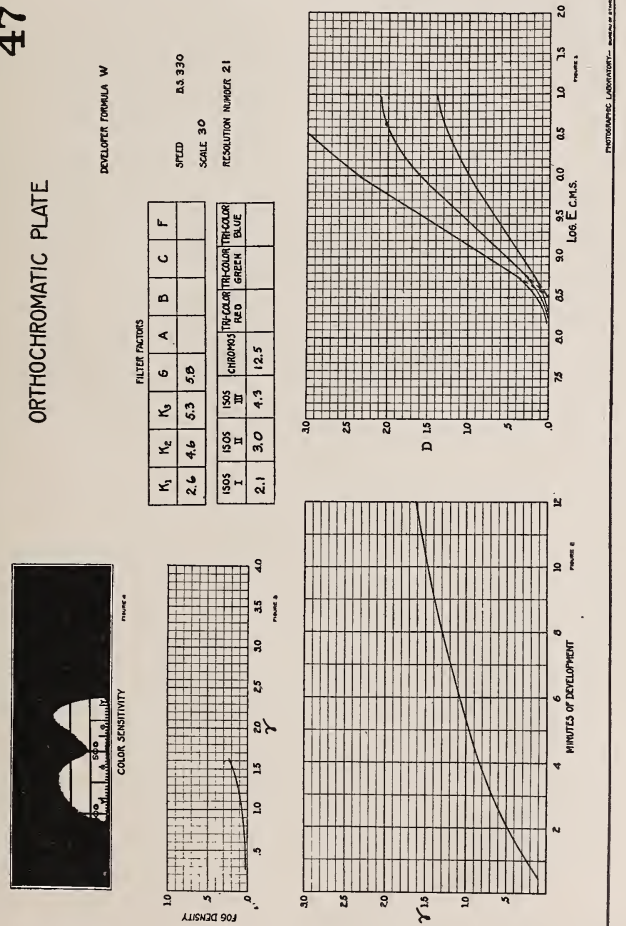


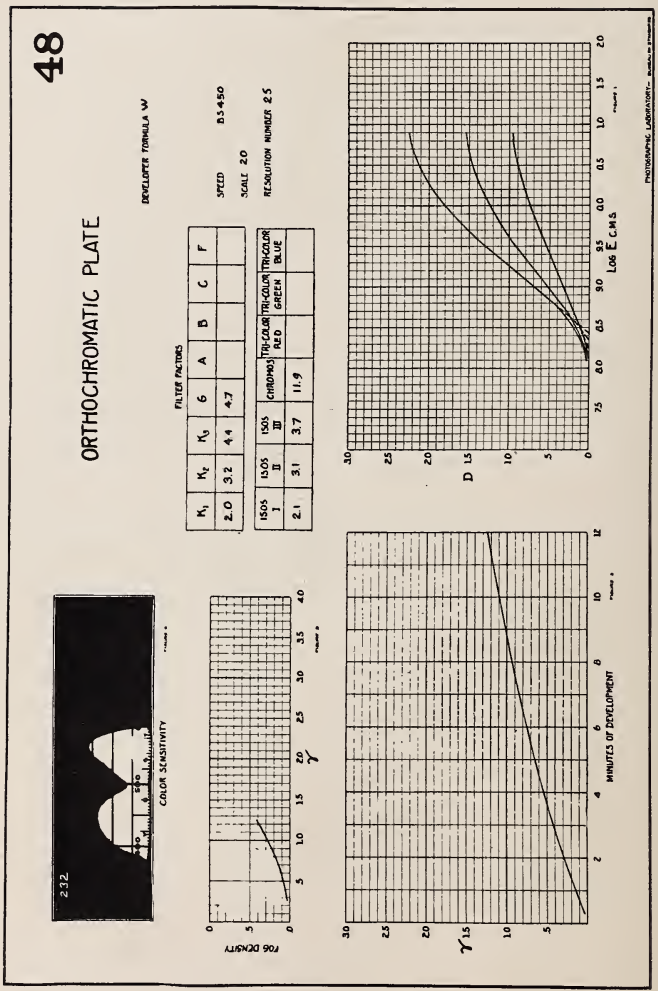




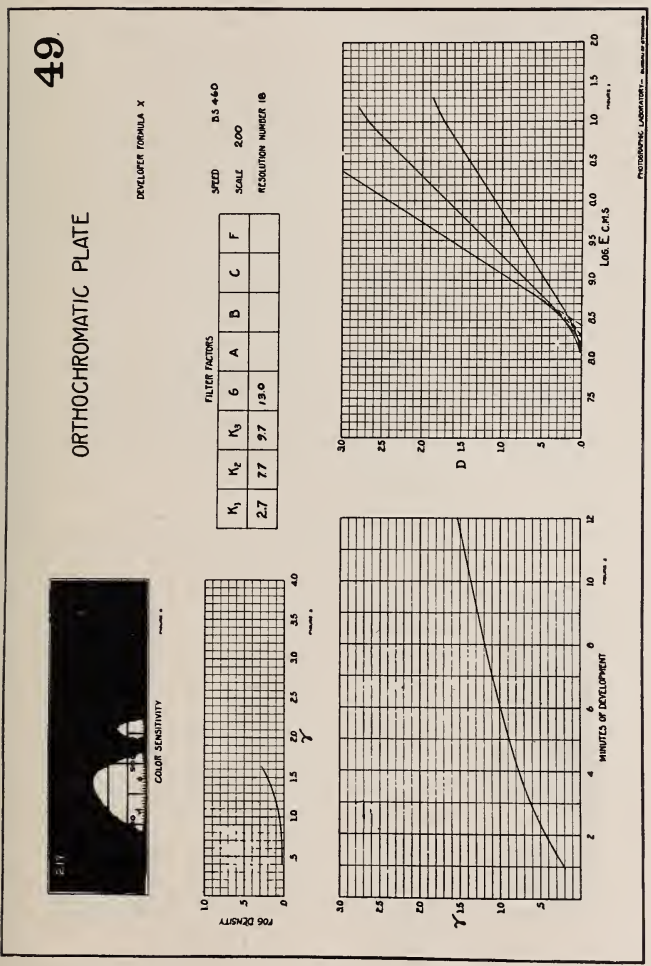


음
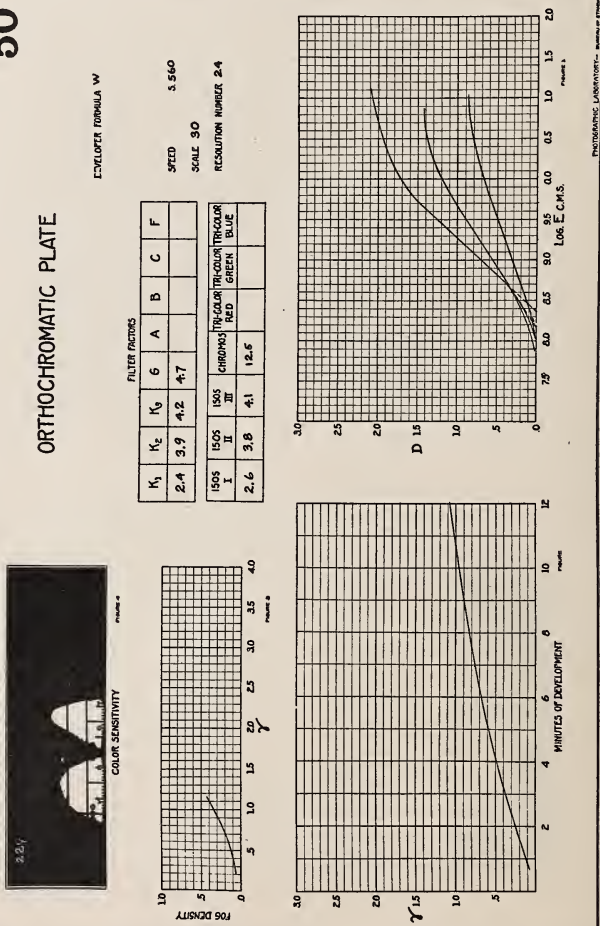


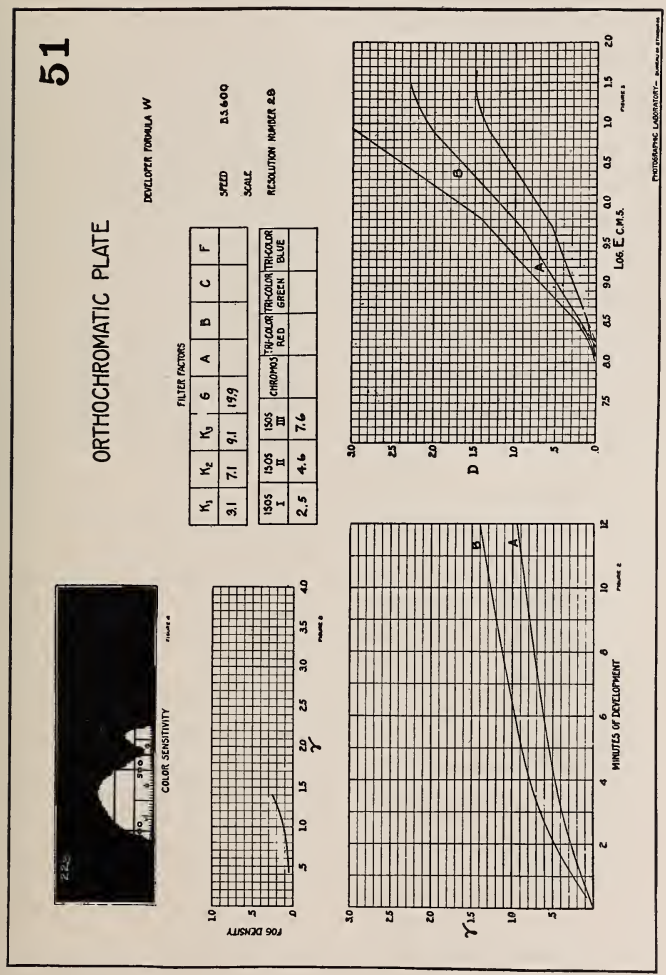




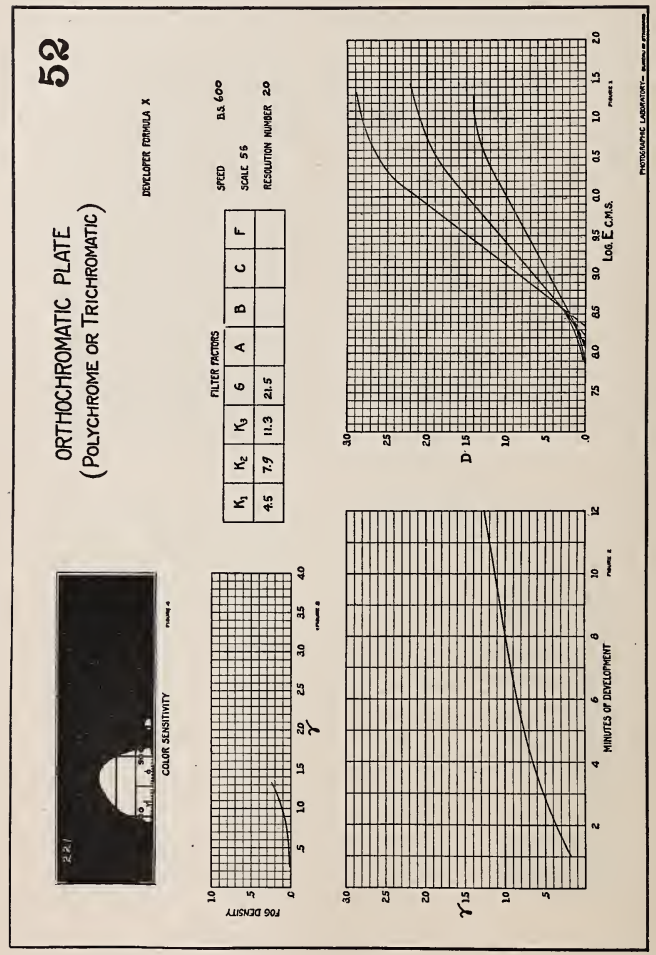




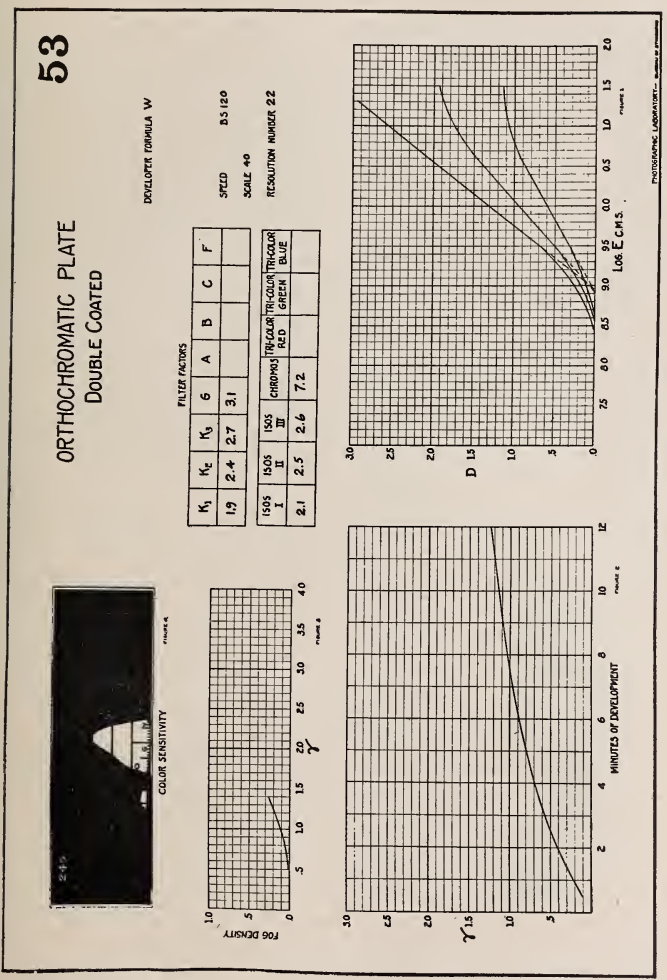




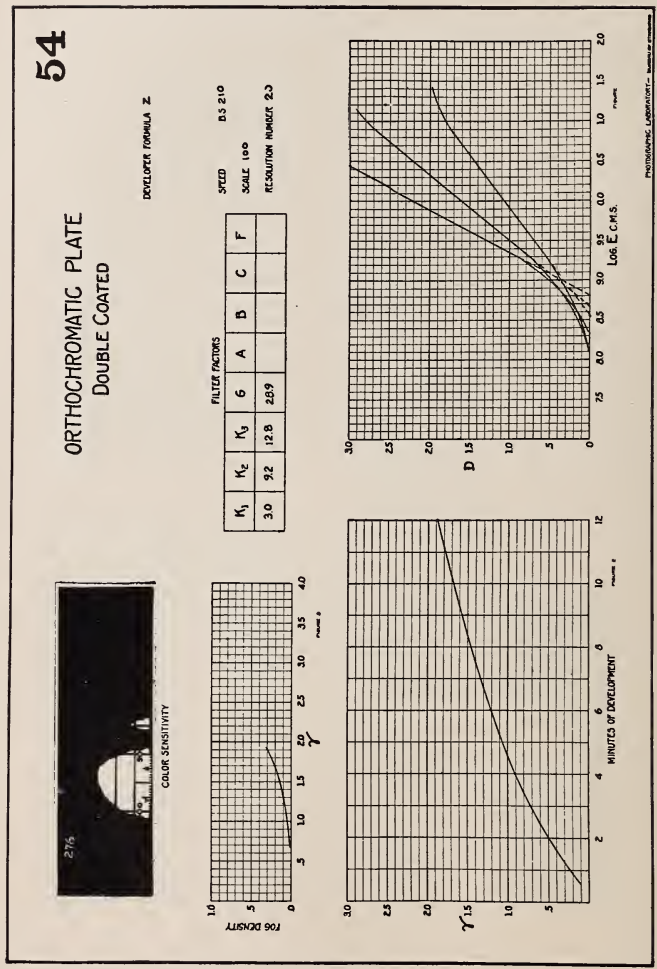




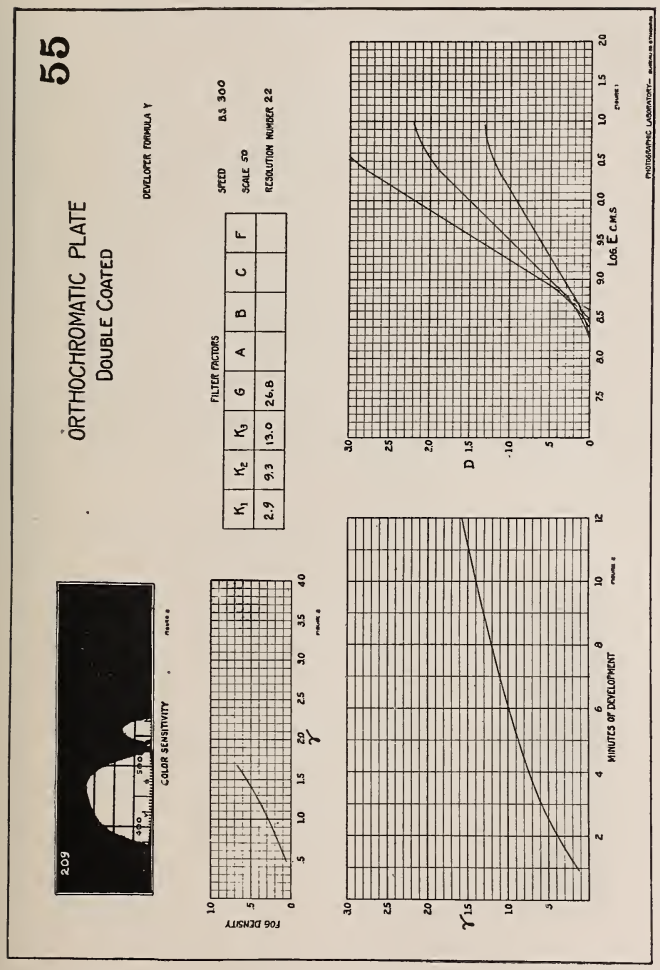




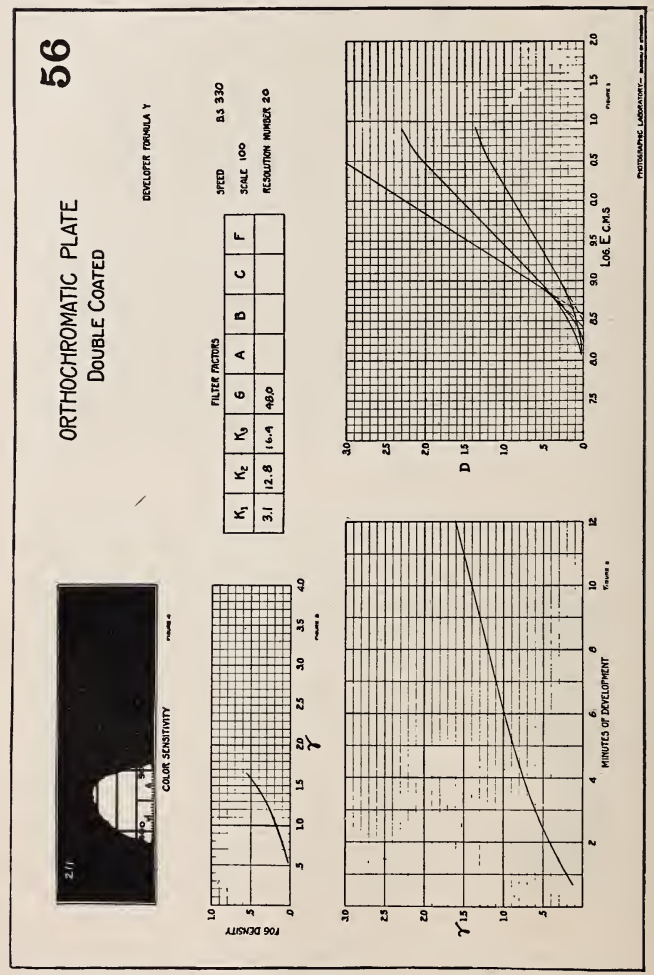




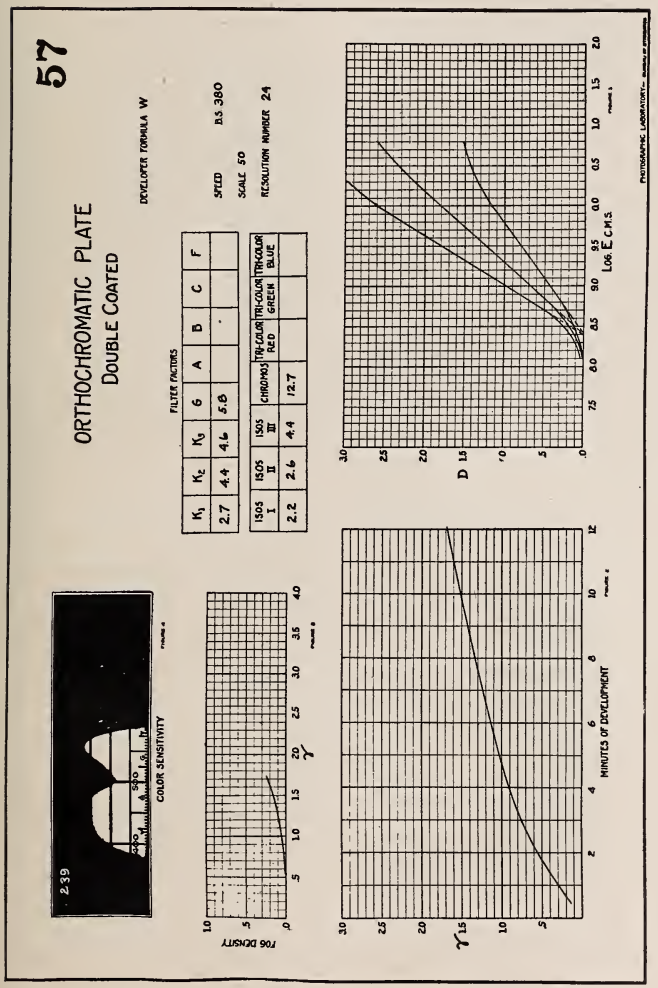




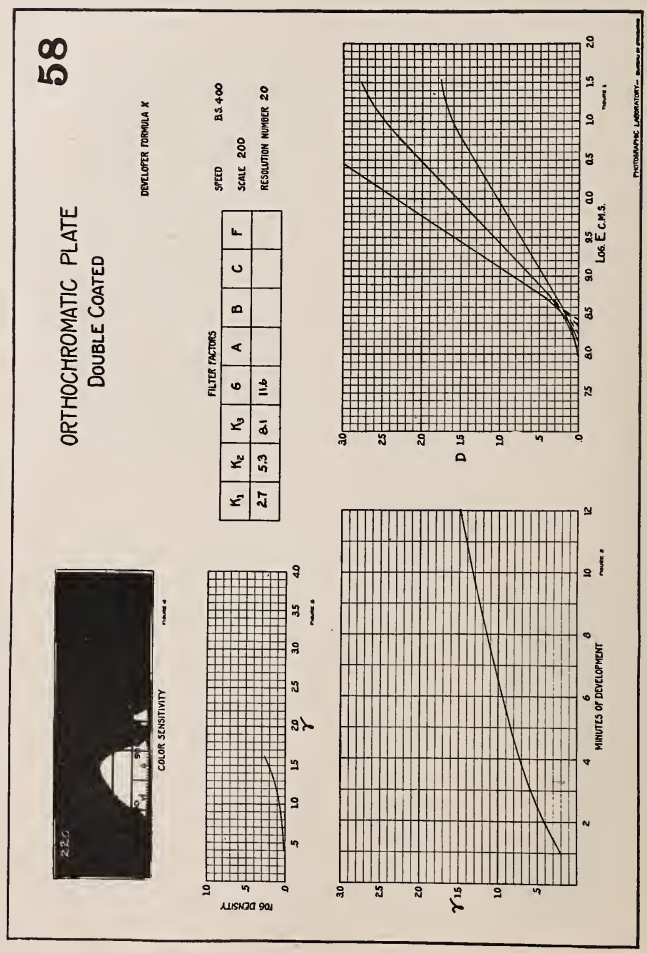




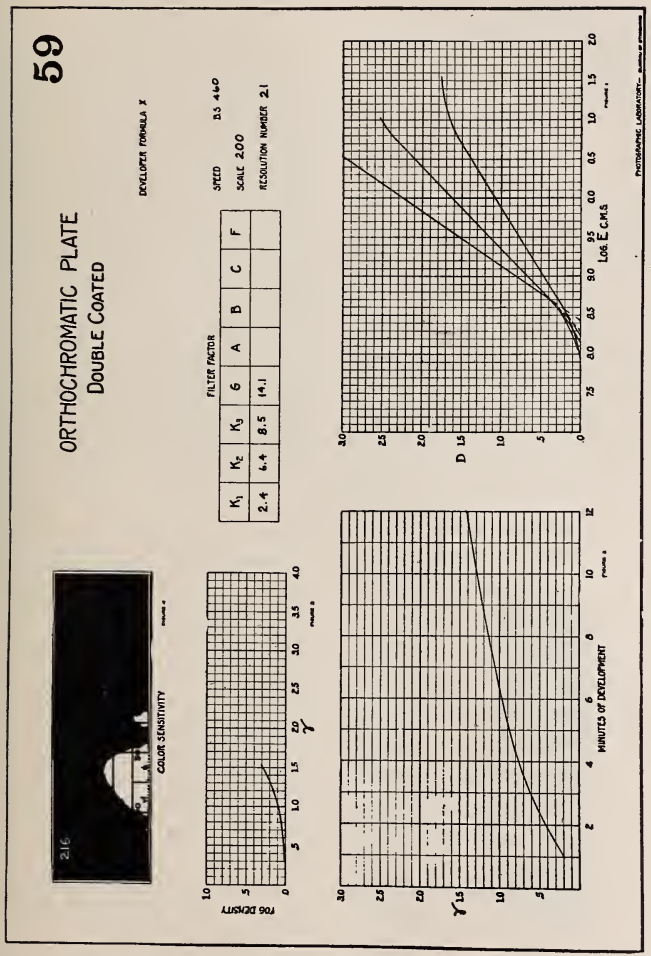




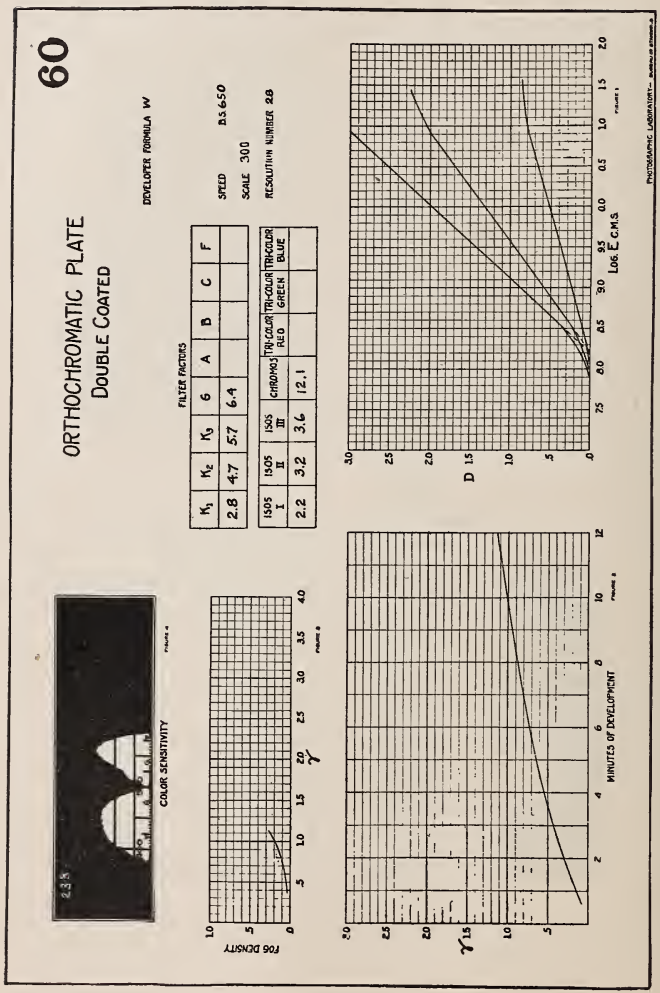




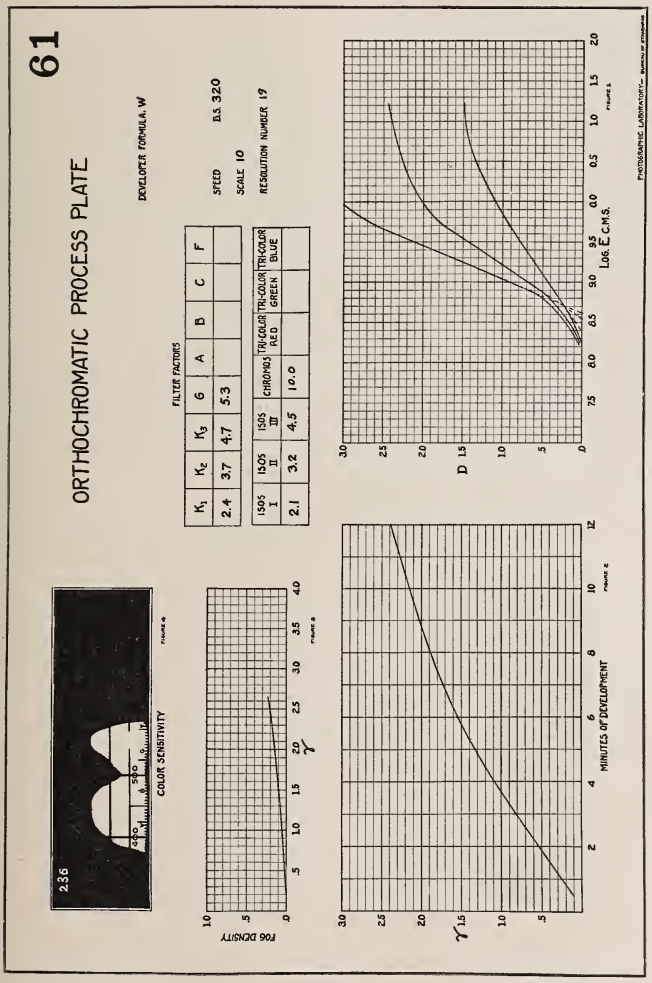

$90002^{\circ}-22-7$ 


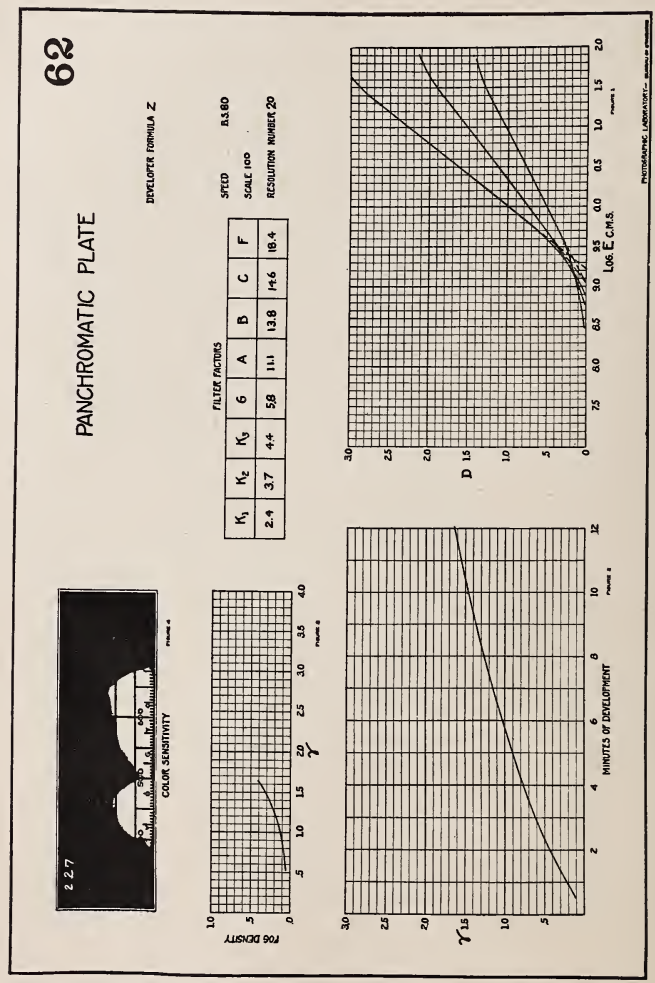




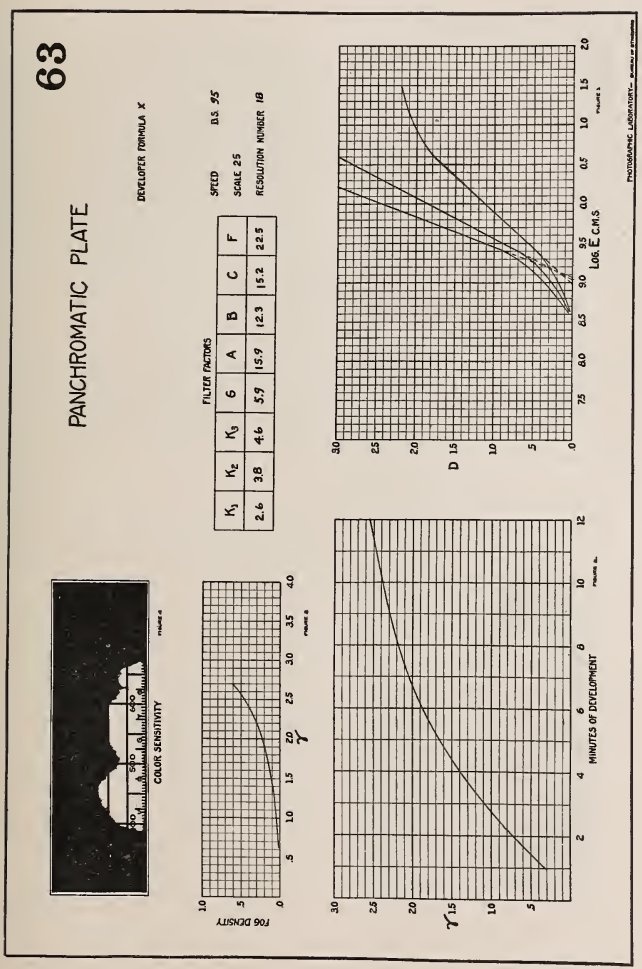




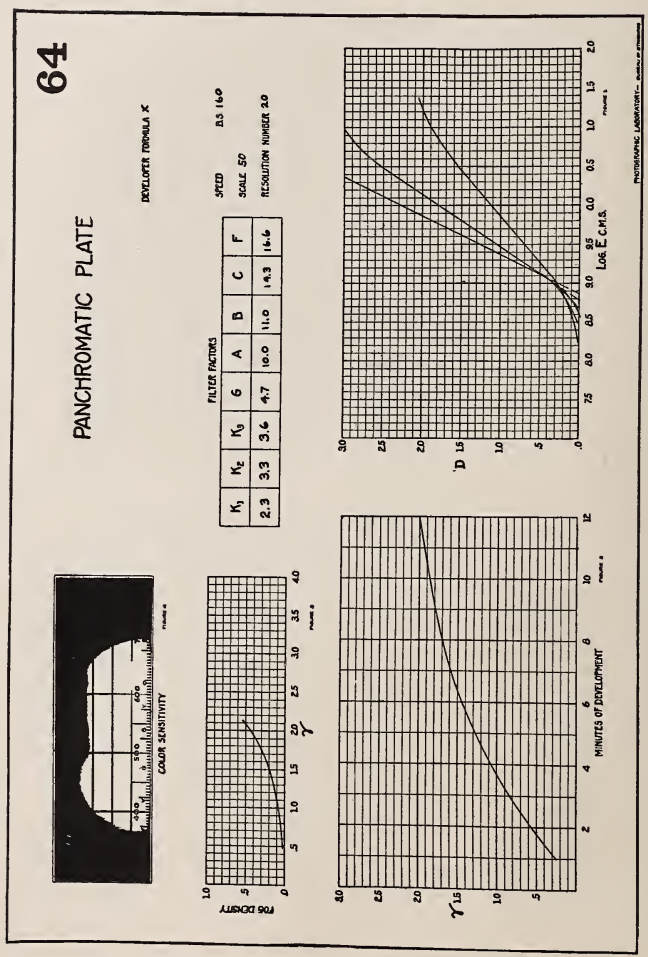




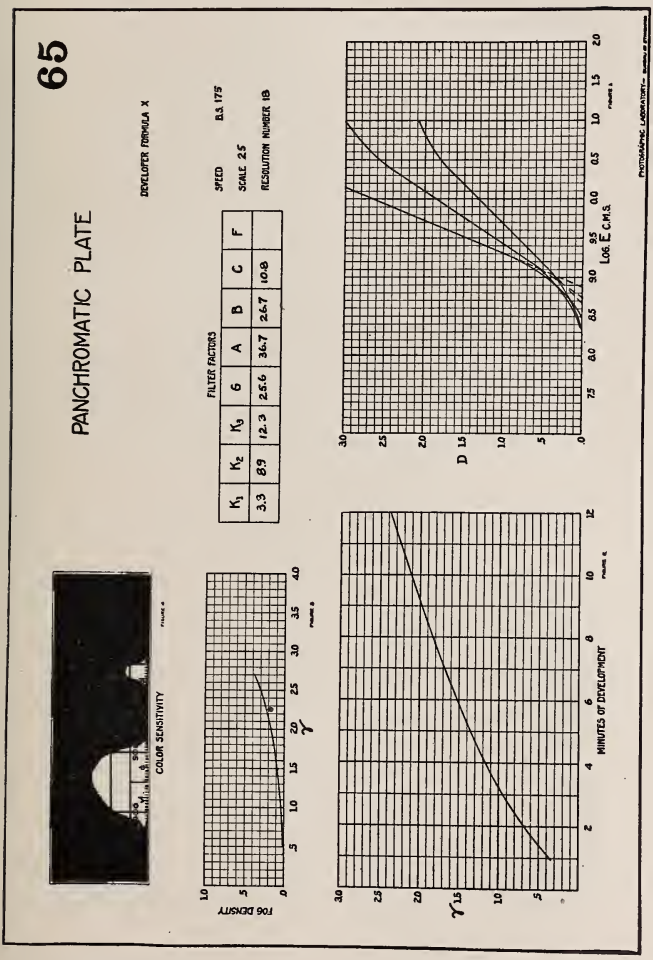




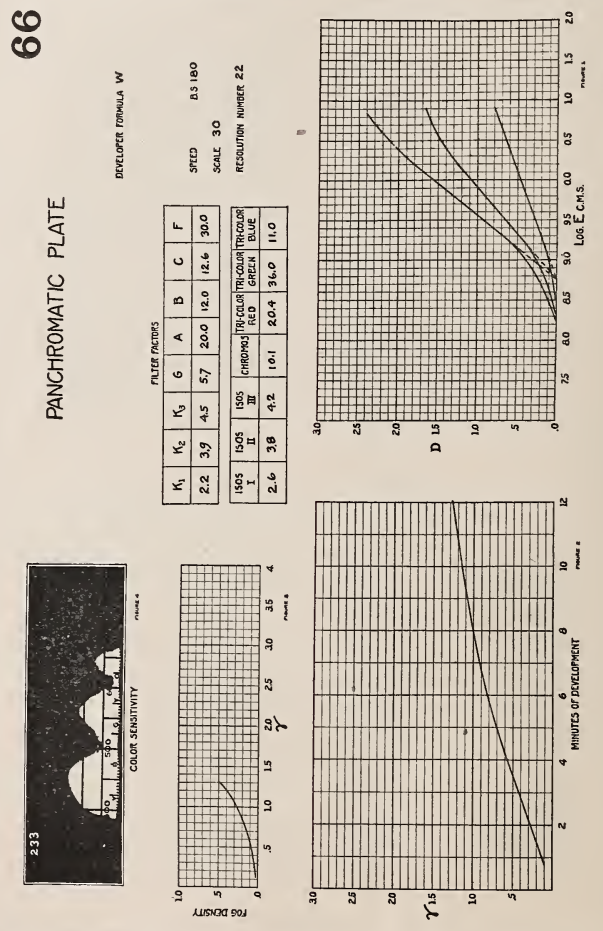




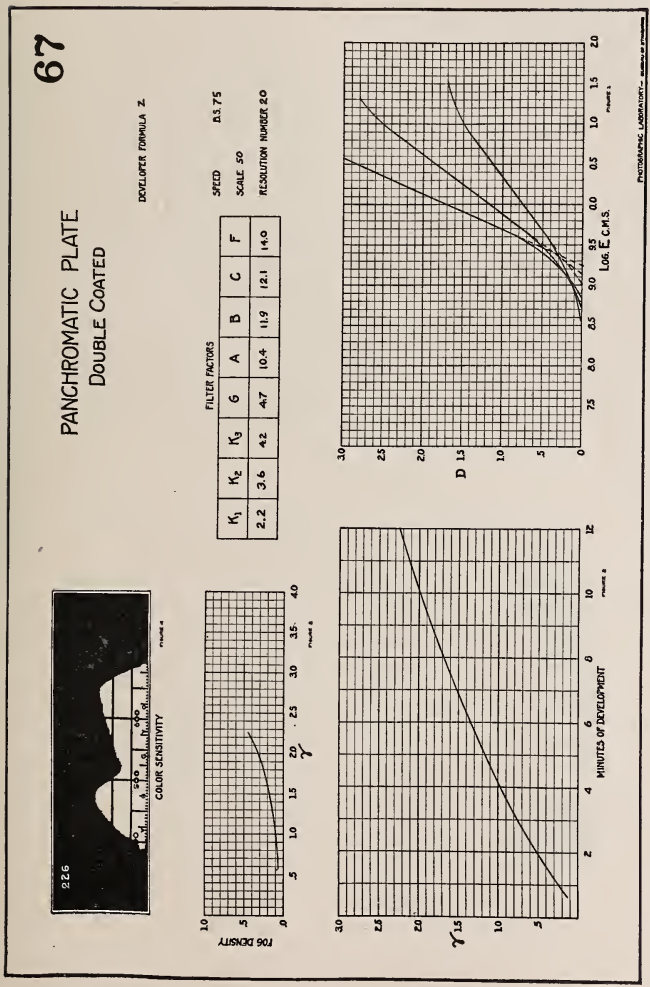




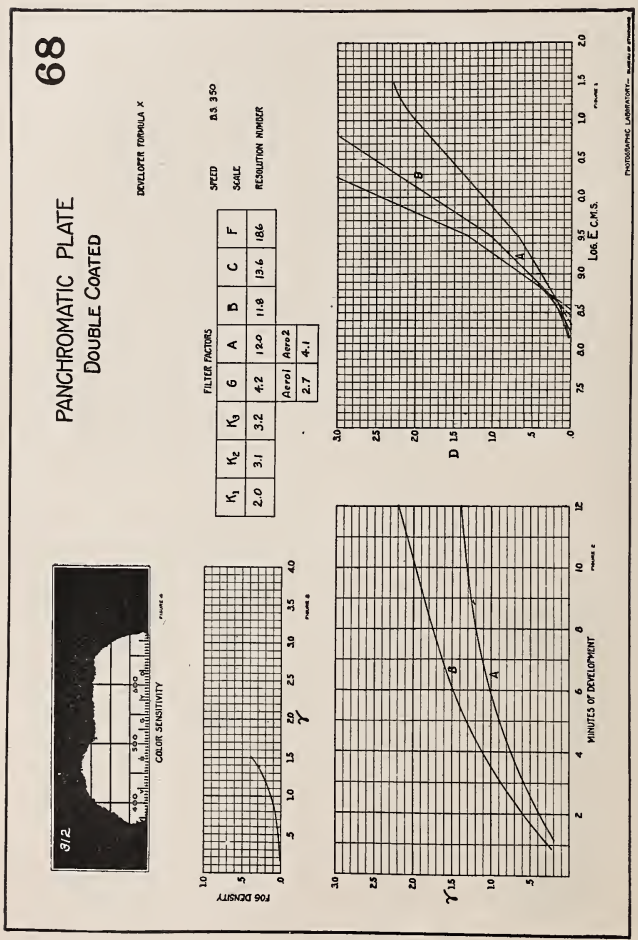




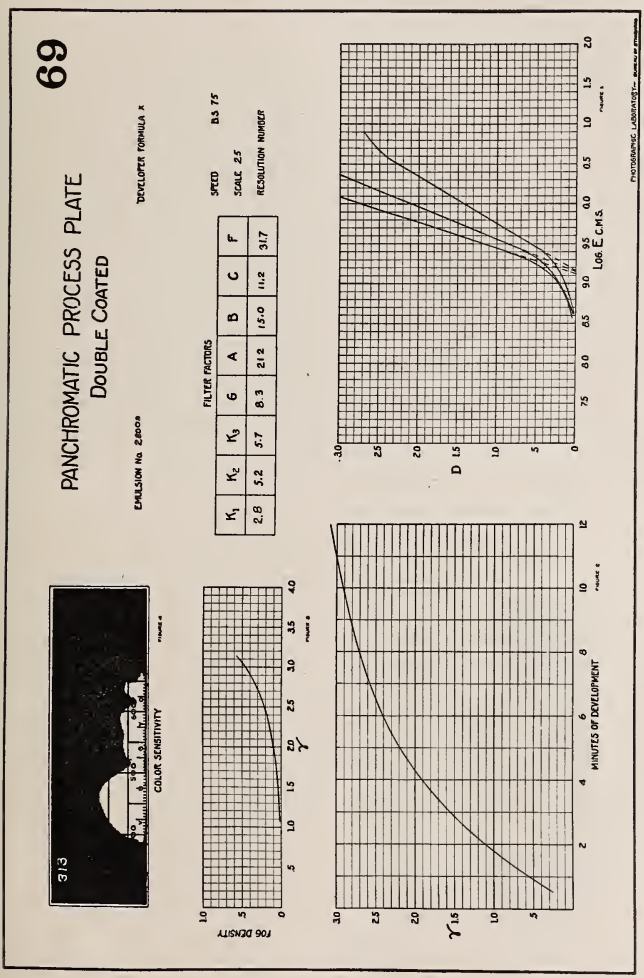


운
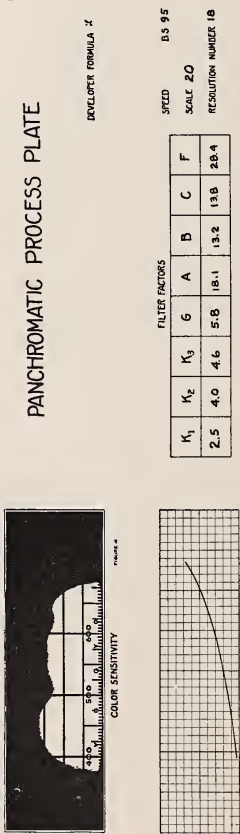

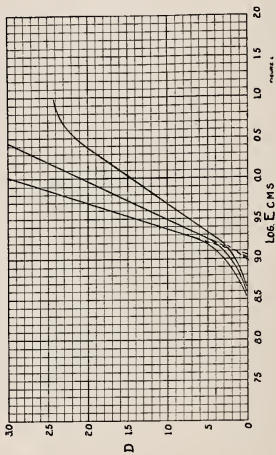

운
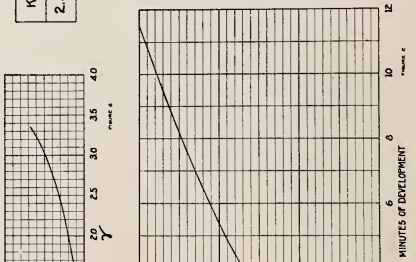

-

9

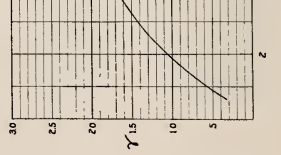




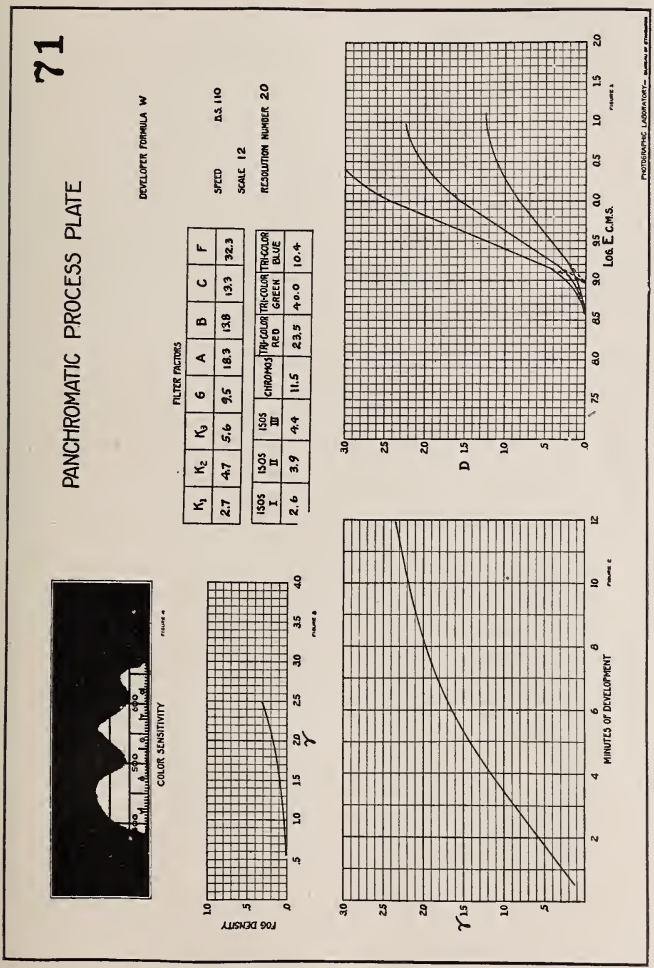




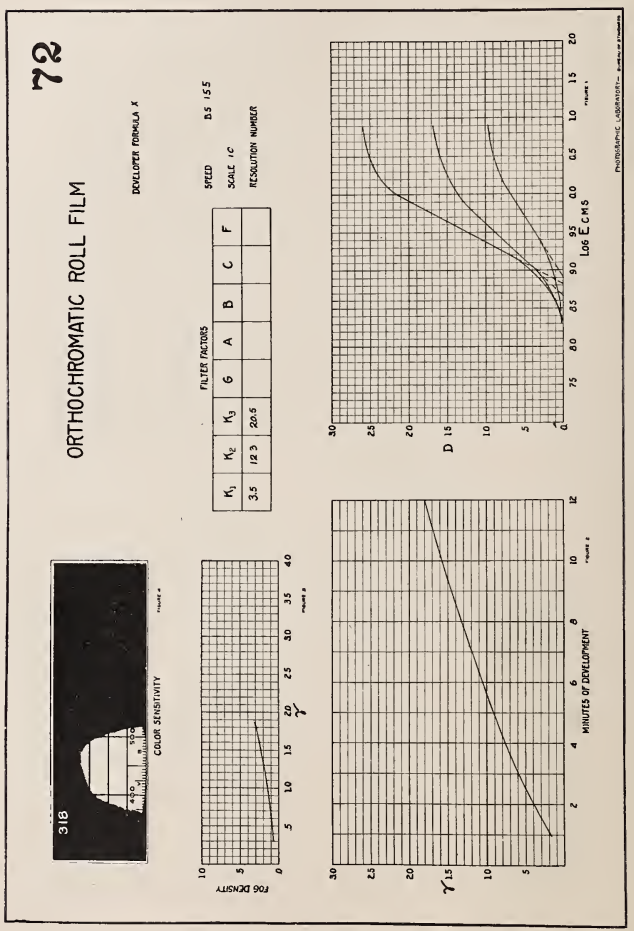




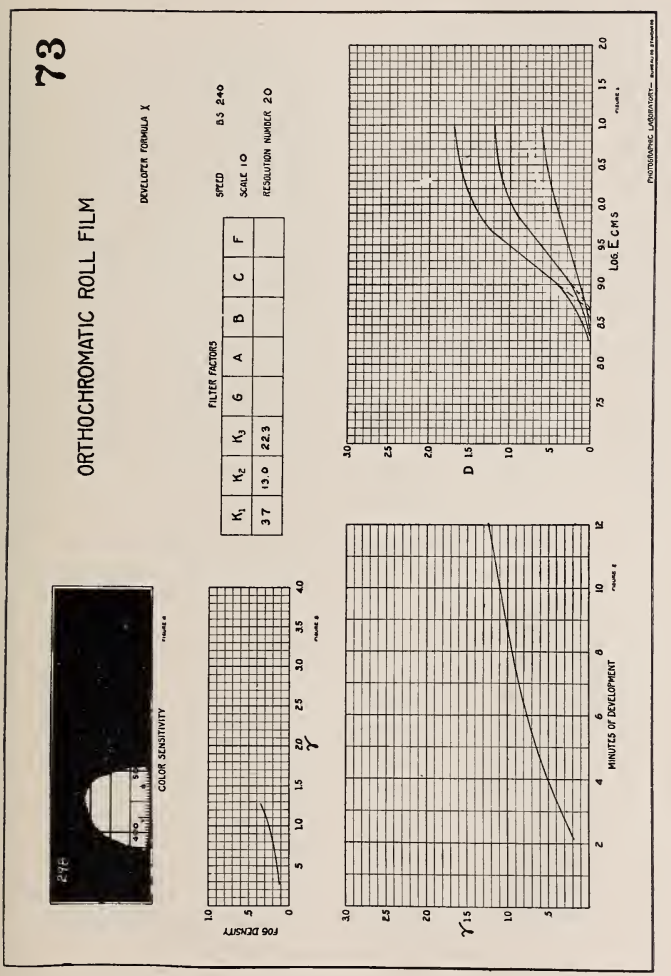




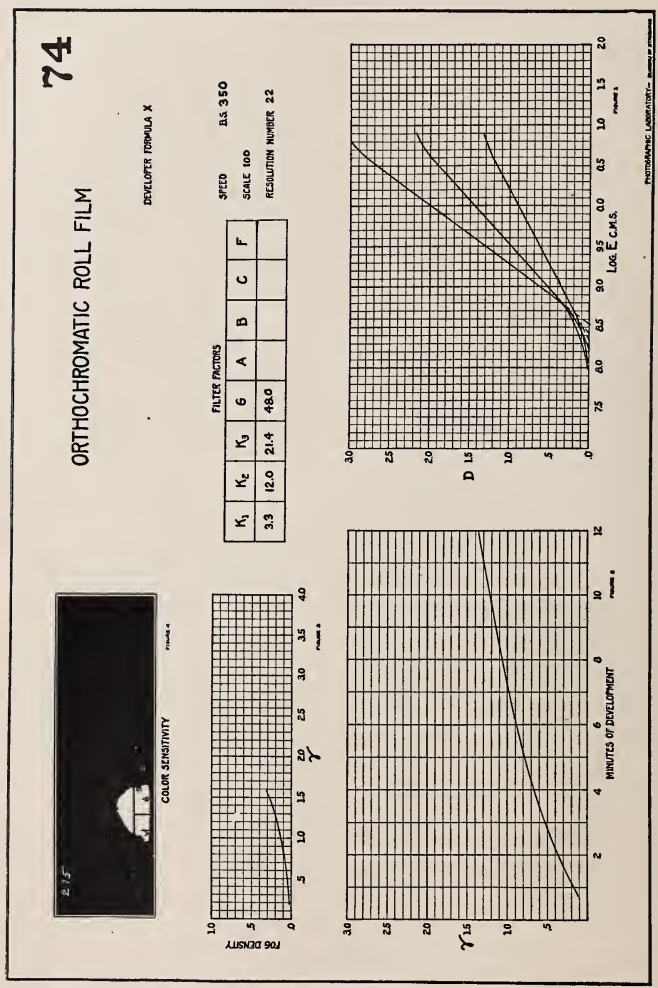




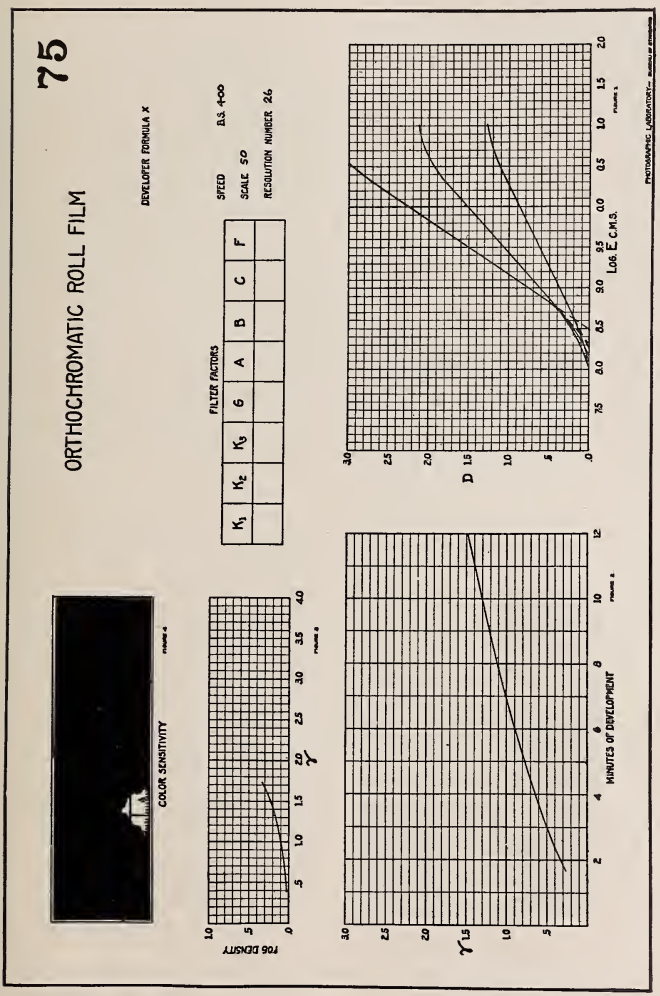




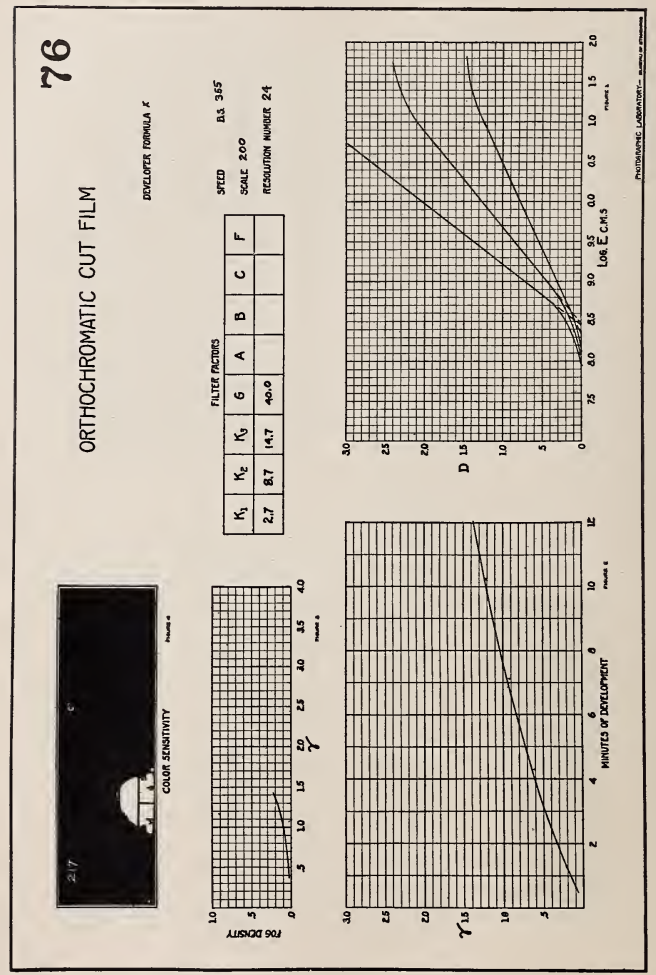




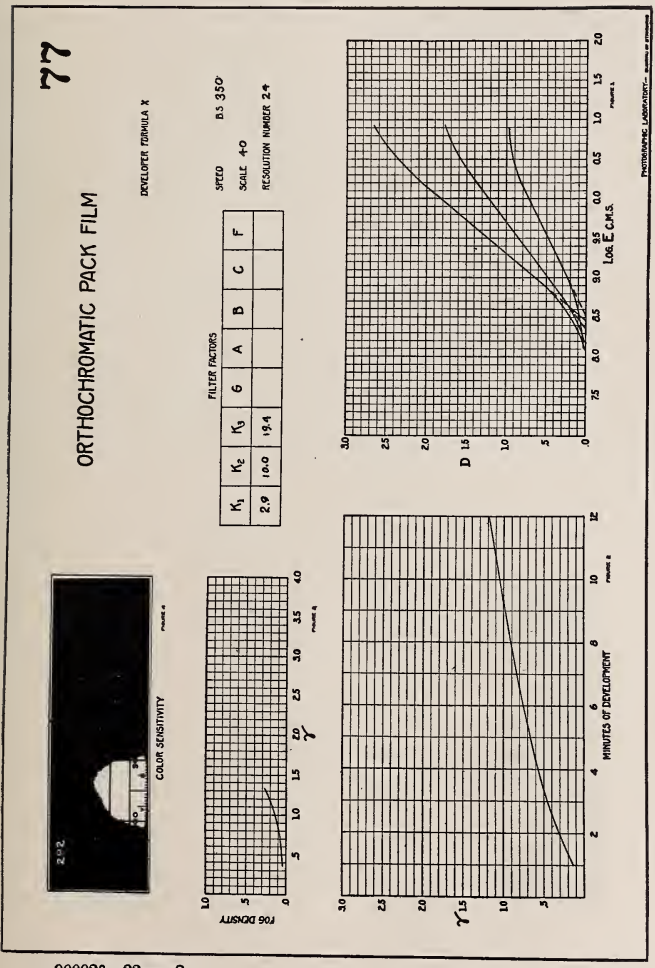

$90002^{\circ}-22-8$ 


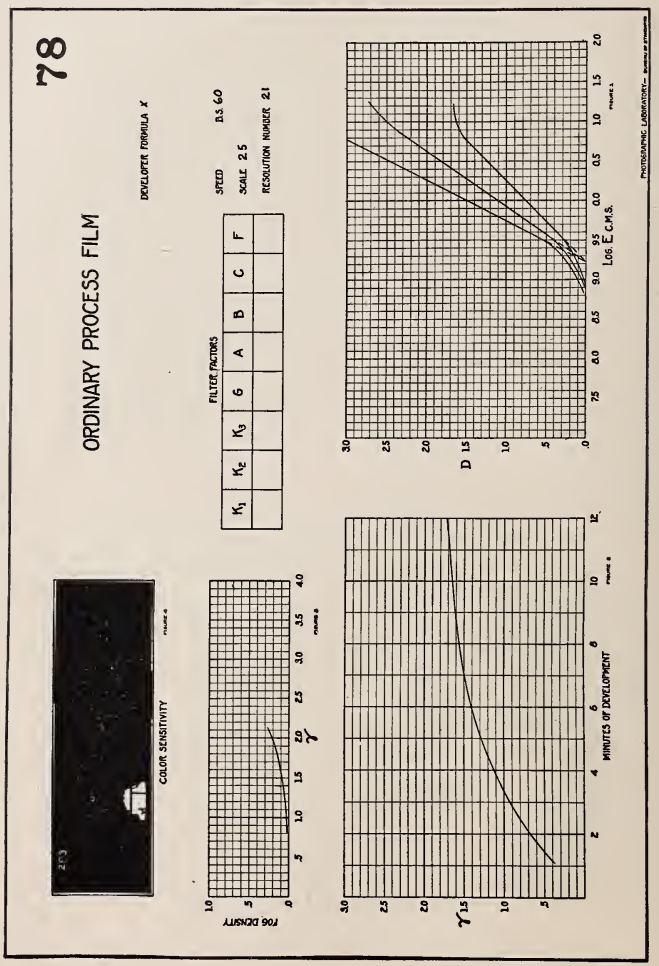




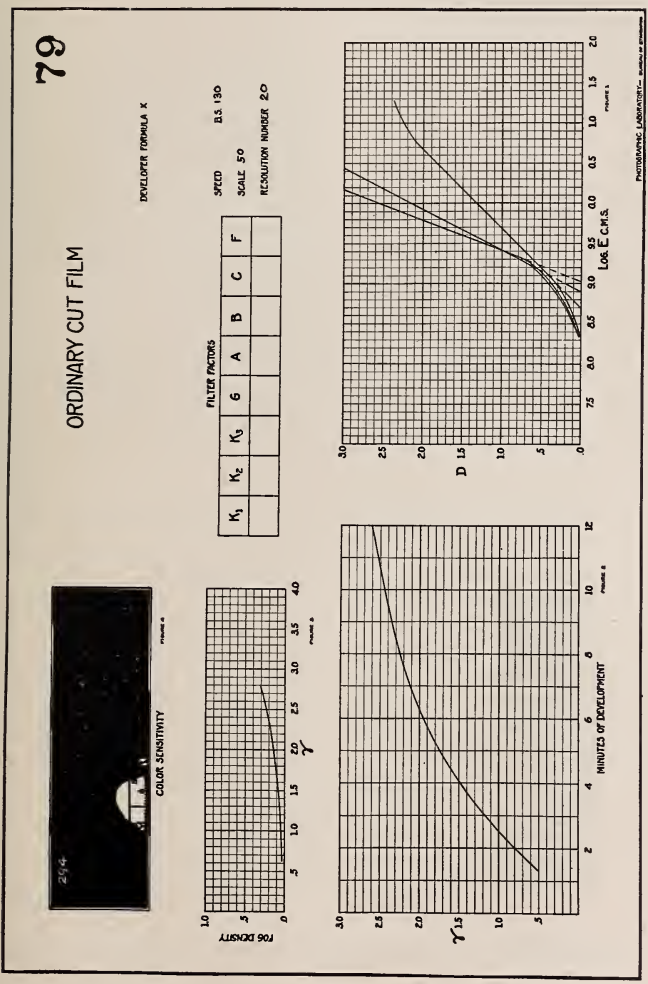




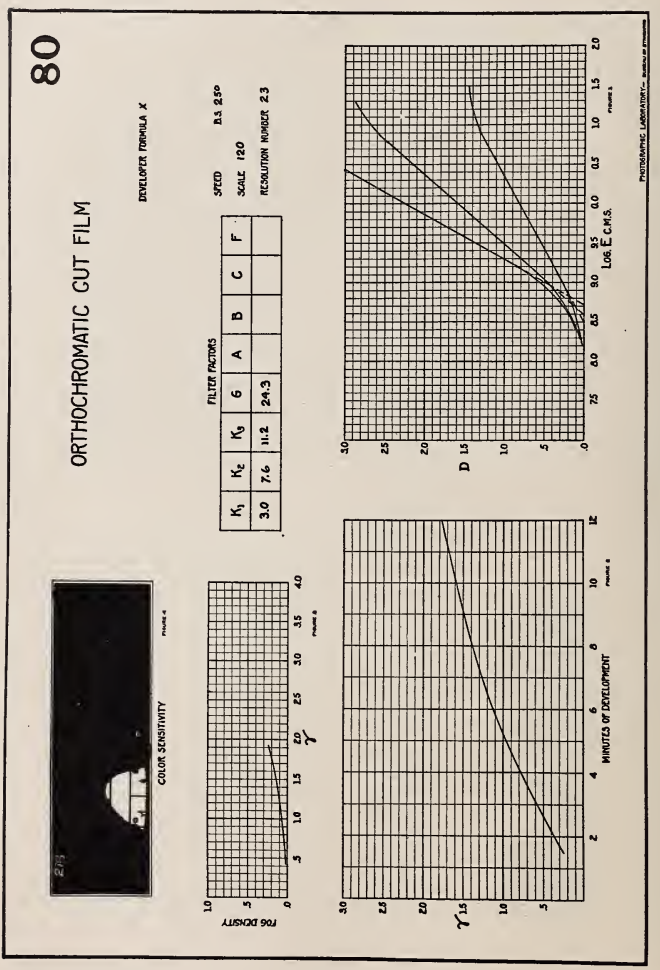




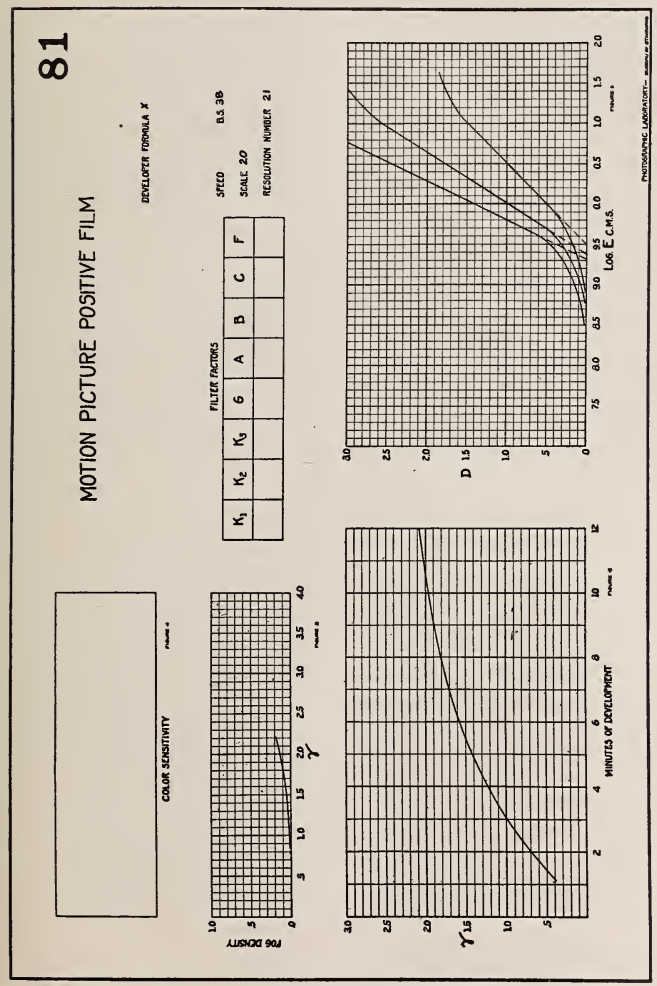




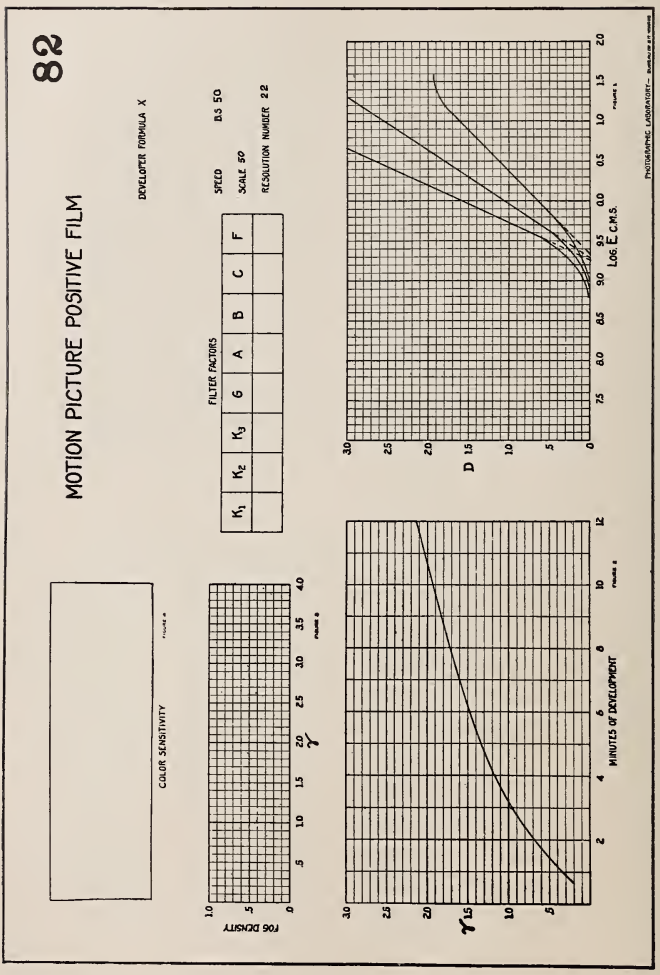




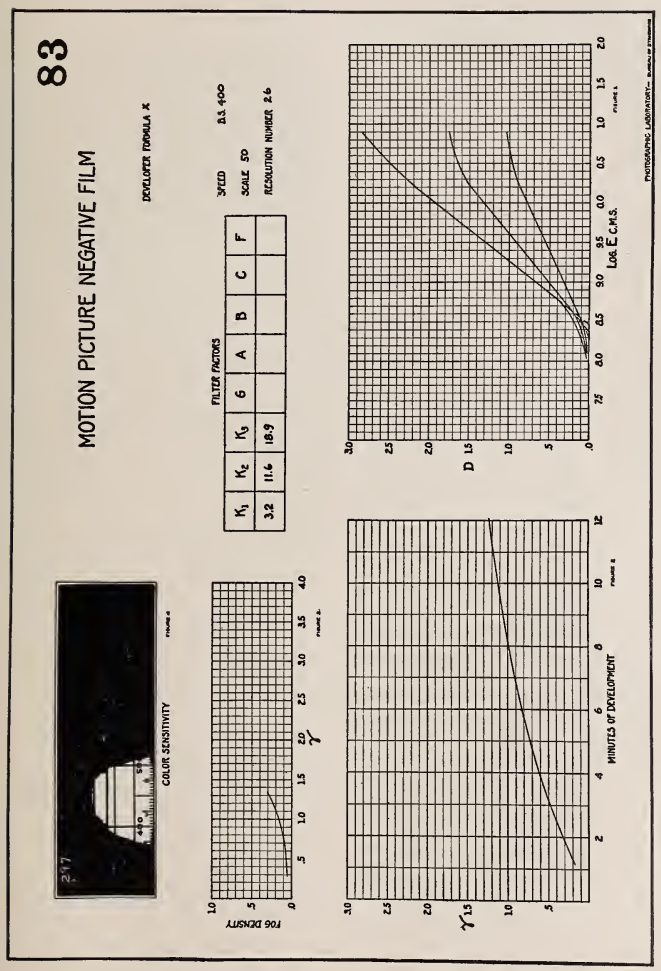




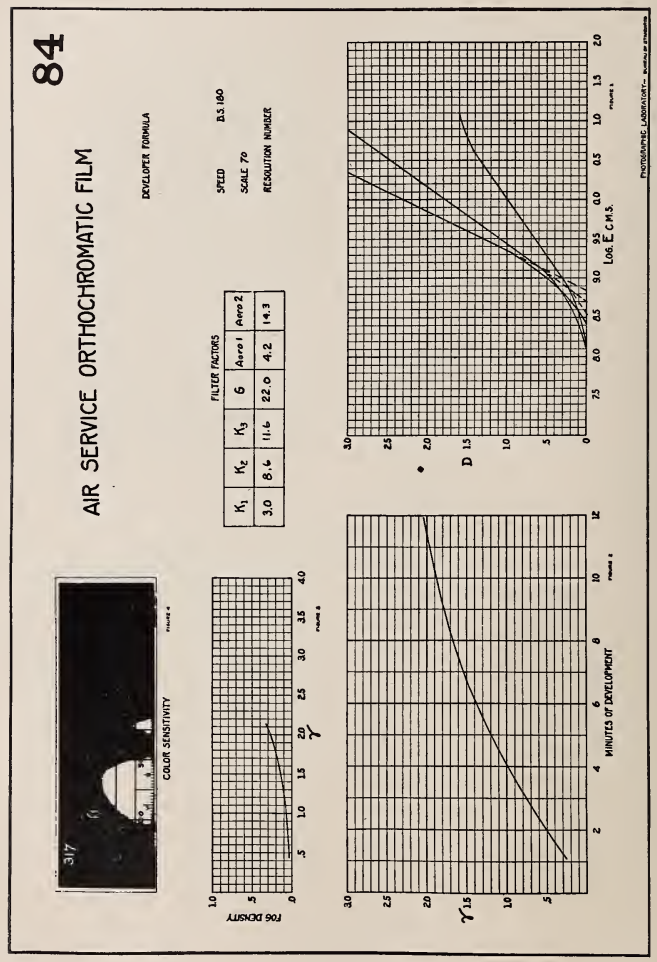




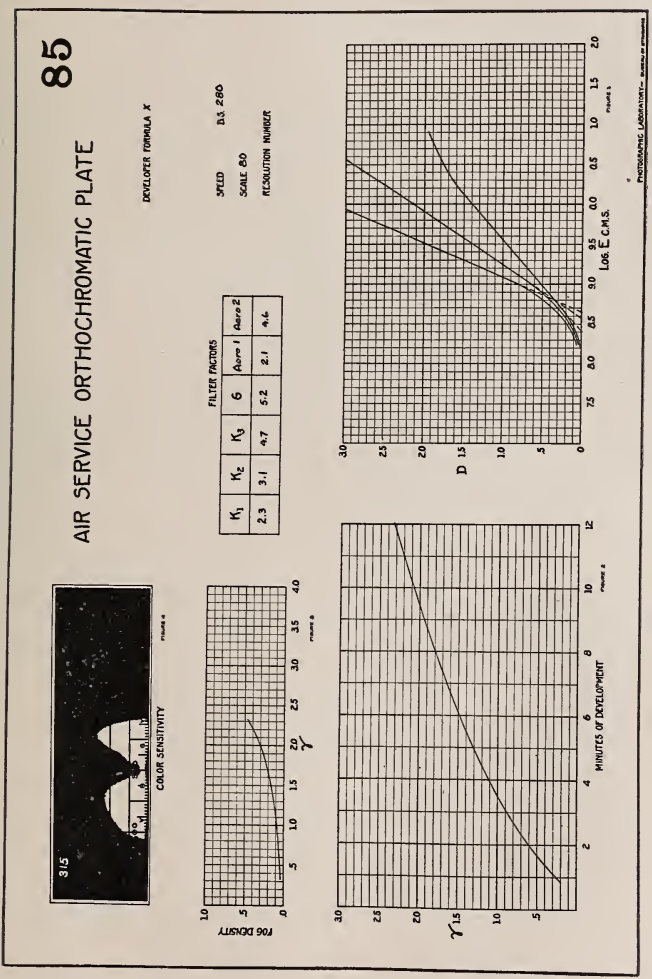




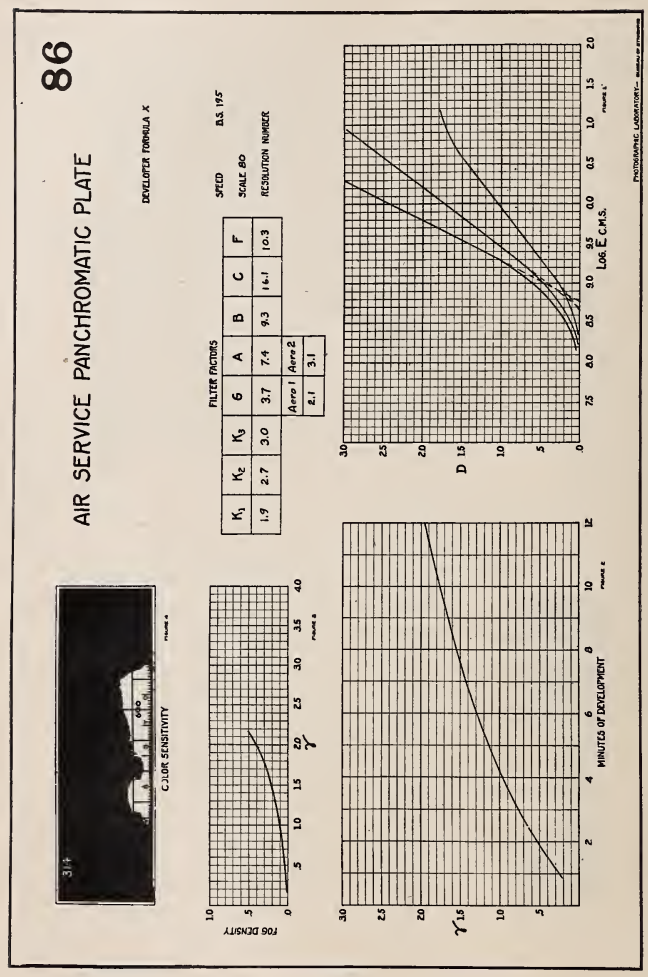

तू 